\title{
Phorbol diesters and 12-deoxy-16-hydroxyphorbol 13,16- diesters induce TGF $\alpha$ release and adult mouse neurogenesis
}

Abdellah Ezzanad ${ }^{1}$, Ricardo Gómez-Oliva ${ }^{2,3}$, Felipe Escobar-Montañoº, Mónica DíezSalguero $^{2}$, Noelia Geribaldi-Doldan ${ }^{4}$, Samuel Dominguez-Garcia ${ }^{2,3}$, José Manuel Botubol-Ares ${ }^{1,3}$, Carolina de los Reyes $^{1}$, Rosa Durán-Patrón ${ }^{1,3}$, Pedro NunezAbades $^{5}$, Antonio J. Macías-Sánchez ${ }^{1,3,6}$, Carmen Castro ${ }^{2,3}$ and Rosario HernándezGalán. ${ }^{1,3,6^{*}}$

${ }^{1}$ Departamento de Química Orgánica, Facultad de Ciencias, Universidad de Cádiz, 11510 Puerto Real, Cádiz (Spain)

2 Área de Fisiología, Facultad de Medicina, Universidad de Cádiz, 11002, Cádiz (Spain)

${ }^{3}$ Instituto de Investigación e Innovación Biomédica de Cádiz (INIBICA), 11009, Cádiz (Spain)

${ }^{4}$ Departamento de Anatomía y Embriología Humanas, Universidad de Cádiz, 11002 Cádiz, (Spain)

${ }^{5}$ Departamento de Fisiología, Facultad de Farmacia, Universidad de Sevilla, 41012 Sevilla (Spain)

${ }^{6}$ Instituto de Investigación en Biomoléculas (INBIO), Universidad de Cádiz, 11510 Puerto Real, Cádiz (Spain)

\section{Table of Contents}

1. Figure S1. Structure of active phorbol derivatives

2. Preparation of phorbol 20-trityl ether (1a)

Scheme S1. Preparation of 1a from Croton oil

Figure S2. ${ }^{1} \mathrm{H}$ NMR spectrum of compound 3 in $\mathrm{CD}_{3} \mathrm{OD}(400 \mathrm{MHz})$

Figure S3. ${ }^{13} \mathrm{C}$ NMR spectrum of compound 3 in $\mathrm{CD}_{3} \mathrm{OD}(100 \mathrm{MHz})$

Figure S4. ${ }^{1} \mathrm{H}$ NMR spectrum of compound $3 \mathrm{a}$ in $\mathrm{CD}_{3} \mathrm{OD}(400 \mathrm{MHz})$

Figure S5. ${ }^{13} \mathrm{C}$ NMR spectrum of compound $3 a$ in $\mathrm{CD}_{3} \mathrm{OD}(100 \mathrm{MHz})$

Figure S6. ${ }^{1} \mathrm{H}$ NMR spectrum of compound 4 in $\mathrm{CD}_{3} \mathrm{OD}(400 \mathrm{MHz})$ S9

Figure S7. ${ }^{13} \mathrm{C}$ NMR spectrum of compound 4 in $\mathrm{CD}_{3} \mathrm{OD}(100 \mathrm{MHz})$ S10

Figure S8. ${ }^{1} \mathrm{H}$ NMR spectrum of compound 5 in $\mathrm{CD}_{3} \mathrm{OD}(400 \mathrm{MHz})$

Figure S9. ${ }^{13} \mathrm{C}$ NMR spectrum of compound 5 in $\mathrm{CD}_{3} \mathrm{OD}(100 \mathrm{MHz})$

Figure S10. ${ }^{1} \mathrm{H}$ NMR spectrum of compound 5 a in $\mathrm{CD}_{3} \mathrm{OD}(400 \mathrm{MHz})$

Figure S11. ${ }^{13} \mathrm{C}$ NMR spectrum of compound $5 \mathrm{a}$ in $\mathrm{CD}_{3} \mathrm{OD}(100 \mathrm{MHz})$ S14

Figure S12. ${ }^{1} \mathrm{H}$ NMR spectrum of compound 6 in $\mathrm{CDCl}_{3}(500 \mathrm{MHz})$ S15 


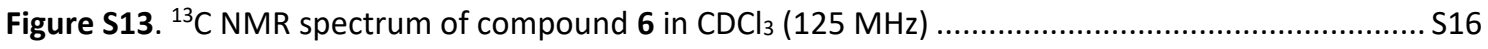

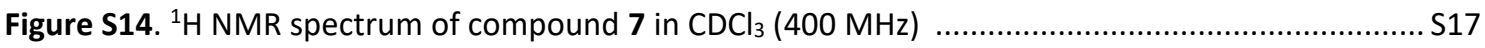

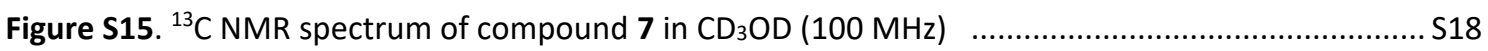

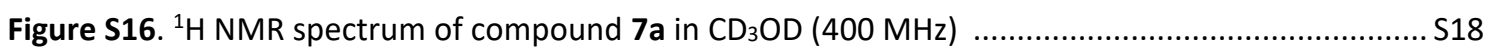

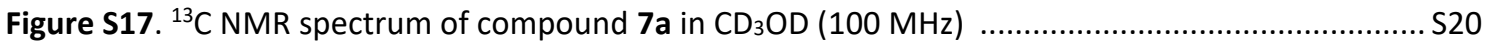

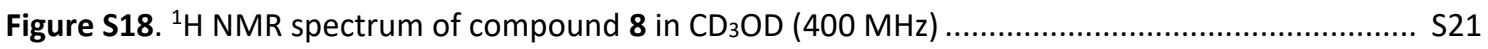

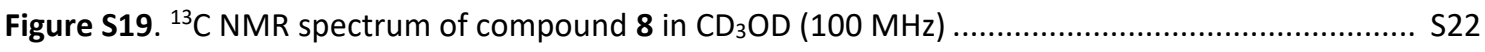

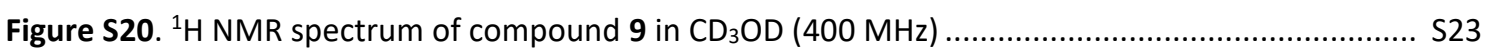

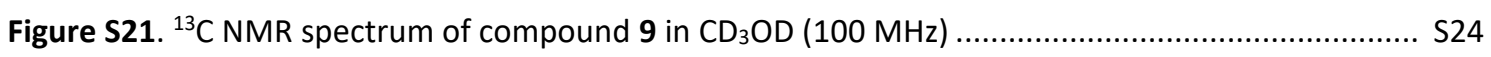

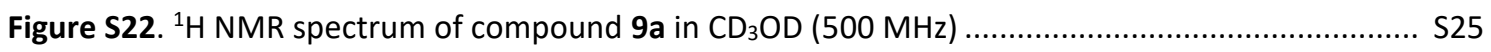

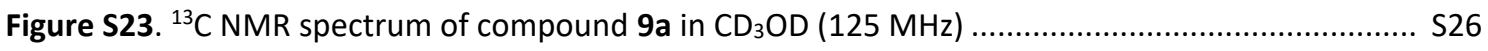

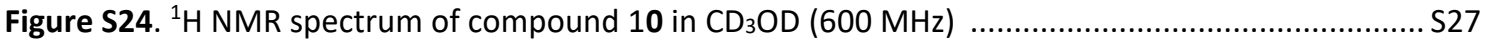

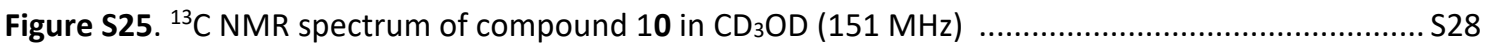

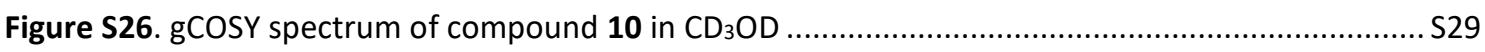

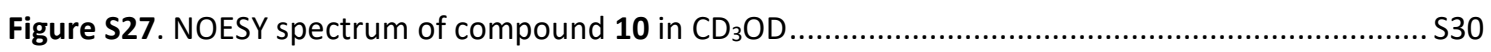

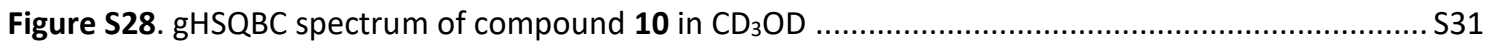

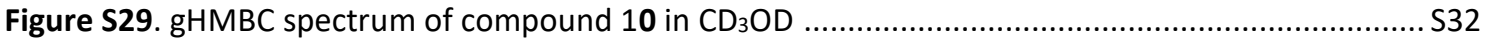

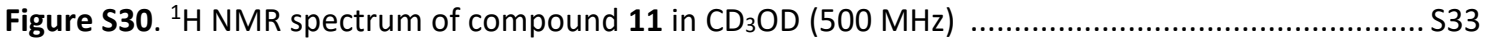

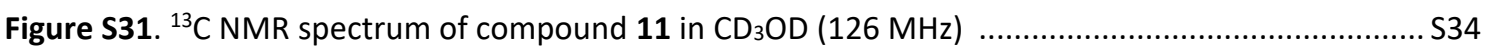

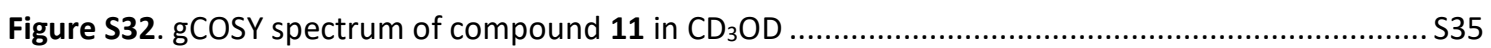

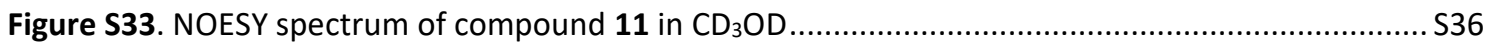

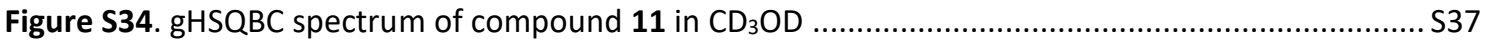

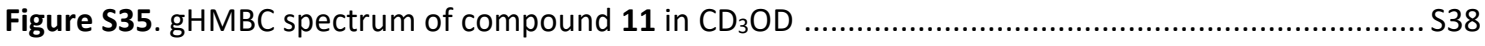

\section{HPLC chromatograms for compounds 5-11}

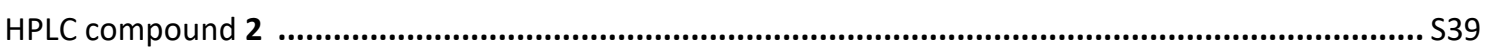

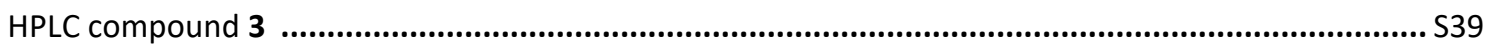

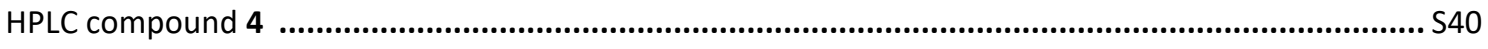

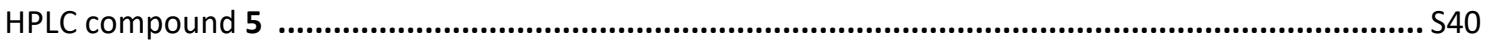


HPLC compound 6

HPLC compound 7

HPLC compound 8

HPLC compound 9

HPLC compound 10

HPLC compound 11

\section{UPLC-HRMS Assisted Identification of 12-deoxyphorbol-13,16-diesters from E. resinifera}

Figure S36. TIC and XIC for $\mathrm{m} / \mathrm{z}=575.2621$ in ESI (-) mode . .544

Figure S37. TIC and XIC for $\mathrm{m} / \mathrm{z}=597.2700$ in ESI (-) mode .545

Scheme S2. Proposed fragmentation route for selected ion on MSE spectrum for compound 9...........S46

Scheme S3. Proposed fragmentation route for selected ion on MSE spectrum for compound 10.........S47

Scheme S4. Proposed fragmentation route for selected ion on MSE spectrum for compound 11..........S48

\section{Effect of intranasal admisnistration of compounds}

Figure S38. Effect of the intranasal administration of $\mathbf{3}$

\section{Physicochemical properties}

Table S1. Physicochemical properties of compounds 1-11 S50

Table S2. Physicochemical properties of 12-deoxyphorbols

\section{Docking Analysis of phorbol derivatives}

Figure S39. Molecular docking of DPB, DPPI (10), 7 and 3 and Phorbol (1), DPA and DPPT (11) on PKC $8 C 1 B$ (PDB: 1PTR) S52

Figure S40. Molecular docking of DPA and DPPT (11), 7 and 3 and Phorbol (1), DPB, DPPI (10) on PKC $\beta$ X1B S53 


\section{Figure S1. Structure of active phorbol derivatives}

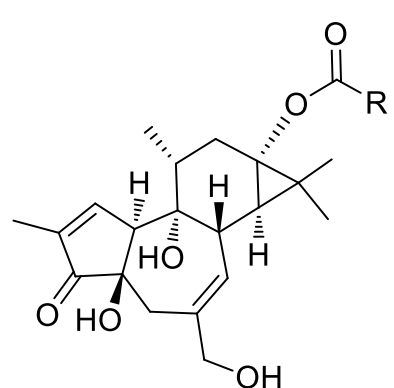

Prostratin

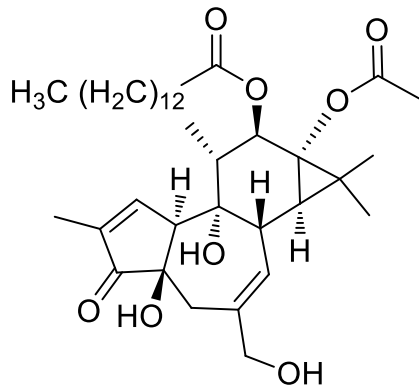

PMA

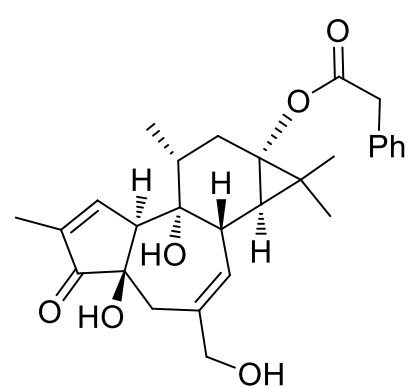

DPP

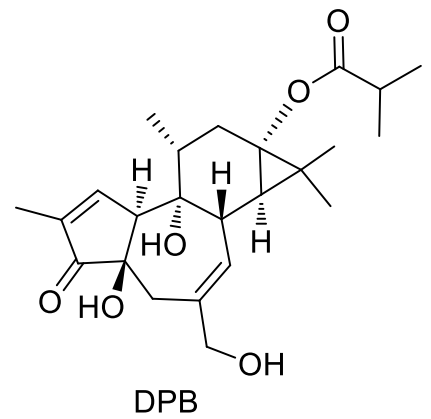

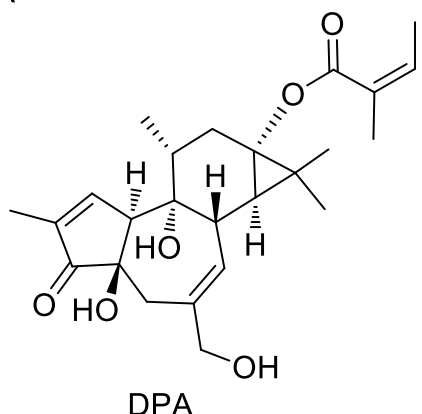

Figure S1. Phorbol derivatives capable of induction of neural progenitor cell (NPC) proliferation via PKC activation

\section{Preparation of phorbol 20-trityl ether (1a).}

Phorbol 20-trityl ether (1a) was used as starting material. Compound 1a was obtained from commercial croton oil following a modified protocol from that reported by Bertolini et al. ${ }^{1}$ which enables the transformation of the phorbol esters present in croton oil into a single product for further chemical transformations. This protocol involves the selective hydrolysis of acyl groups of phorbol esters at $\mathrm{C}-20$ position by treatment with a methanolic solution of $\mathrm{HClO}_{4}$, followed by protection of $20-\mathrm{OH}$ group by using trityl chloride in pyridine and further hydrolysis with sodium methoxide of acyl groups at C-12 and C-13 position (Scheme I). Final purification by silica gel column chromatography using hexane: ethyl acetate $(20: 80)$ as eluent is required. Following this procedure, $10.7 \mathrm{mg}$ of $1 \mathrm{a}$ per gram of croton oil was obtained.
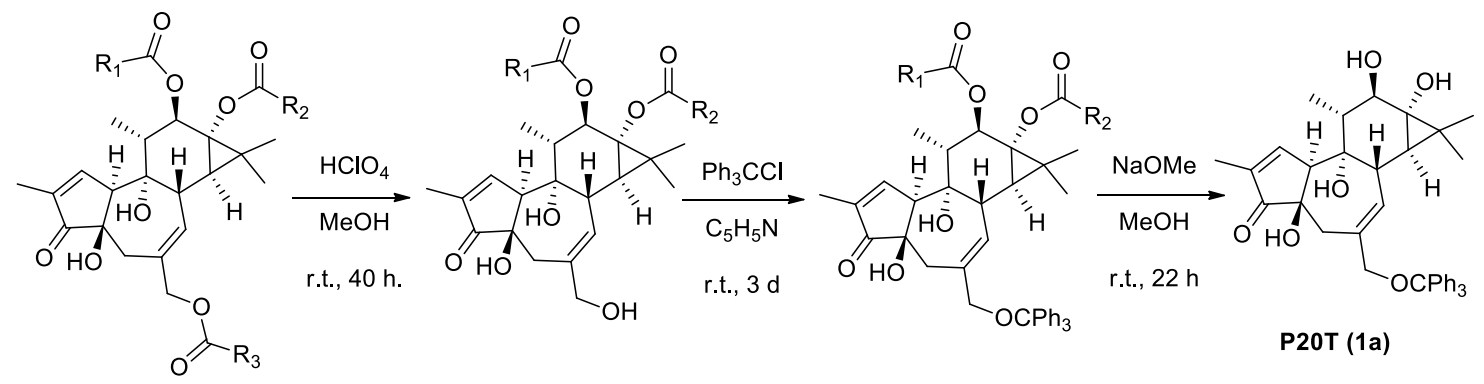

Scheme S1. Preparation of phorbol 20-trityl ether (1a) from Croton oil

\footnotetext{
${ }^{1}$ Bertolini T. M., Giorgione J., Harvey D. F., Newton A. C. Protein kinase C translocation by modified phorbol esters with functionalized lipophilic regions. J. Org. Chem. 2003, 68, 5028-5036.
} 


\section{NMR Spectra}

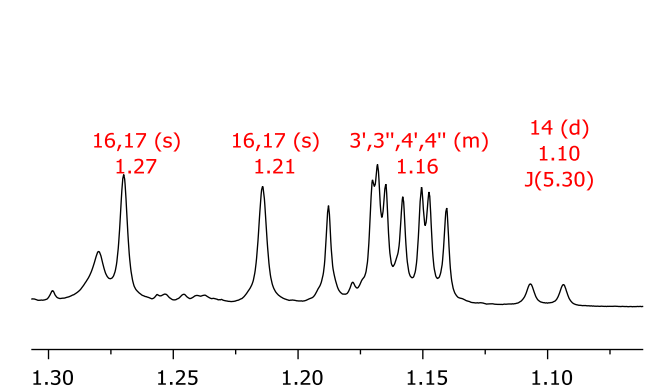

7.54
$J(2.70,1.42)$
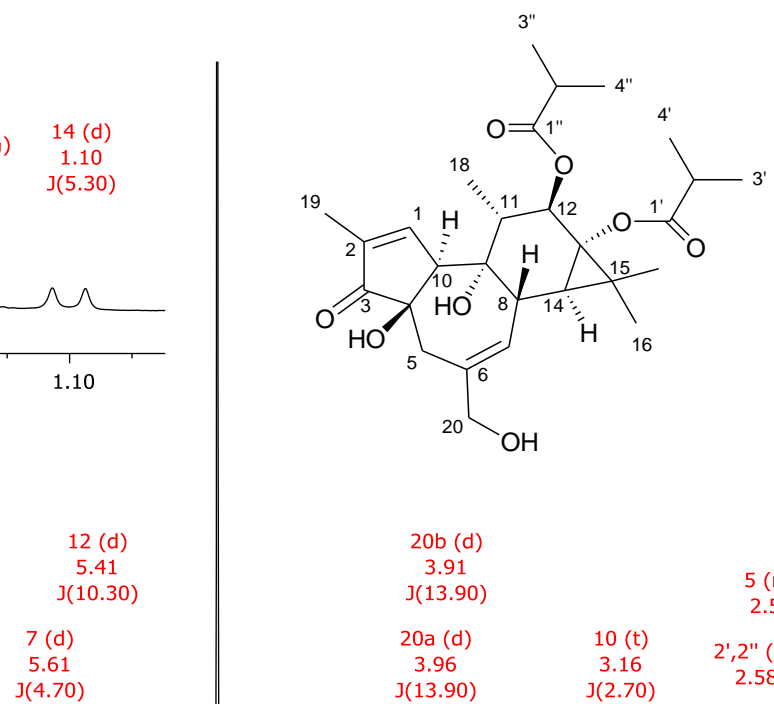

$3^{\prime}, 3^{\prime \prime}, 4^{\prime}, 4^{\prime \prime}(\mathrm{m})$

$$
20 \mathrm{~b}(\mathrm{~d})
$$

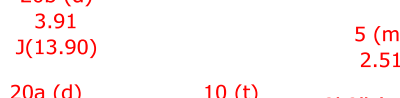

$20 \mathrm{a}(\mathrm{d})$

3.96

$\begin{array}{cc}10(\mathrm{t}) & 2^{\prime}, 2^{\prime \prime}(\mathrm{m}) \\ 3.16 & 2.58 \\ J(2.70) & \end{array}$

$14(\mathrm{~d})$
1.10
$\mathrm{~J}(5.30)$

$\begin{array}{ccc} & 19(\mathrm{dd}) & 18(\mathrm{~d}) \\ 2.58 & 1.73 & 0.88 \\ & \mathrm{~J}(2.70,1.39) & \mathrm{J}(6.50)\end{array}$ $(4.70)$

4.

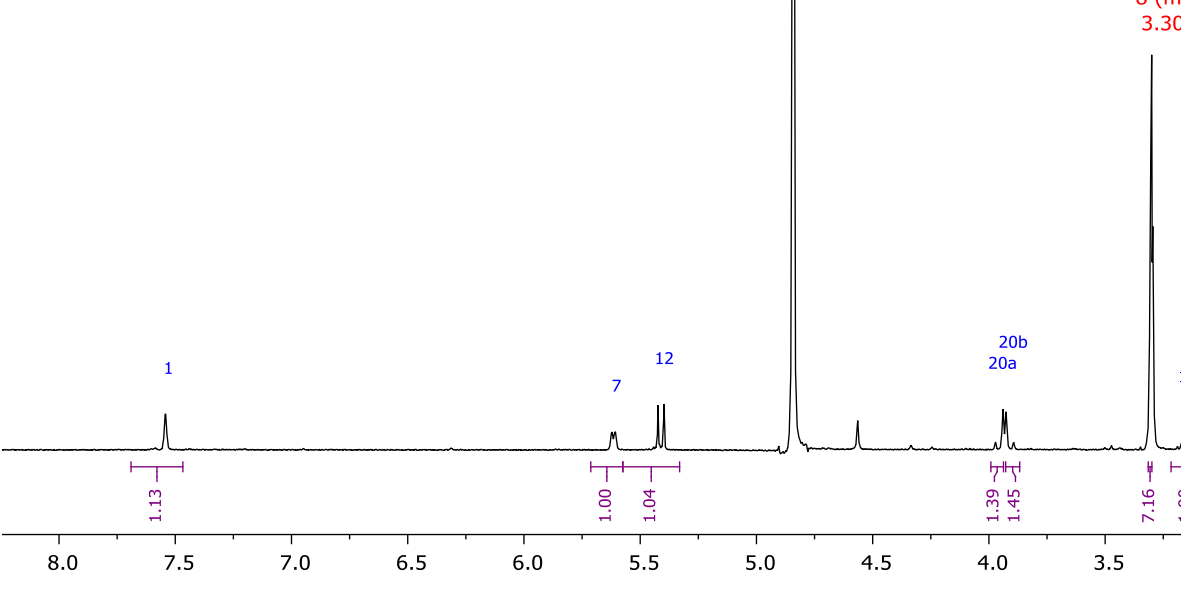

\begin{tabular}{lcc|}
$8(\mathrm{~m})$ & $11(\mathrm{dq})$ & $16,17(\mathrm{~s})$ \\
3.30 & 2.22 & 1.27 \\
& $J(10.46,6.33)$ & $16,17(\mathrm{~s})$ \\
& & 1.21 \\
& & $4.4^{\prime \prime}, 3^{\prime}, 3^{\prime \prime}$
\end{tabular}

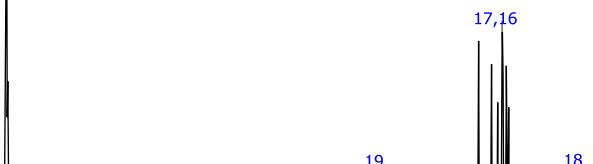

Figure S2. ${ }^{1} \mathrm{H}-\mathrm{NMR}\left(400 \mathrm{MHz}, \mathrm{CD}_{3} \mathrm{OD}\right)$ spectrum of compound 3 


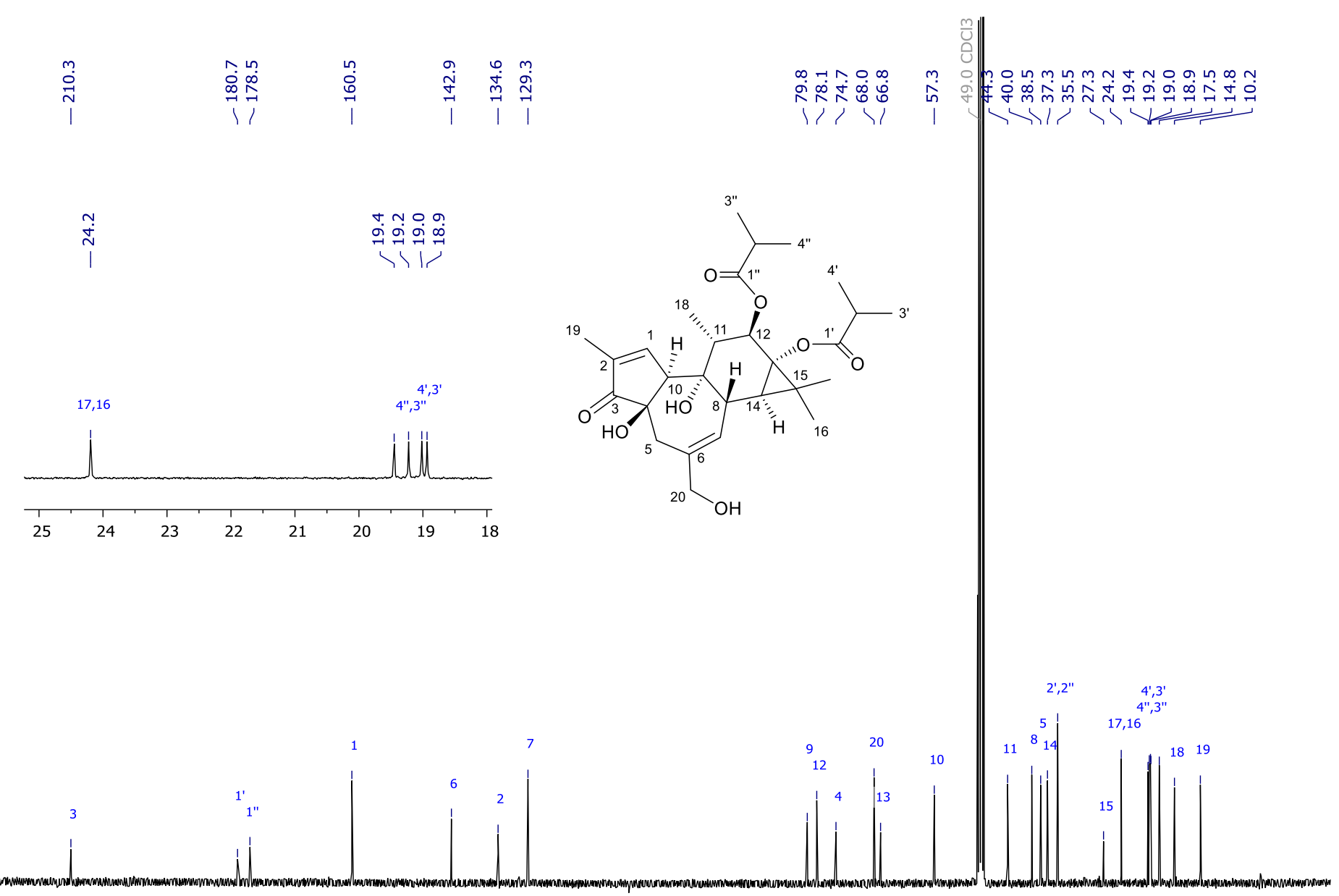

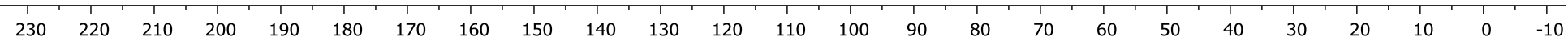

Figure S3. ${ }^{13} \mathrm{C}-\mathrm{NMR}\left(100 \mathrm{MHz}, \mathrm{CD}_{3} \mathrm{OD}\right)$ spectrum of compound 3 


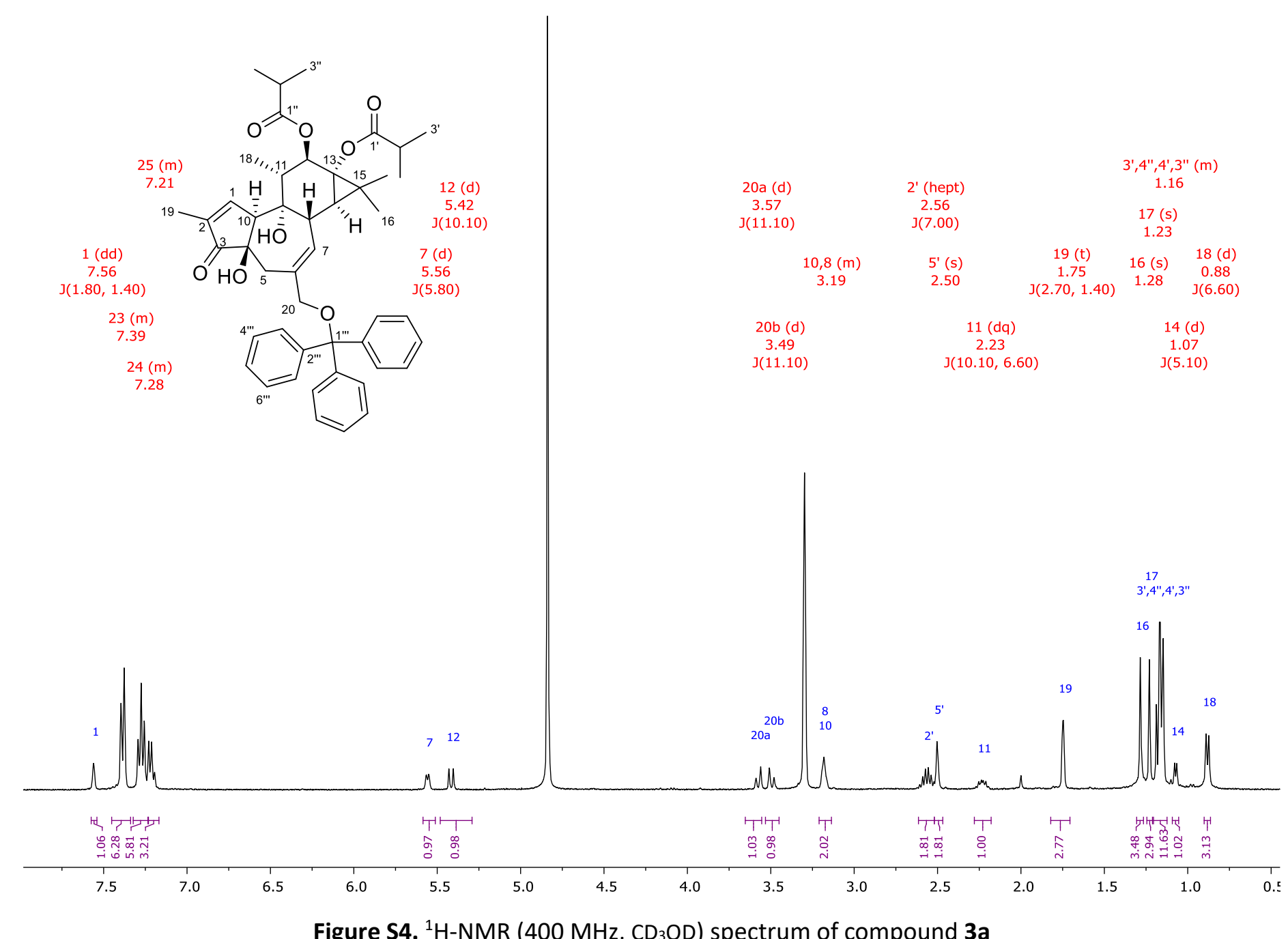

Figure S4. ${ }^{1} \mathrm{H}-\mathrm{NMR}\left(400 \mathrm{MHz}, \mathrm{CD}_{3} \mathrm{OD}\right)$ spectrum of compound $3 \mathrm{a}$ 


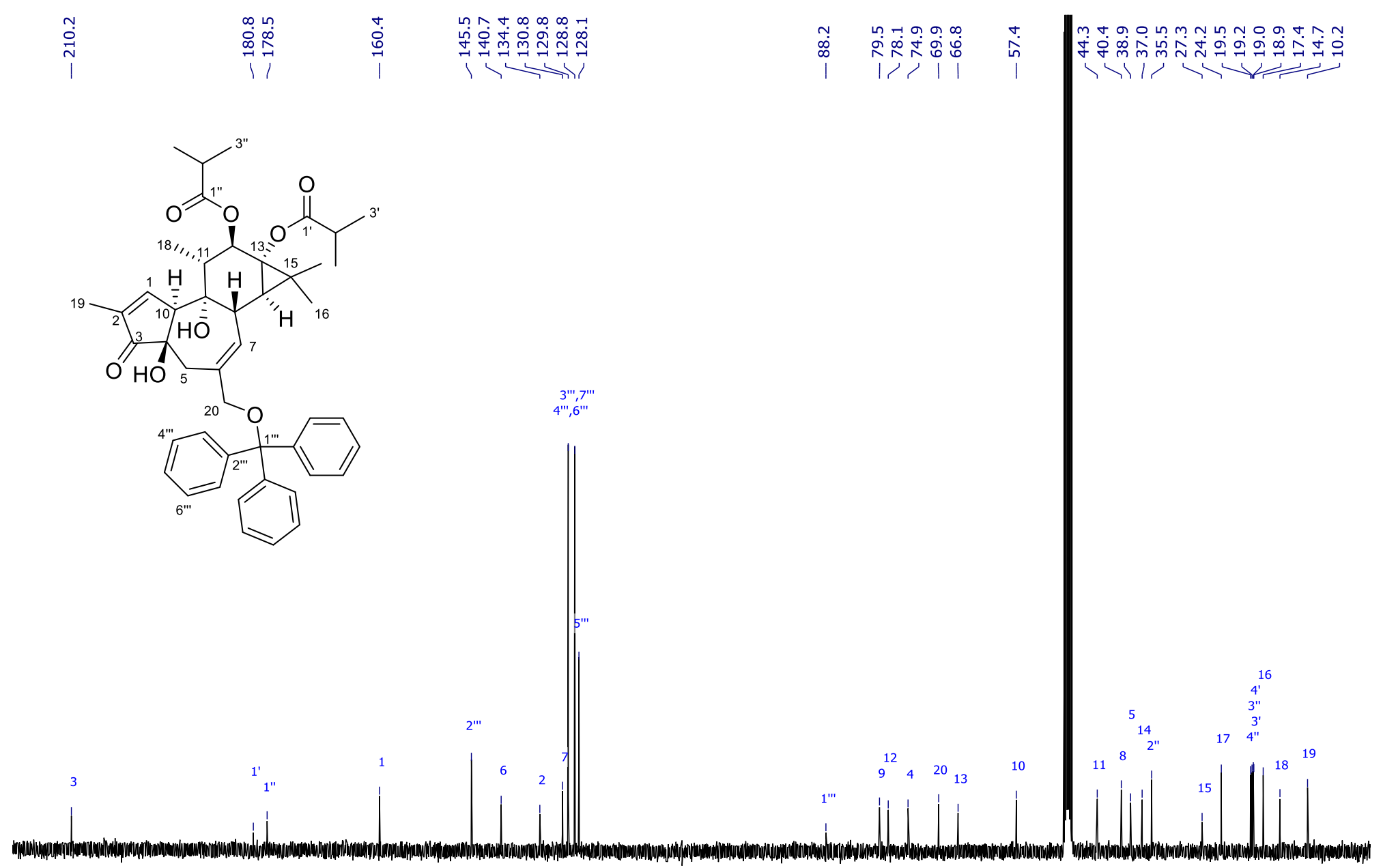

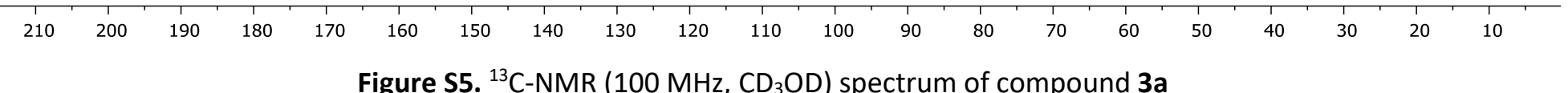




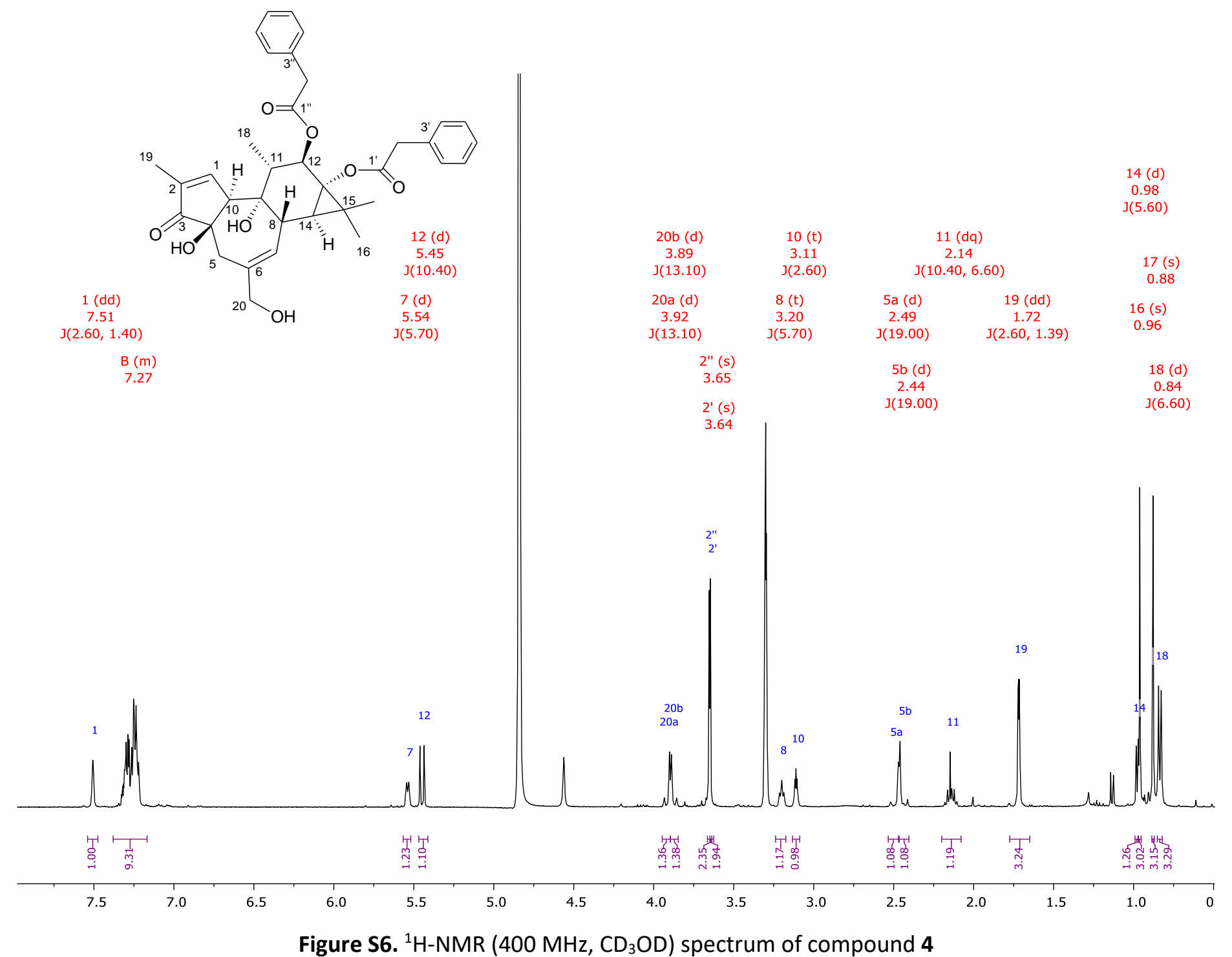




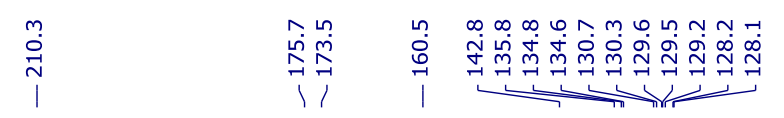
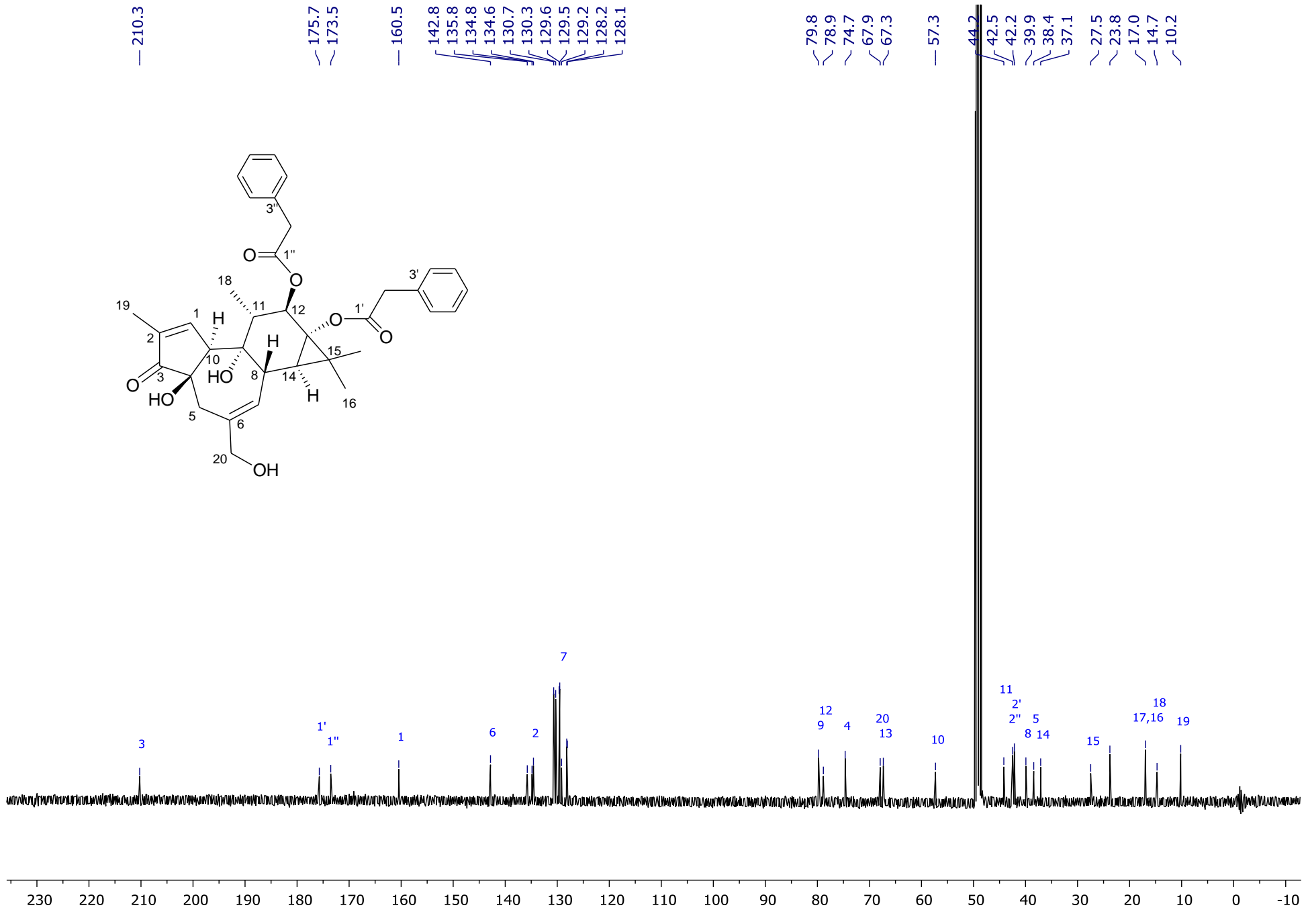

Figure S7. ${ }^{13} \mathrm{C}-\mathrm{NMR}\left(100 \mathrm{MHz}, \mathrm{CD}_{3} \mathrm{OD}\right)$ spectrum of compound 4

S10 


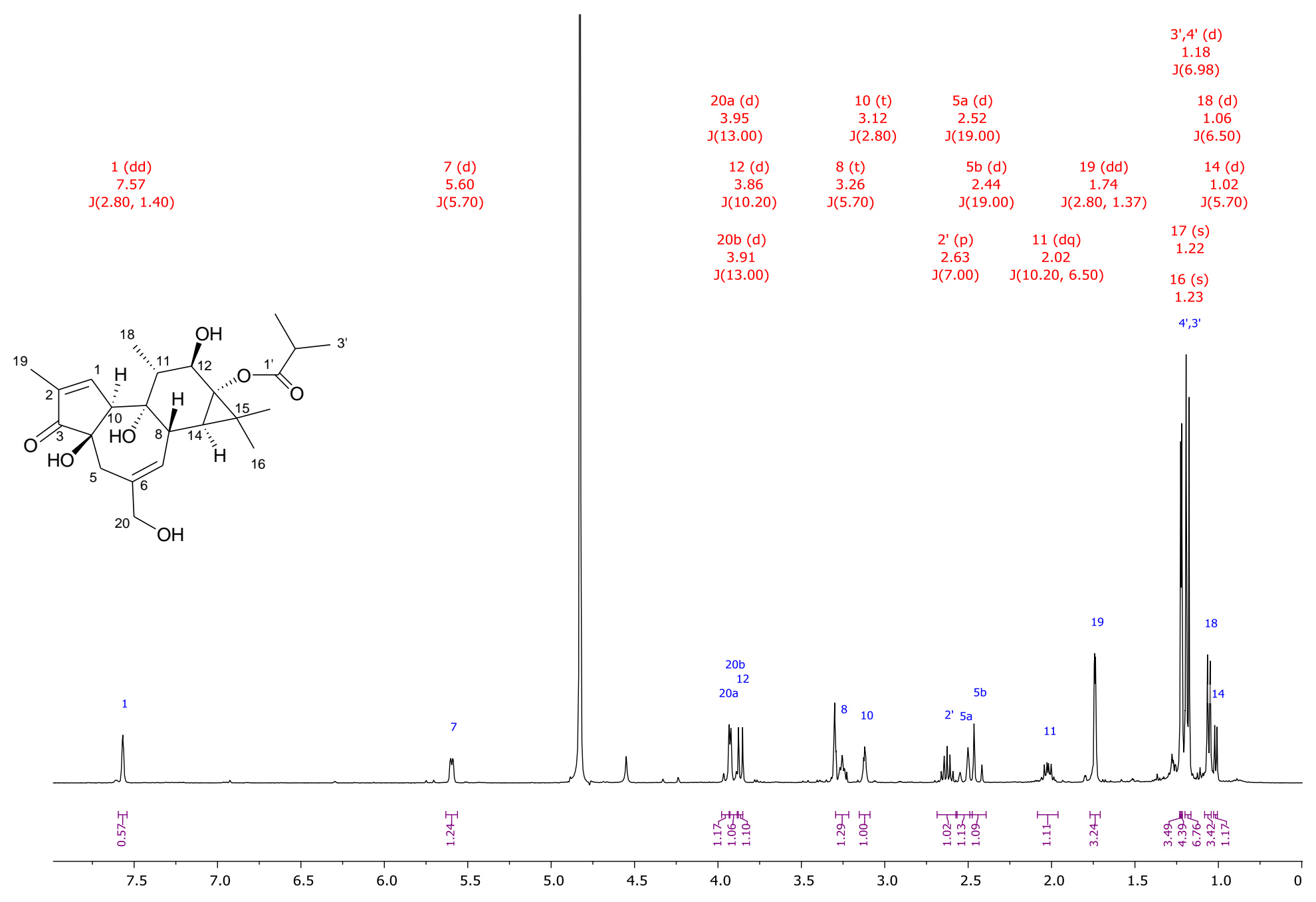

Figure S8. ${ }^{1} \mathrm{H}-\mathrm{NMR}\left(400 \mathrm{MHz}, \mathrm{CD}_{3} \mathrm{OD}\right)$ spectrum of compound $\mathbf{5}$ 


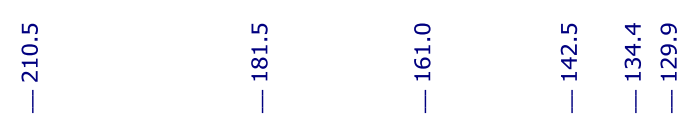
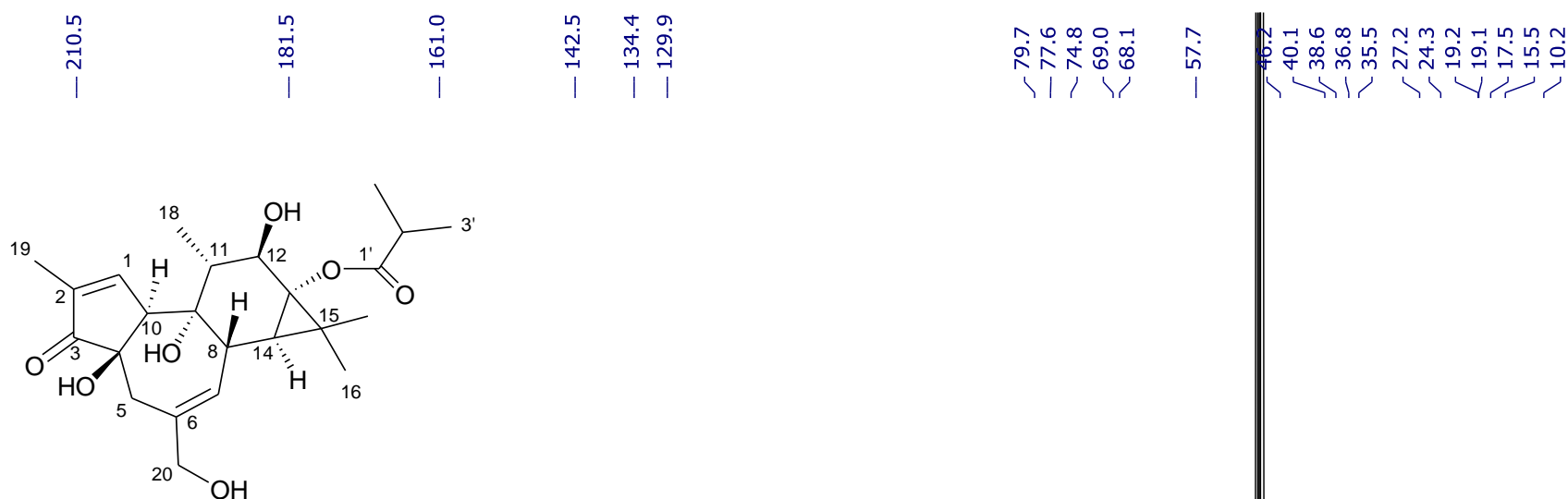

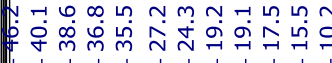

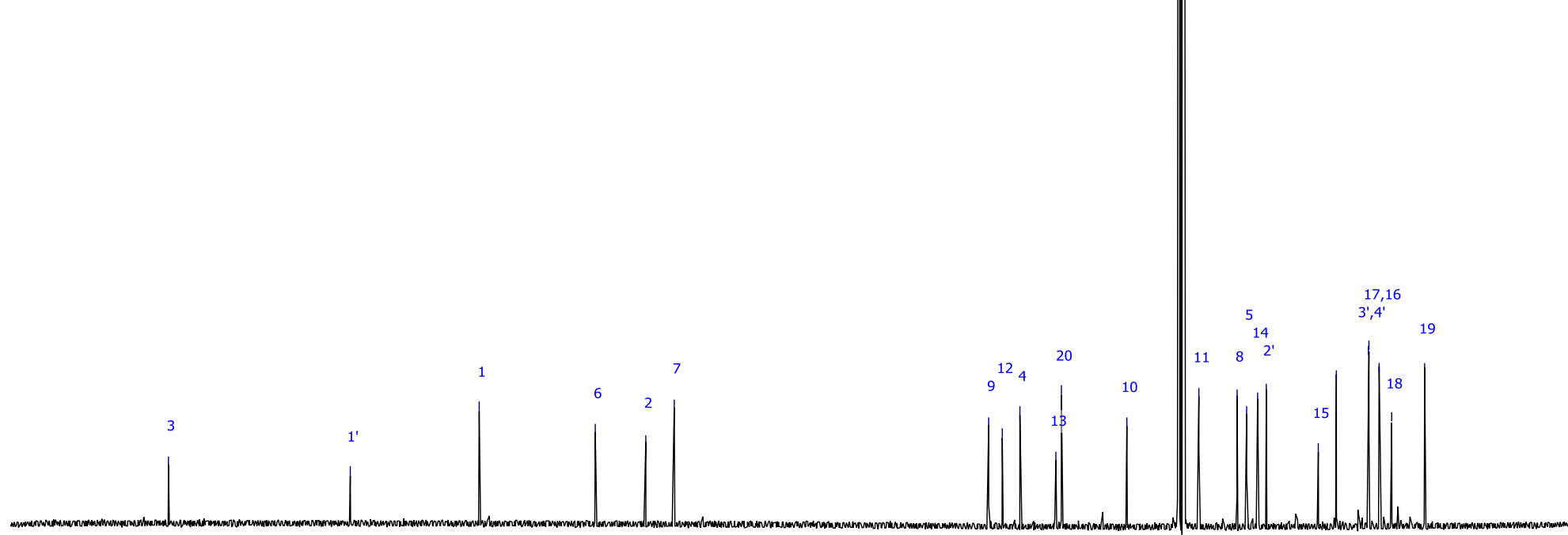

$\begin{array}{lllllllllllllllllll}230 & 220 & 210 & 200 & 190 & 180 & 170 & 160 & 150 & 140 & 130 & 120 & 110 & 100 & 90 & 80 & 70 & 60 & 50\end{array}$

Figure S9. ${ }^{13} \mathrm{C}-\mathrm{NMR}\left(100 \mathrm{MHz}, \mathrm{CD}_{3} \mathrm{OD}\right)$ spectrum of compound $\mathbf{5}$ 


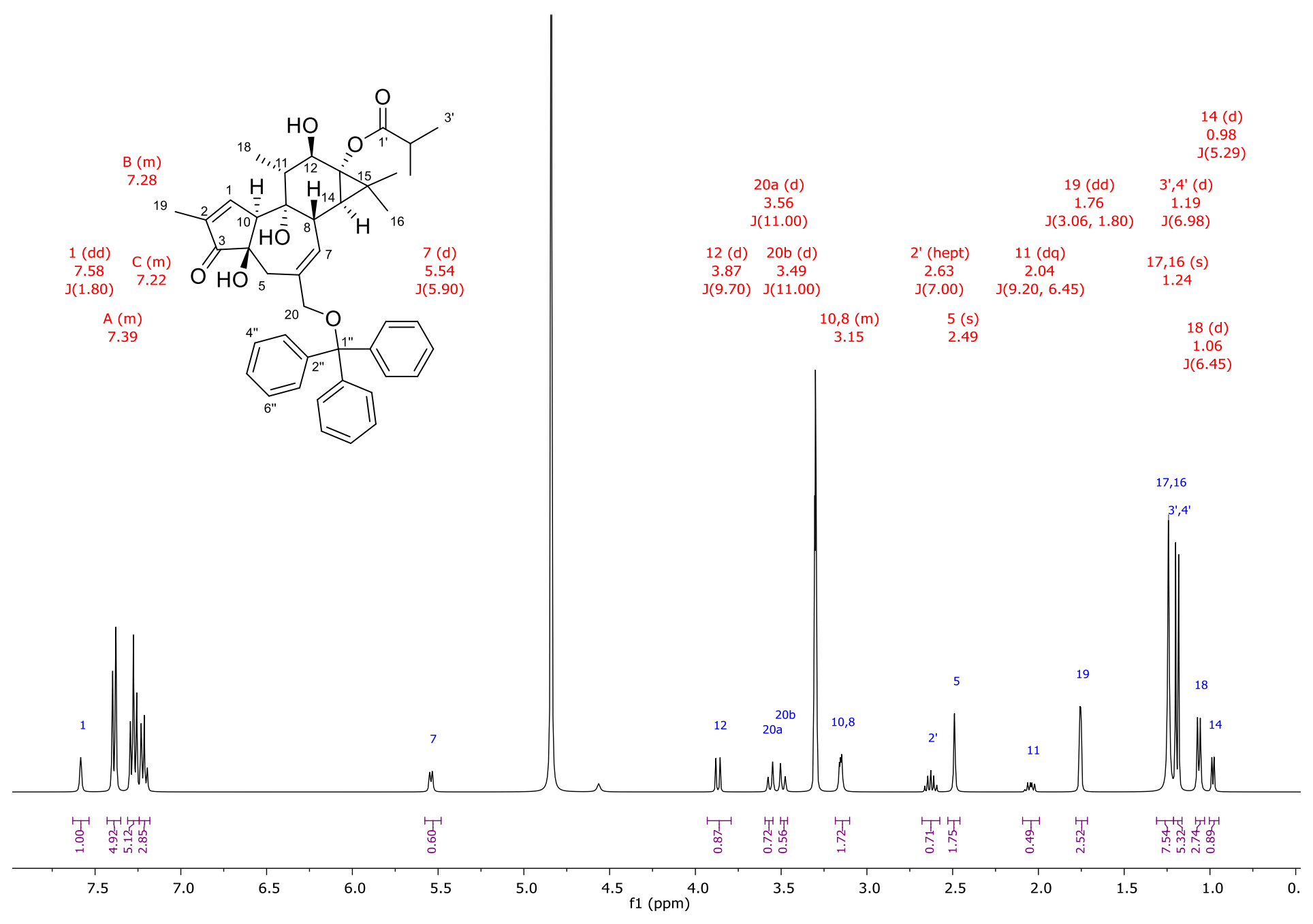

Figure S10. ${ }^{1} \mathrm{H}-\mathrm{NMR}\left(400 \mathrm{MHz}, \mathrm{CD}_{3} \mathrm{OD}\right.$ ) spectrum of compound $\mathbf{5 a}$ 


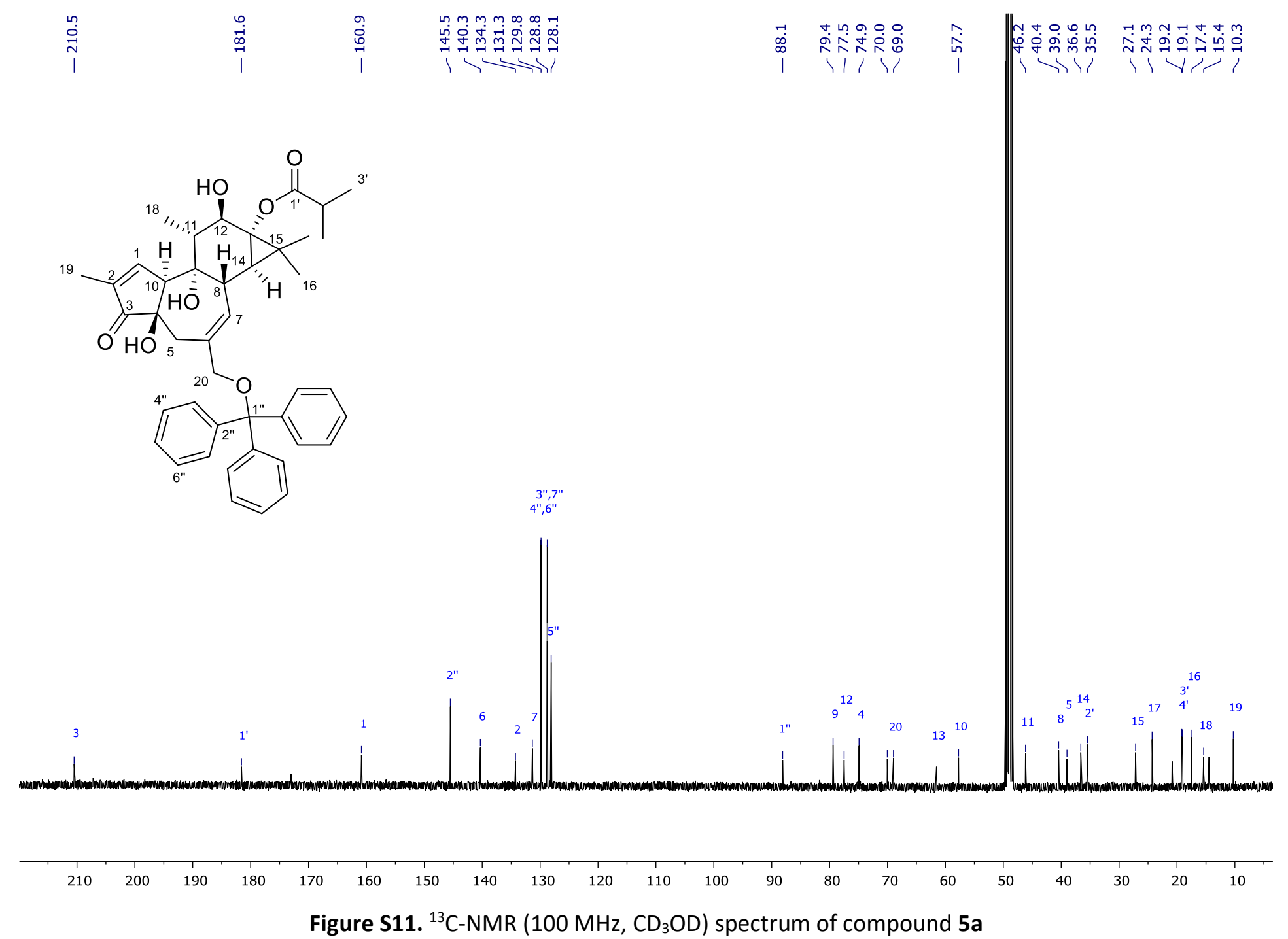




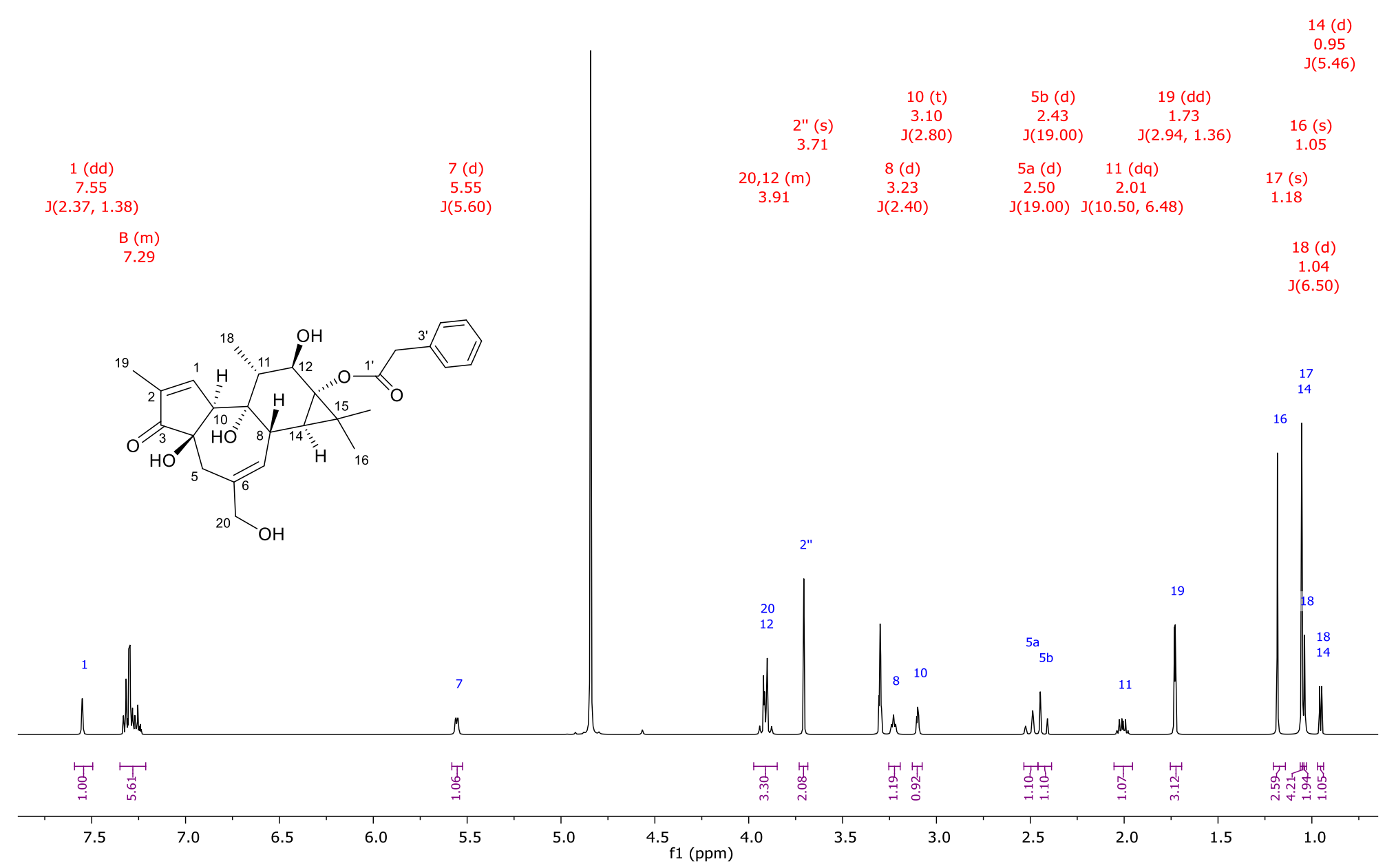

Figure S12. ${ }^{1} \mathrm{H}-\mathrm{NMR}\left(500 \mathrm{MHz}, \mathrm{CD}_{3} \mathrm{OD}\right)$ spectrum of compound 6 

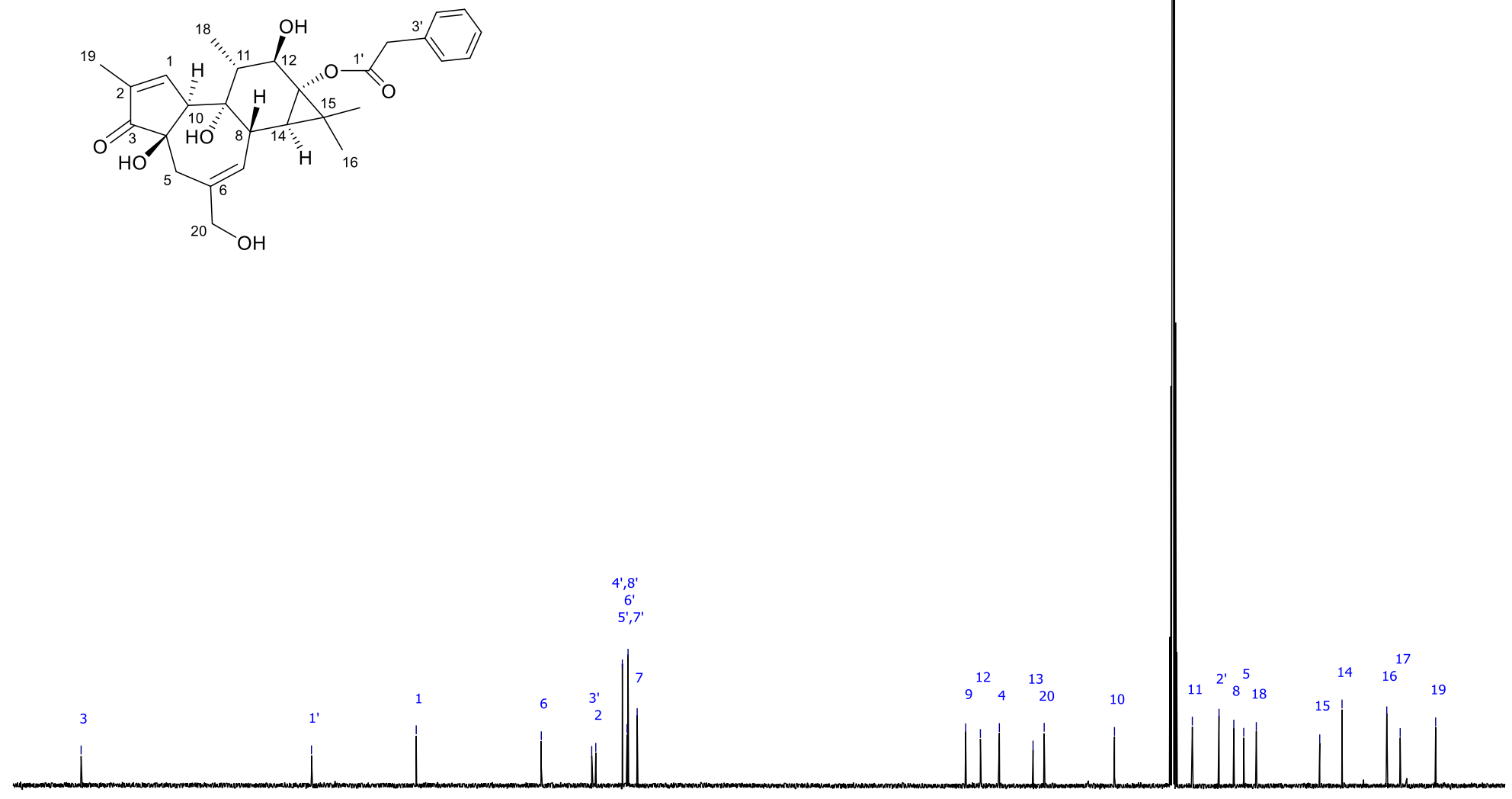

$: 20$

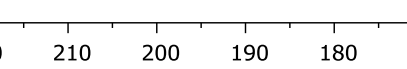

Figure S13. ${ }^{13} \mathrm{C}-\mathrm{NMR}\left(125 \mathrm{MHz}, \mathrm{CD}_{3} \mathrm{OD}\right)$ spectrum of compound 6 


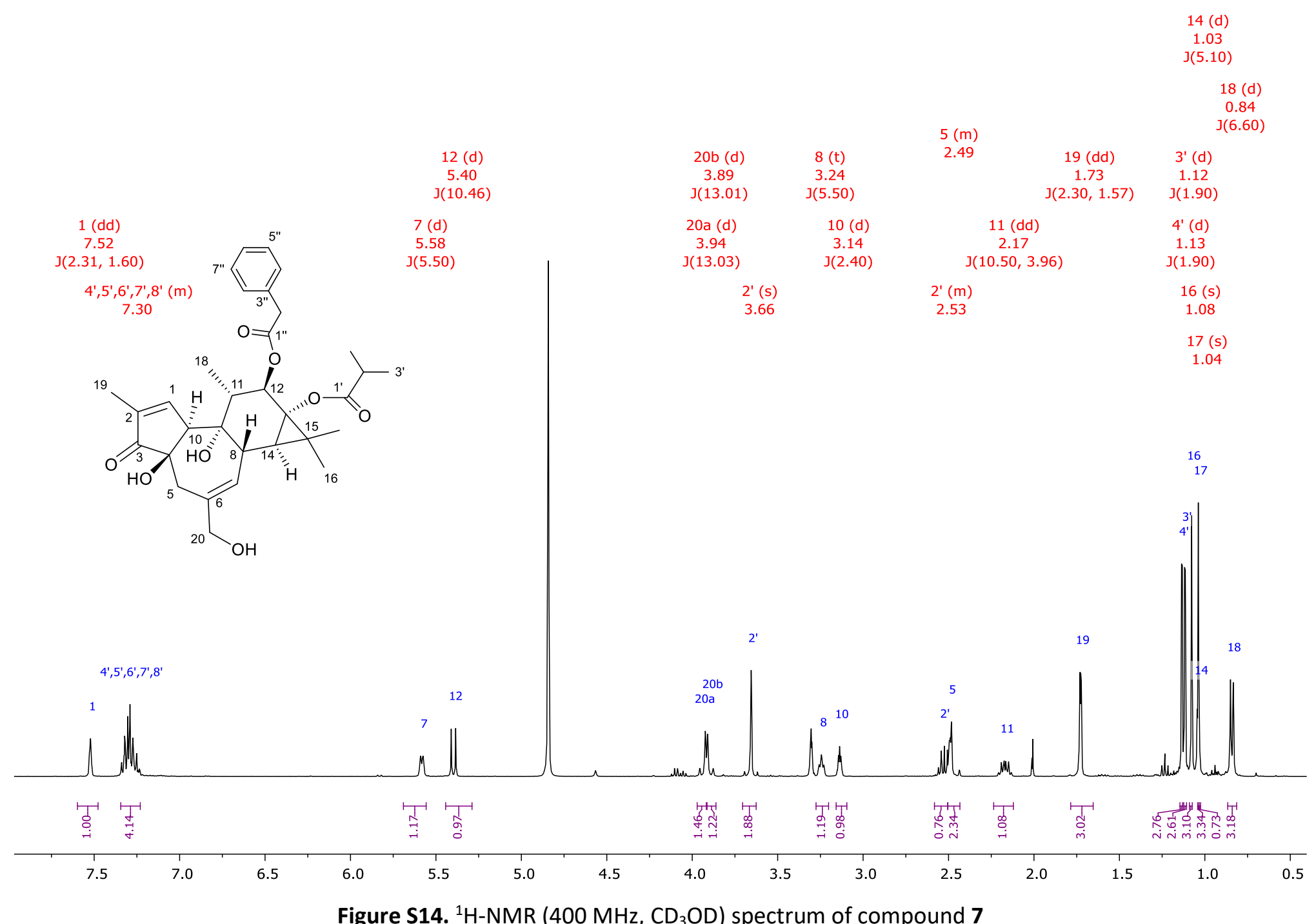



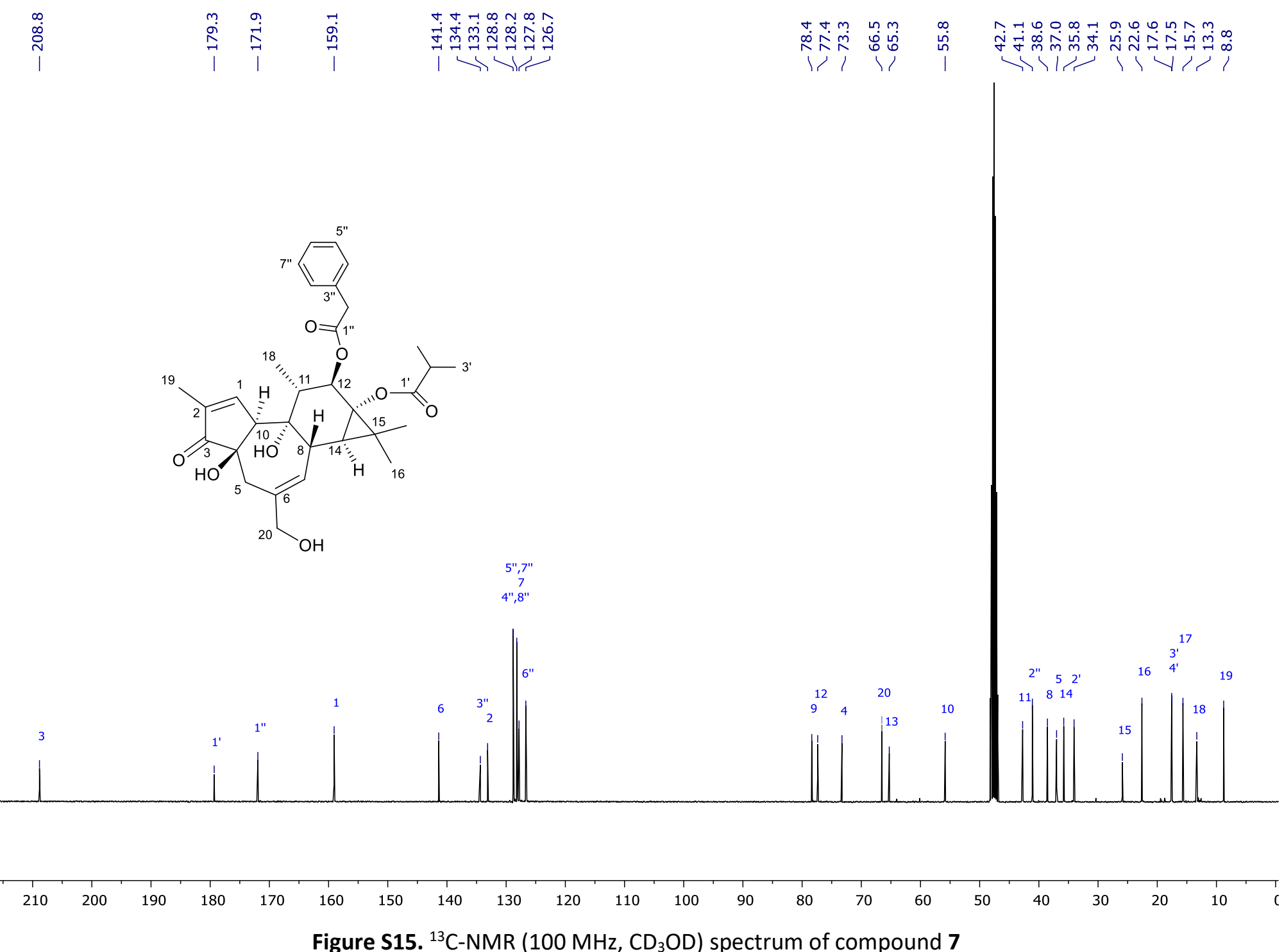


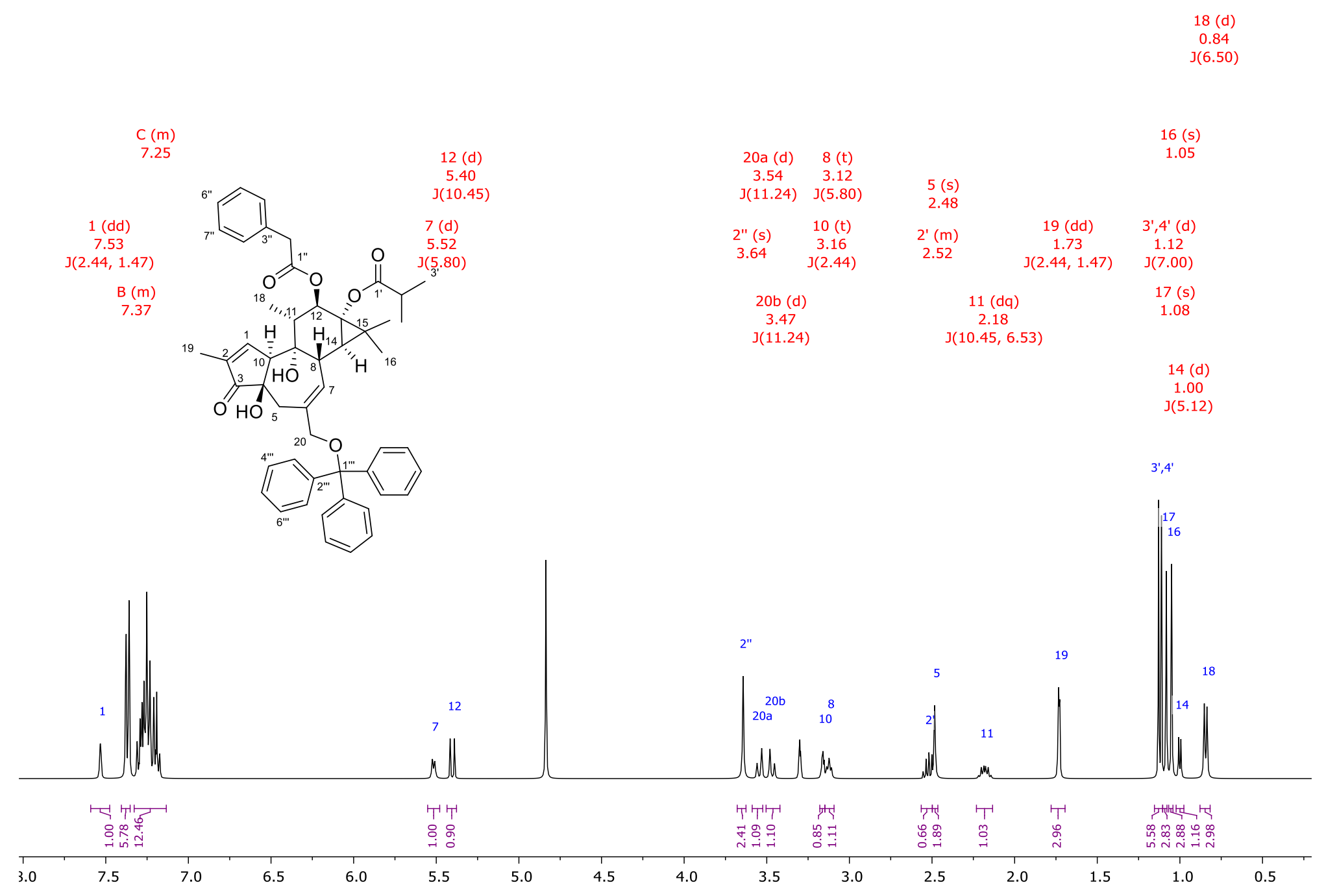

Figure S16. ${ }^{1} \mathrm{H}-\mathrm{NMR}\left(400 \mathrm{MHz}, \mathrm{CD}_{3} \mathrm{OD}\right.$ ) spectrum of compound $7 \mathrm{a}$ 

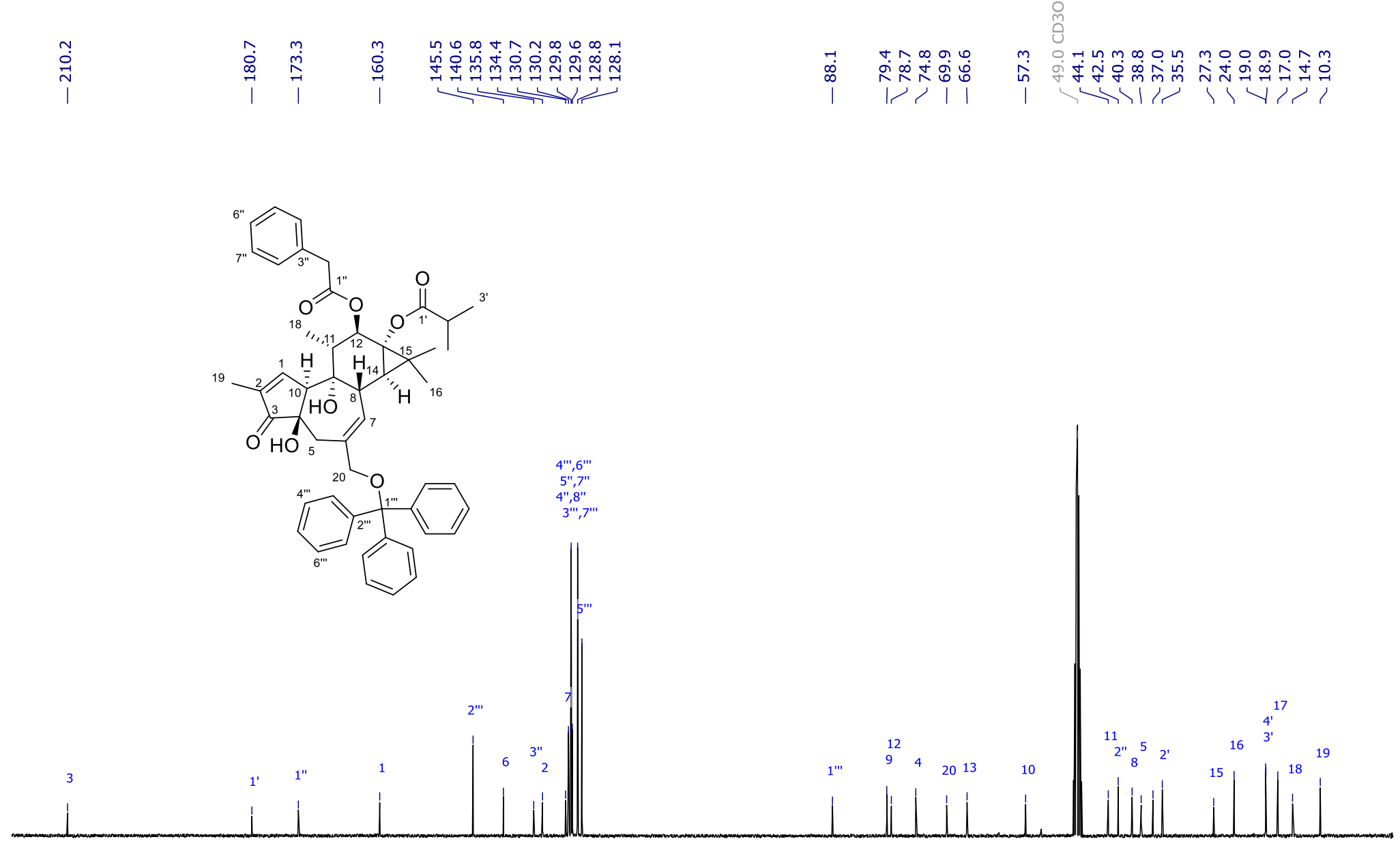

$\begin{array}{llllllllllllllllllllll}1 & 1 \\ 210 & 200 & 190 & 180 & 170 & 160 & 150 & 140 & 130 & 120 & 110 & 100 & 90 & 80 & 70 & 60 & 50 & 40 & 30 & 20 & 10 & 0\end{array}$ Figure S17. ${ }^{13} \mathrm{C}-\mathrm{NMR}\left(100 \mathrm{MHz}, \mathrm{CD}_{3} \mathrm{OD}\right)$ spectrum of compound $7 \mathrm{a}$ 


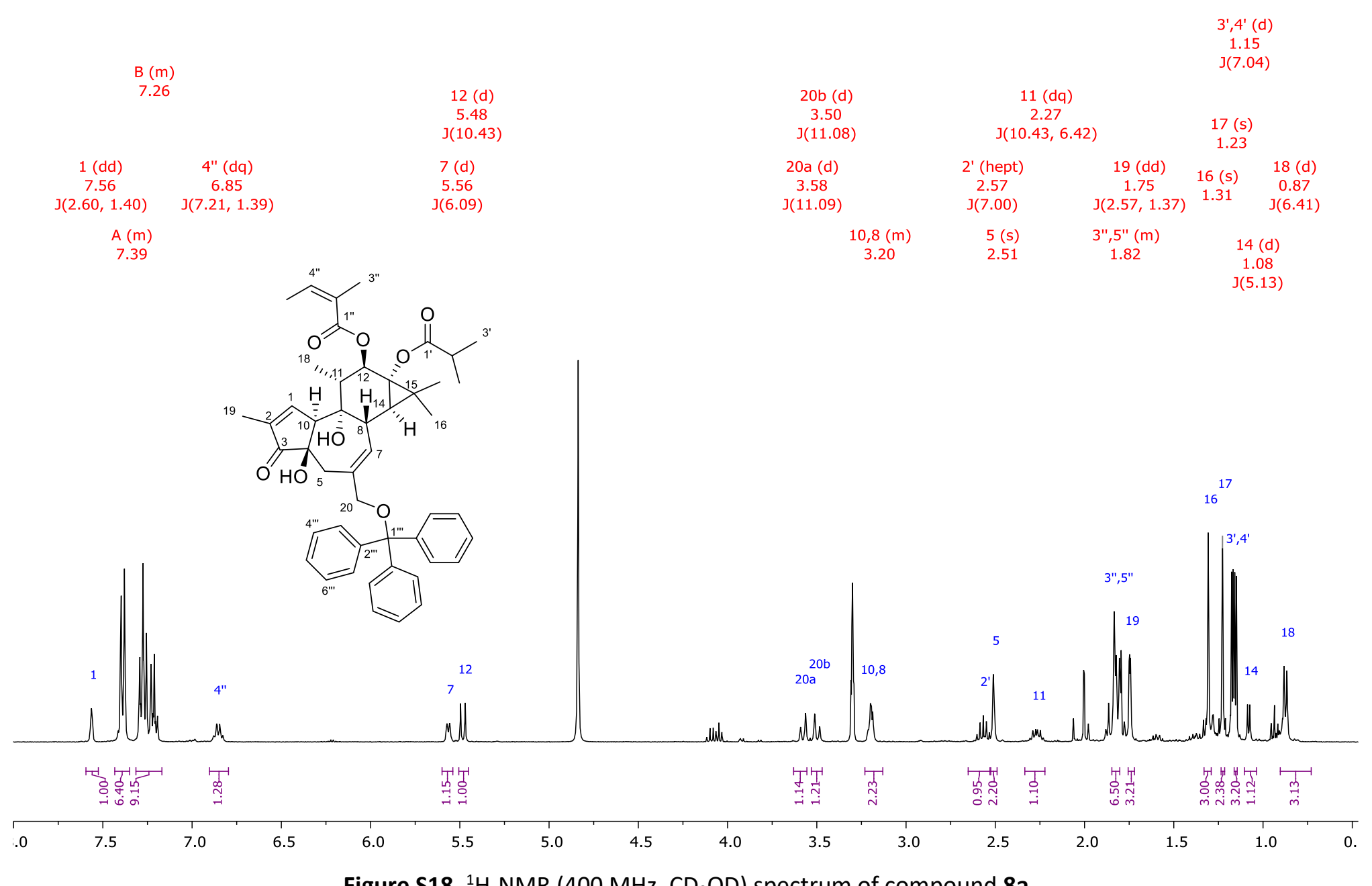




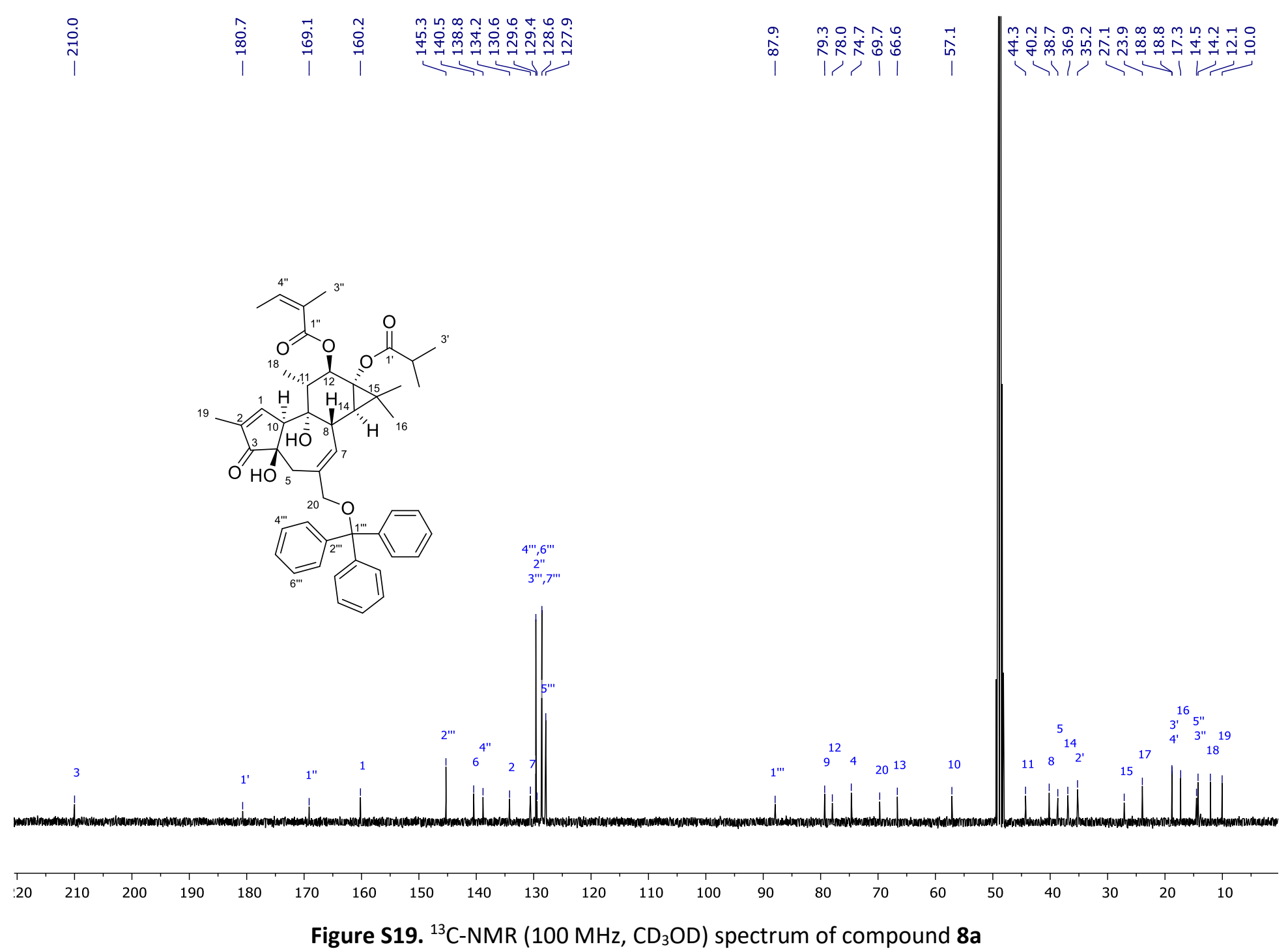



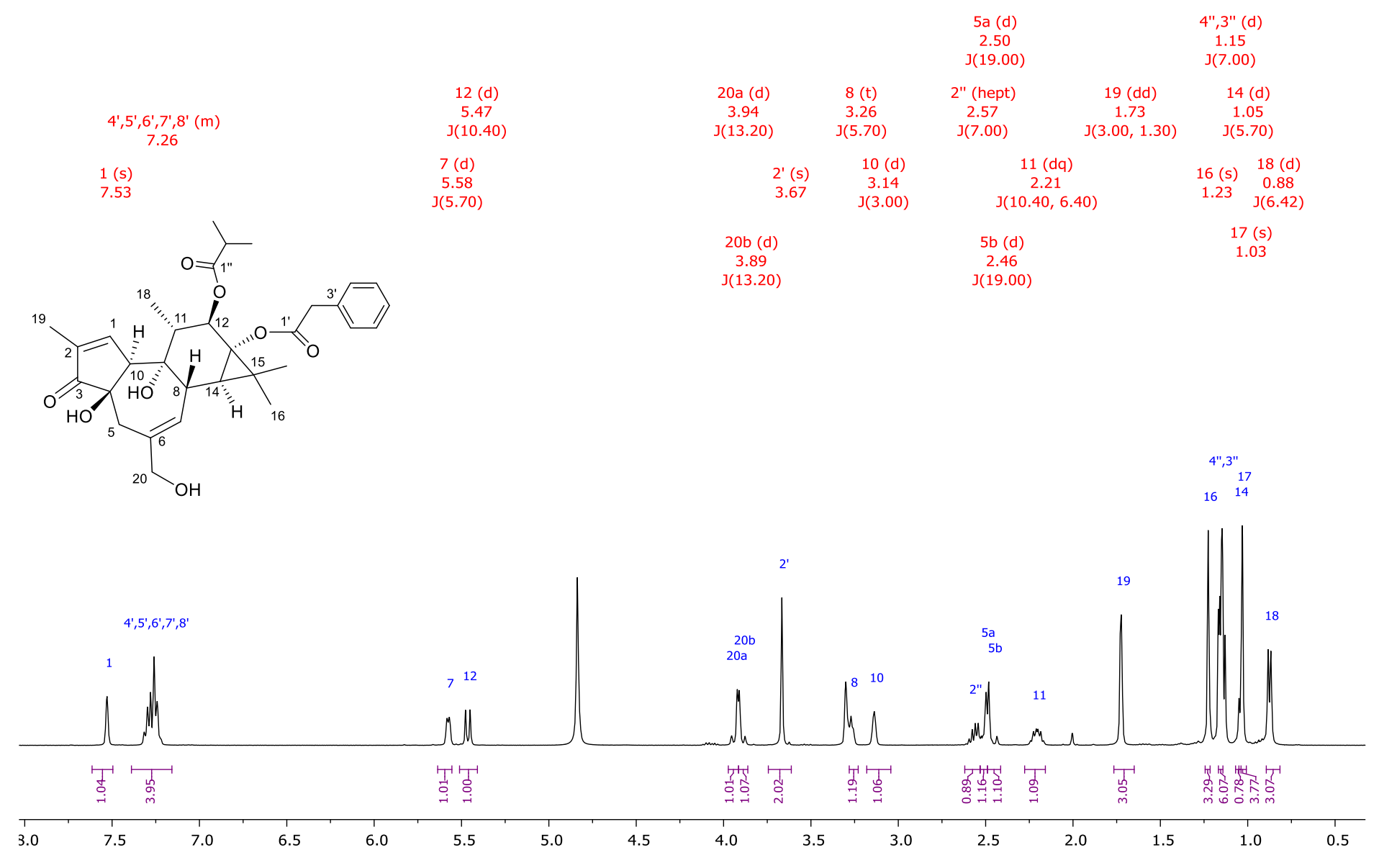

Figure S20. ${ }^{1} \mathrm{H}-\mathrm{NMR}\left(400 \mathrm{MHz}, \mathrm{CD}_{3} \mathrm{OD}\right)$ spectrum of compound 9 


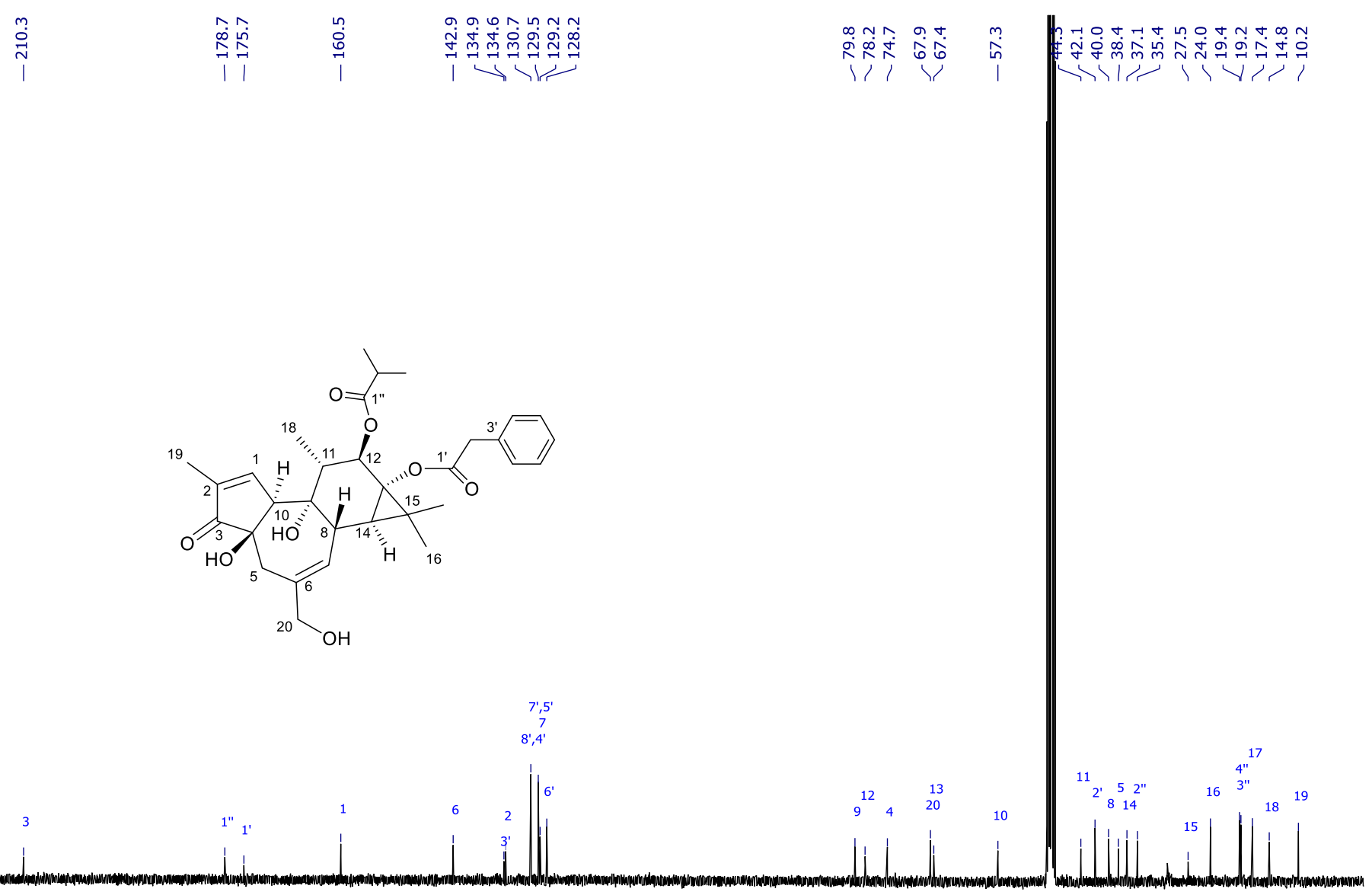

$\begin{array}{llllllllllllllll}210 & 200 & 190 & 180 & 170 & 160 & 150 & 140 & 130 & 120 & 110 & 100 & 90 & 80 & 70 & 60\end{array}$

Figure S21. ${ }^{13} \mathrm{C}-\mathrm{NMR}\left(100 \mathrm{MHz}, \mathrm{CD}_{3} \mathrm{OD}\right)$ spectrum of compound 9 


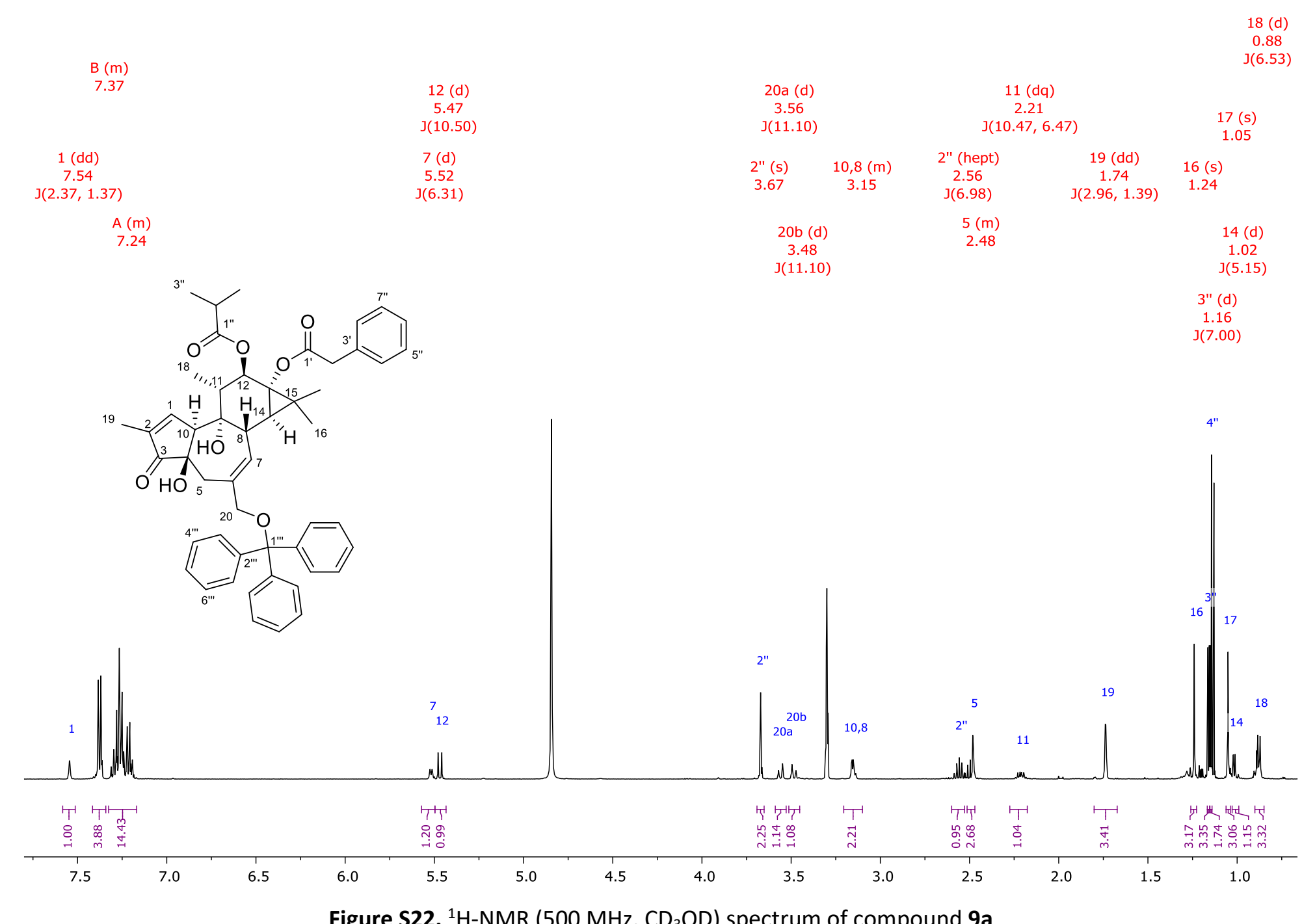




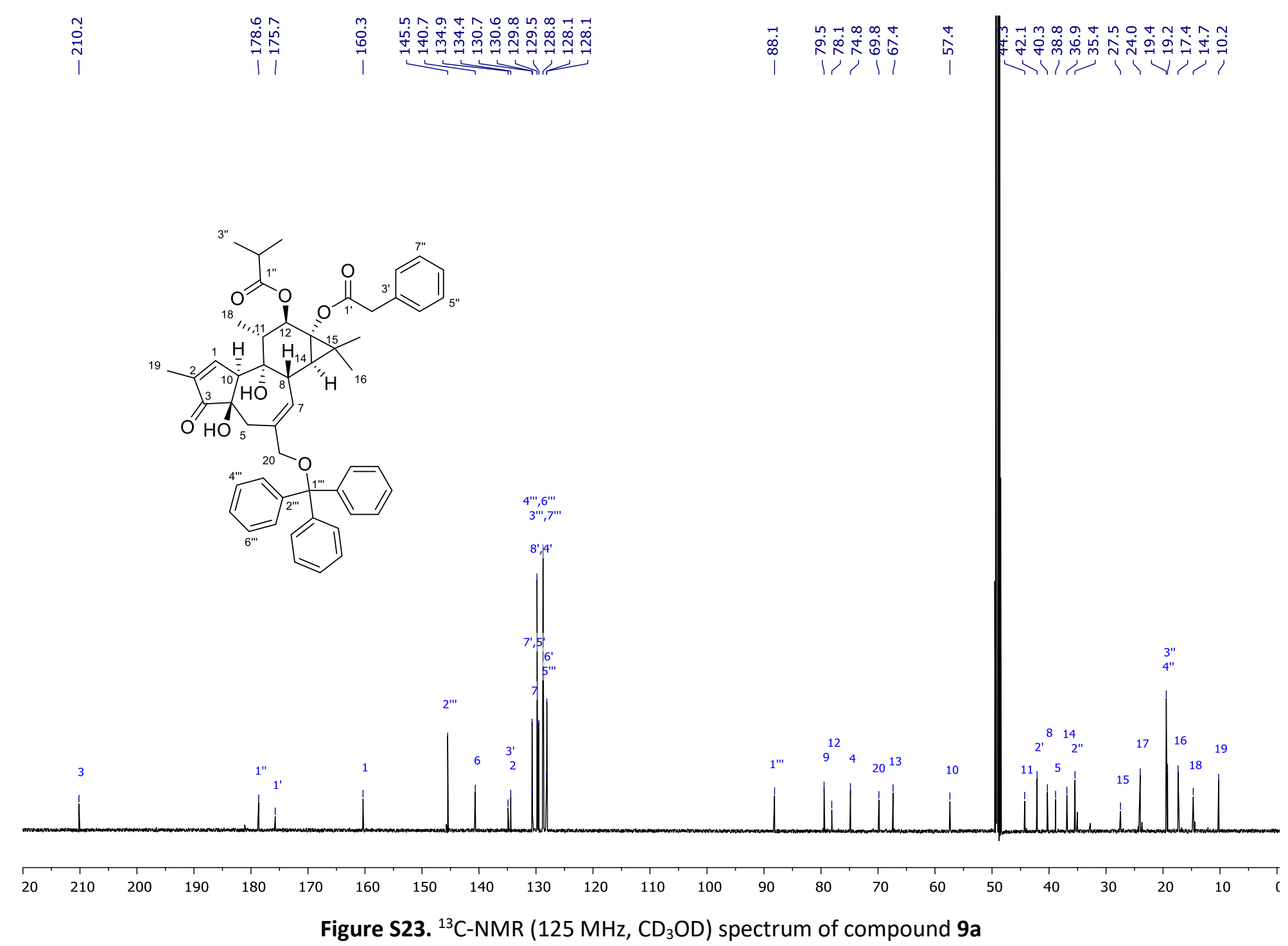




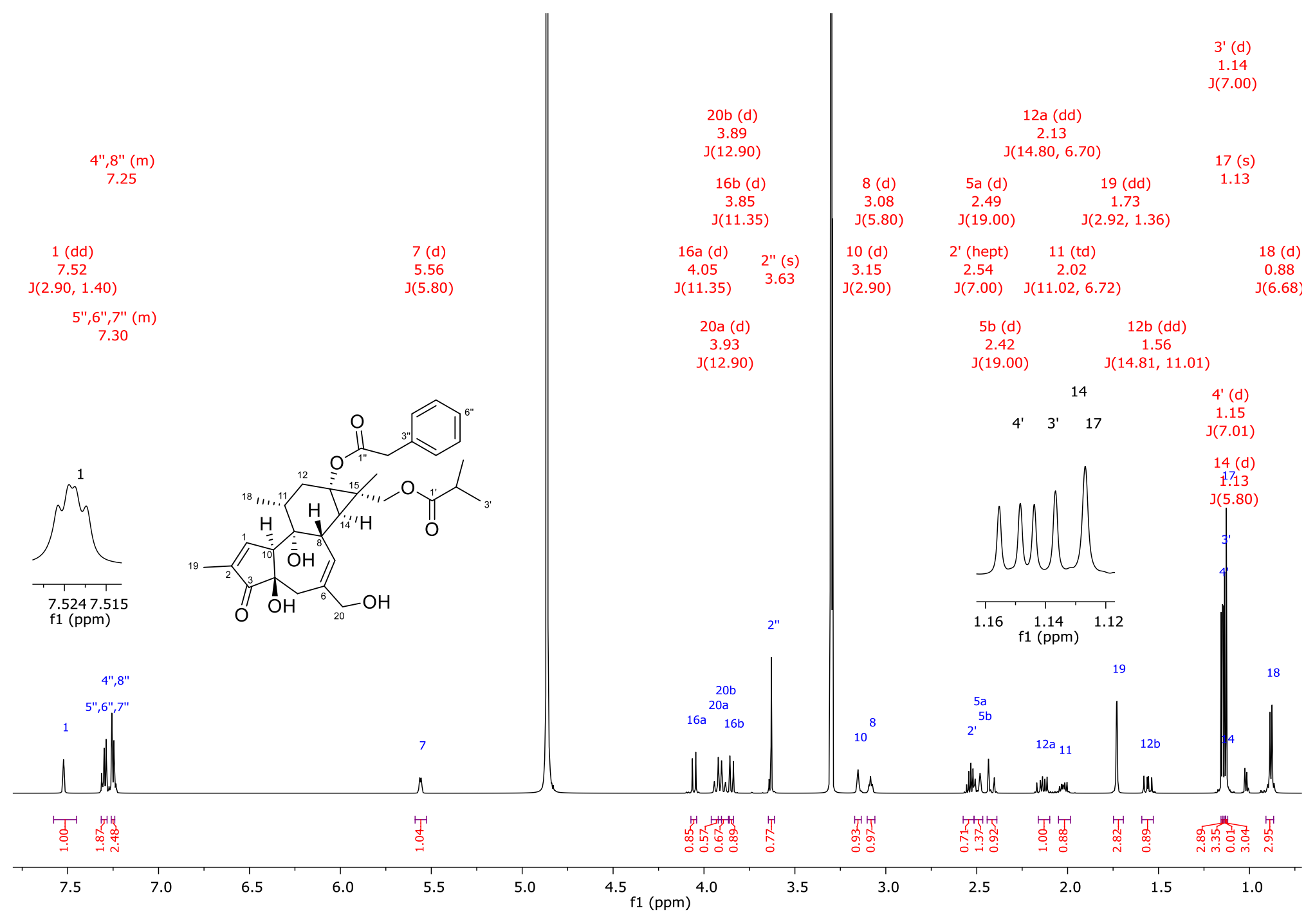

Figure S24. ${ }^{1} \mathrm{H}-\mathrm{NMR}\left(600 \mathrm{MHz}, \mathrm{CD}_{3} \mathrm{OD}\right)$ spectrum of DPPI (10) 

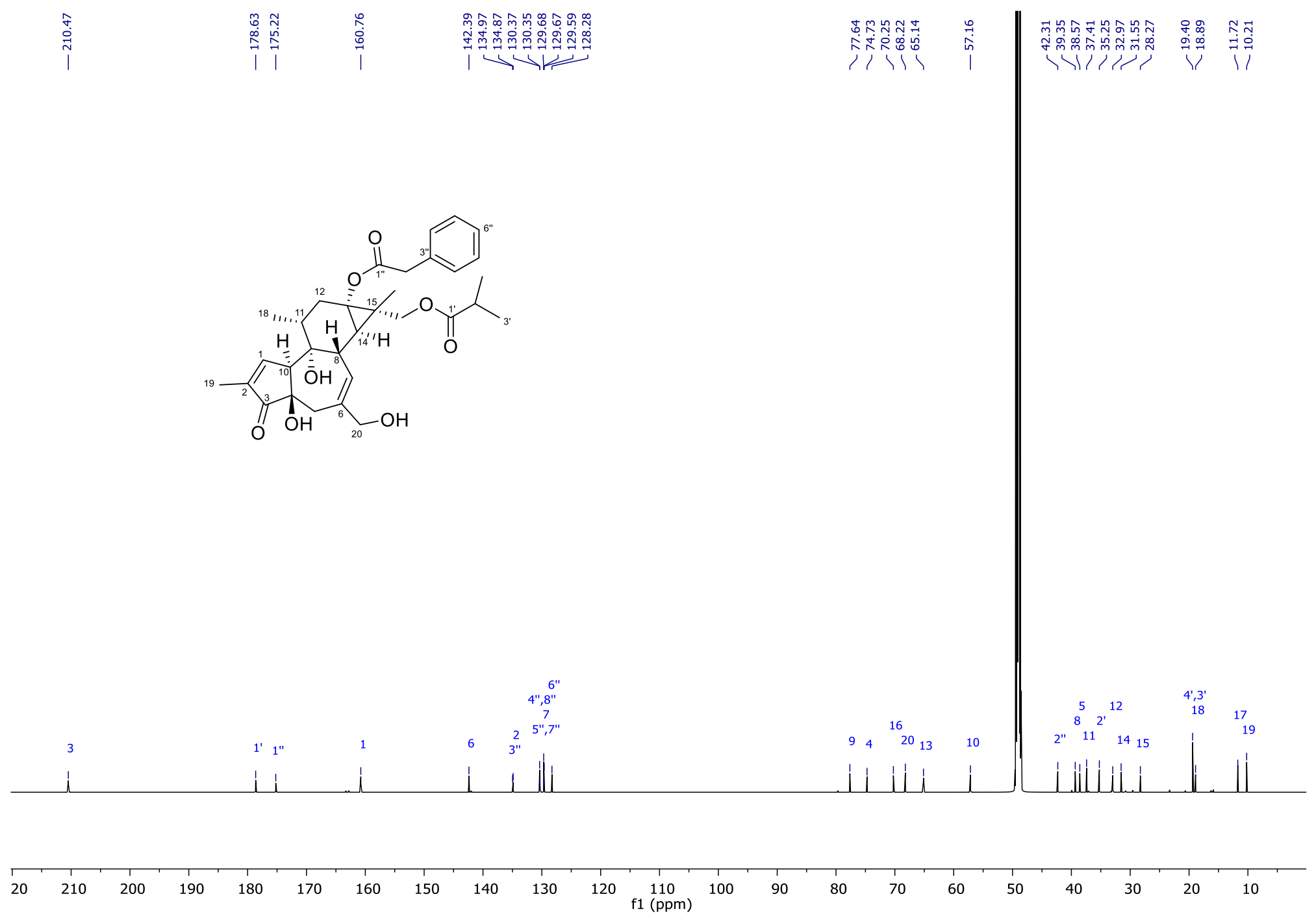

Figure S25. ${ }^{13} \mathrm{C}-\mathrm{NMR}\left(151 \mathrm{MHz}, \mathrm{CD}_{3} \mathrm{OD}\right)$ spectrum of DPPI (10) 


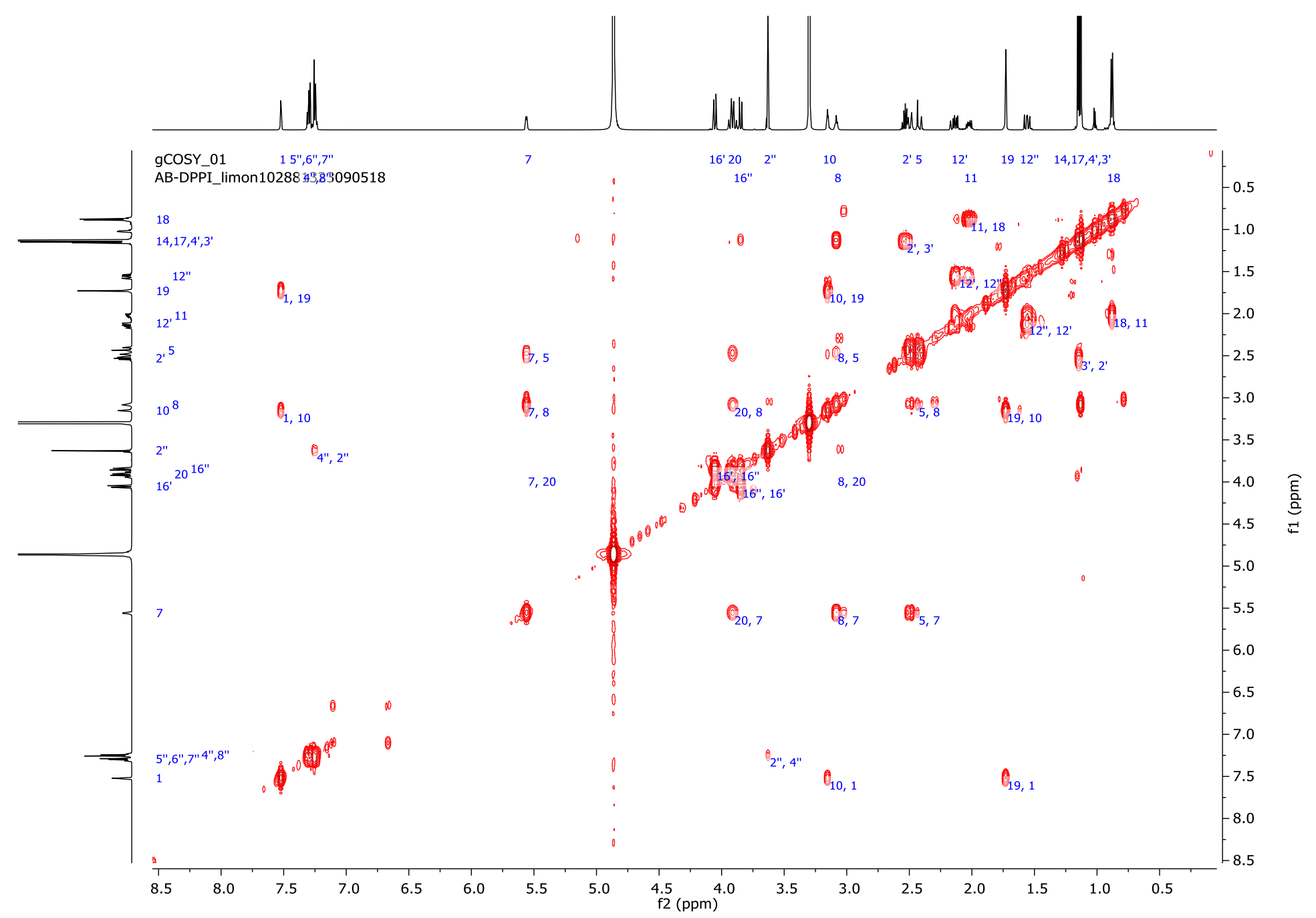

Figure S26. gCOSY (600 MHz, CD ${ }_{3} \mathrm{OD}$ ) spectrum of DPPI (10) 


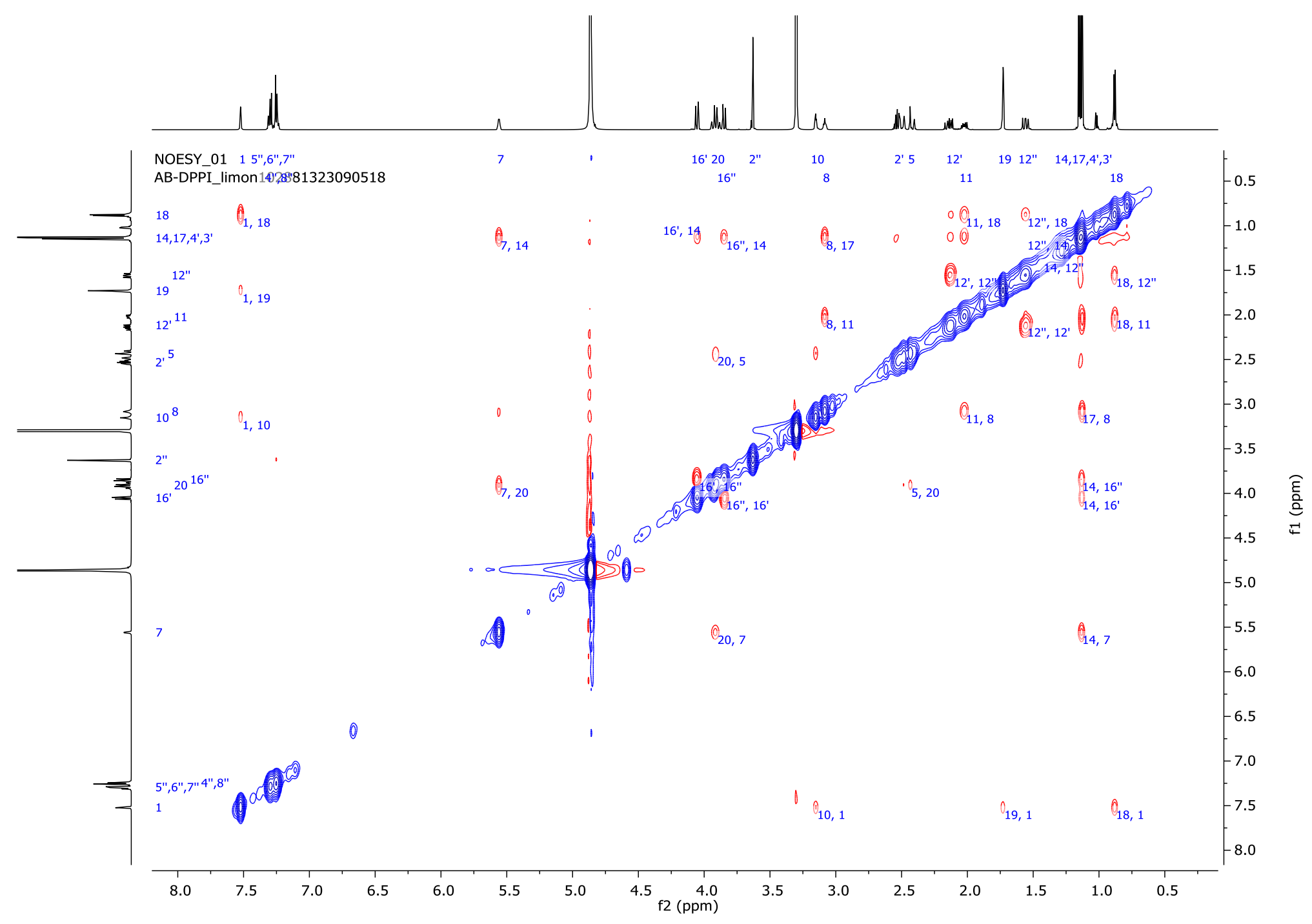

Figure S27. NOESY (600 MHz, CD $\left.{ }_{3} \mathrm{OD}\right)$ spectrum of DPPI (10) 


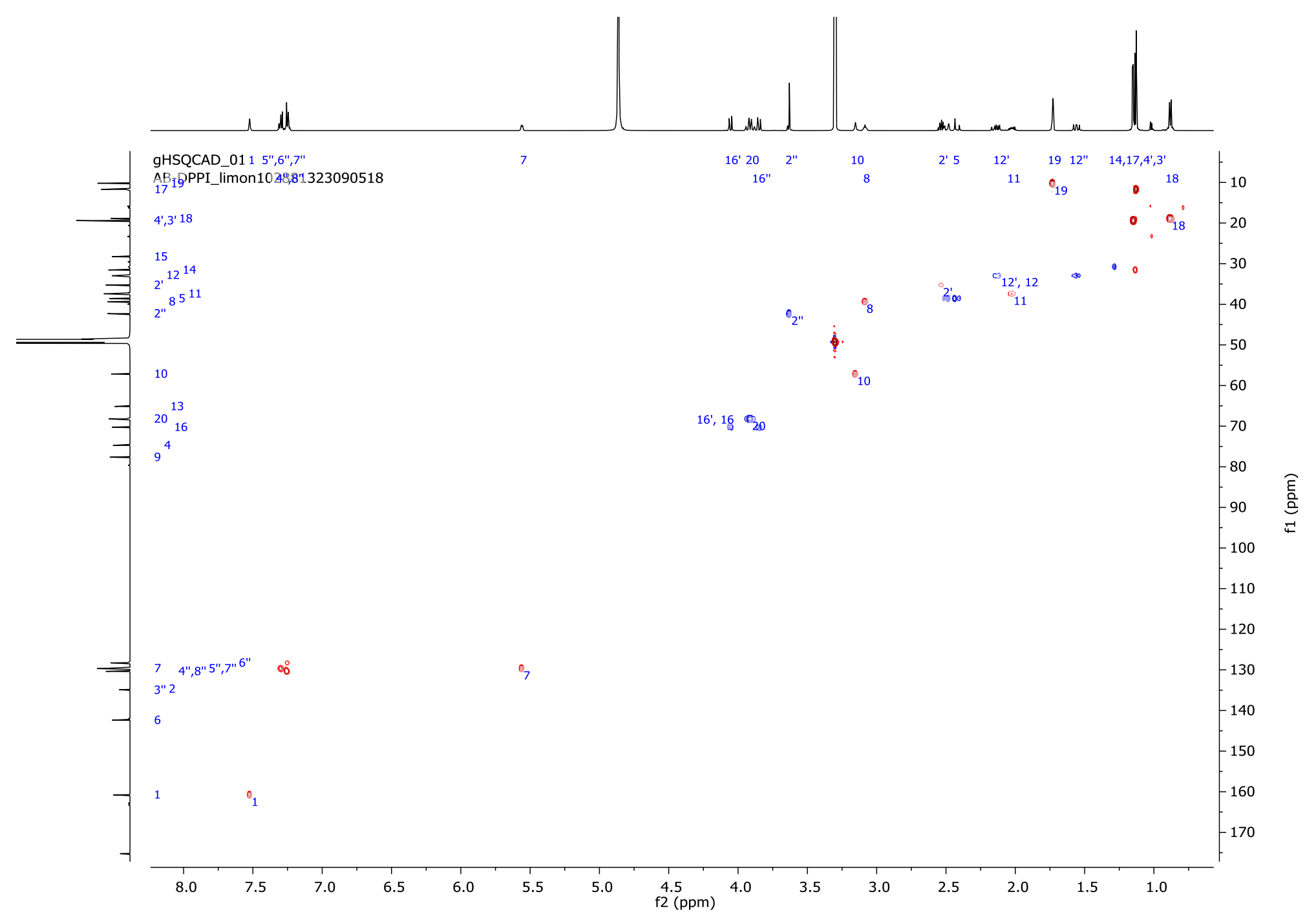

Figure S28. gHSQBC (600 MHz, CD $D_{3} \mathrm{OD}$ ) spectrum of DPPI (10) 


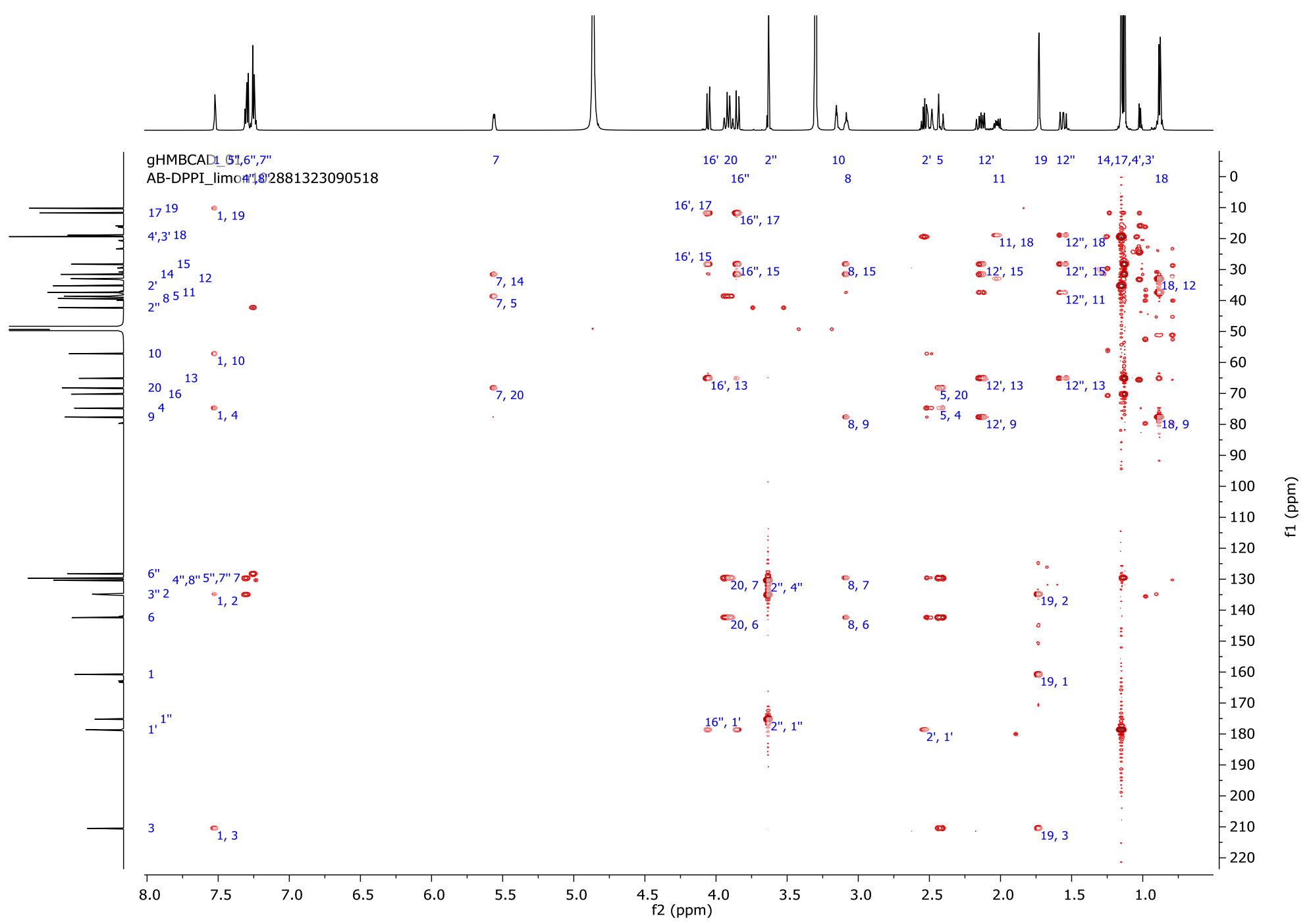

Figure S29. gHMBC (600 MHz, $\left.\mathrm{CD}_{3} \mathrm{OD}\right)$ spectrum of DPPI (10) 


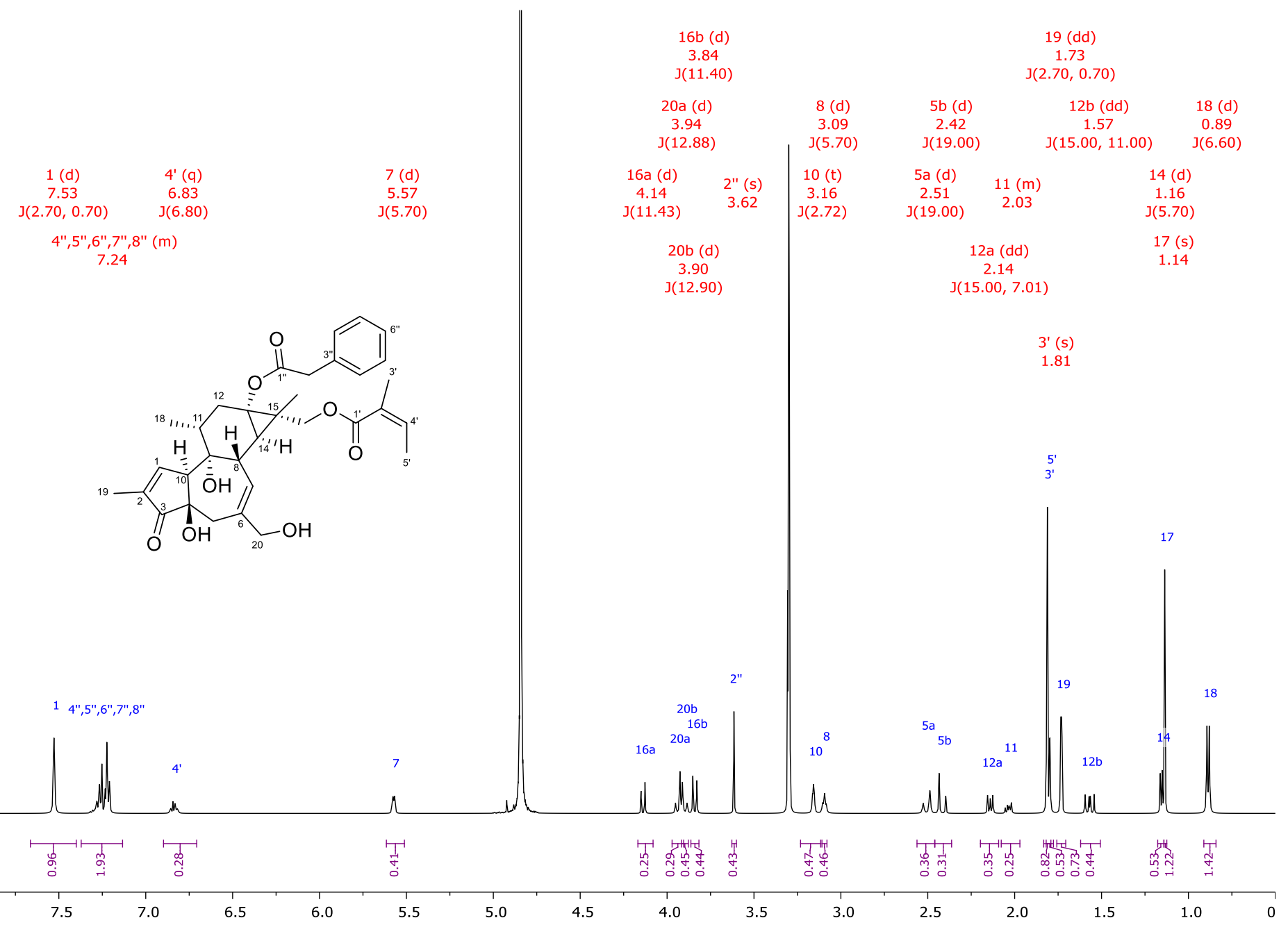

Figure S30. ${ }^{1} \mathrm{H}-\mathrm{NMR}\left(500 \mathrm{MHz}, \mathrm{CD}_{3} \mathrm{OD}\right.$ ) spectrum of DPPT (11) 

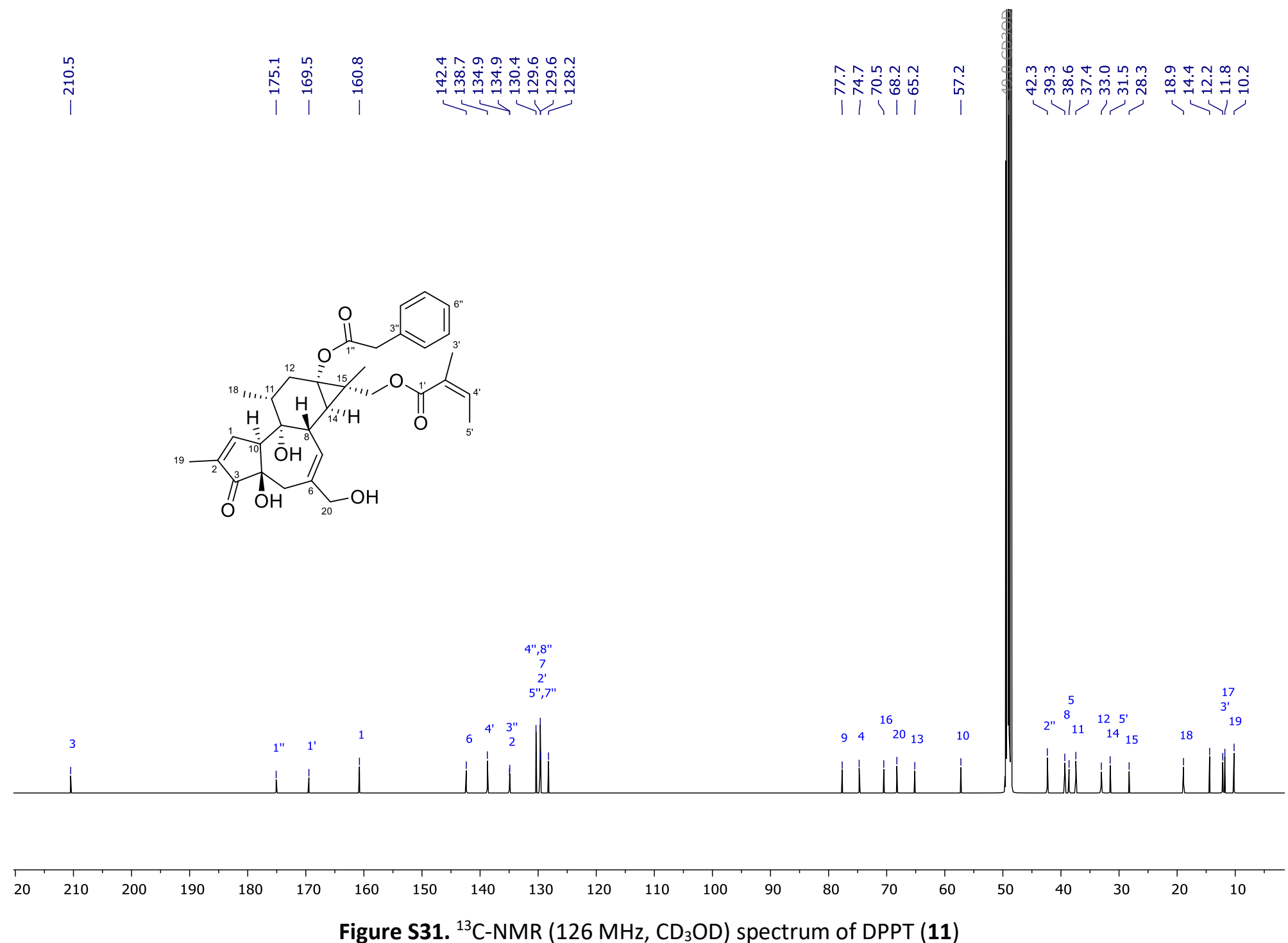


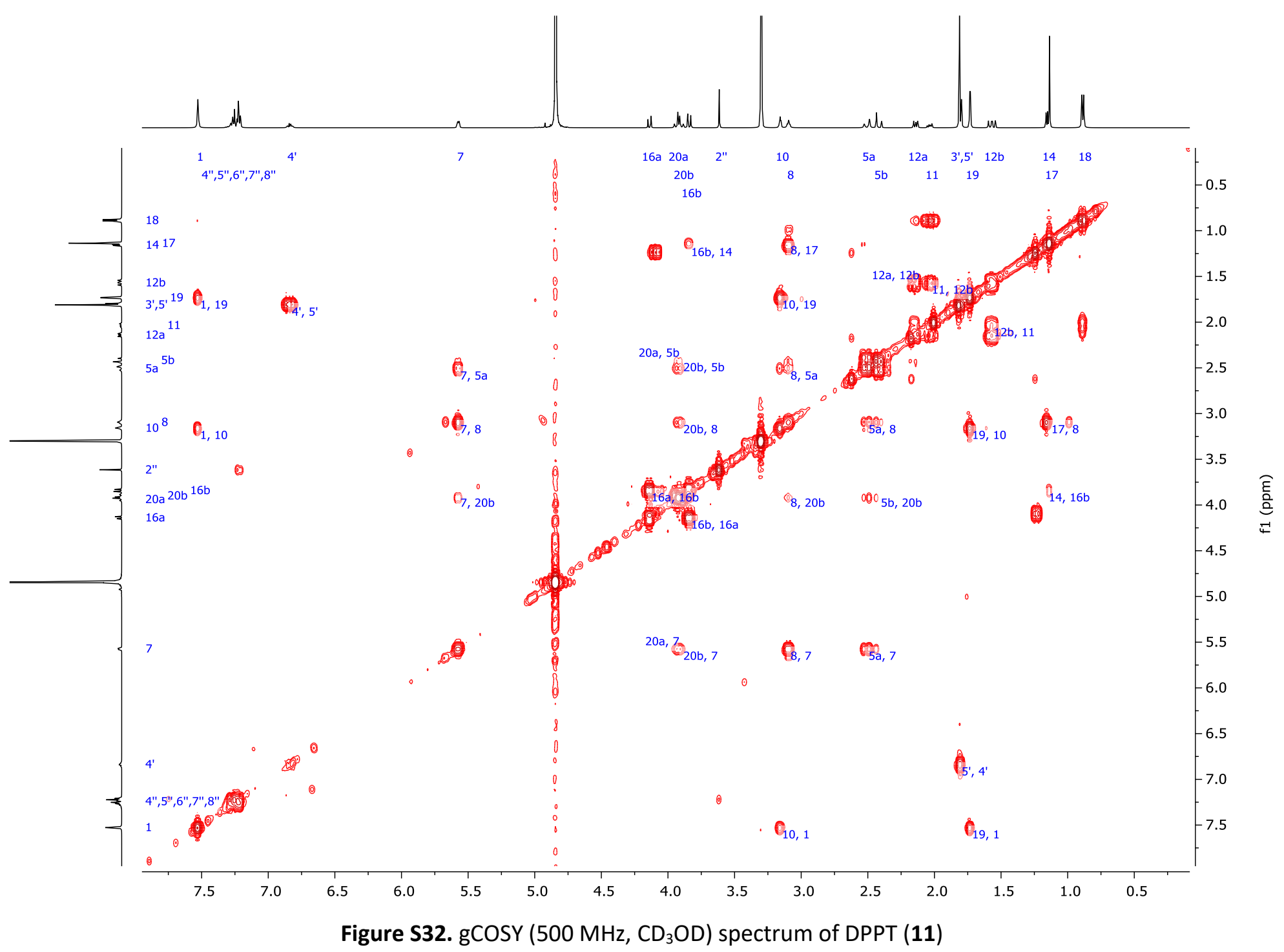




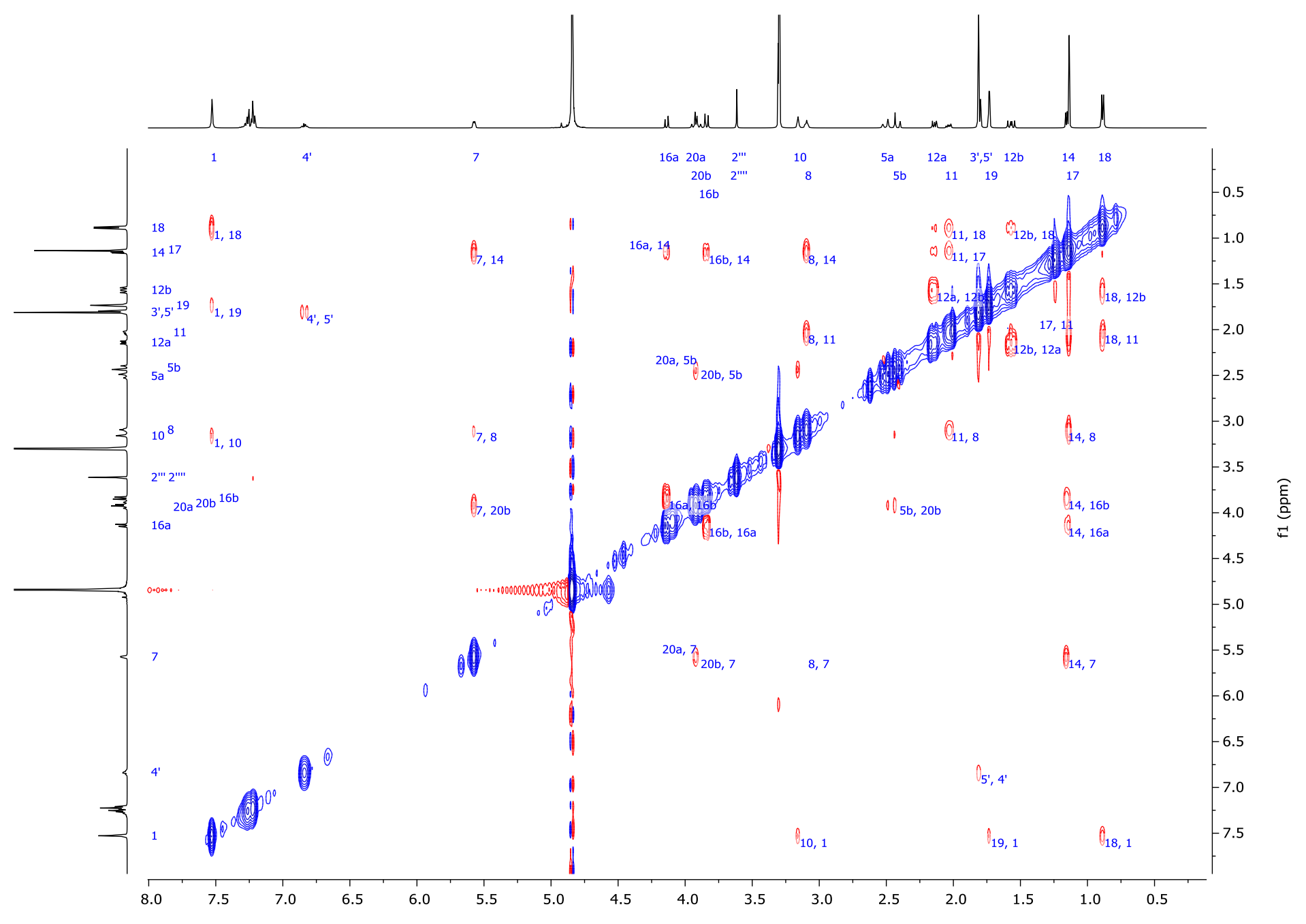

Figure S33. NOESY ( $500 \mathrm{MHz}, \mathrm{CD}_{3} \mathrm{OD}$ ) spectrum of DPPT (11) 


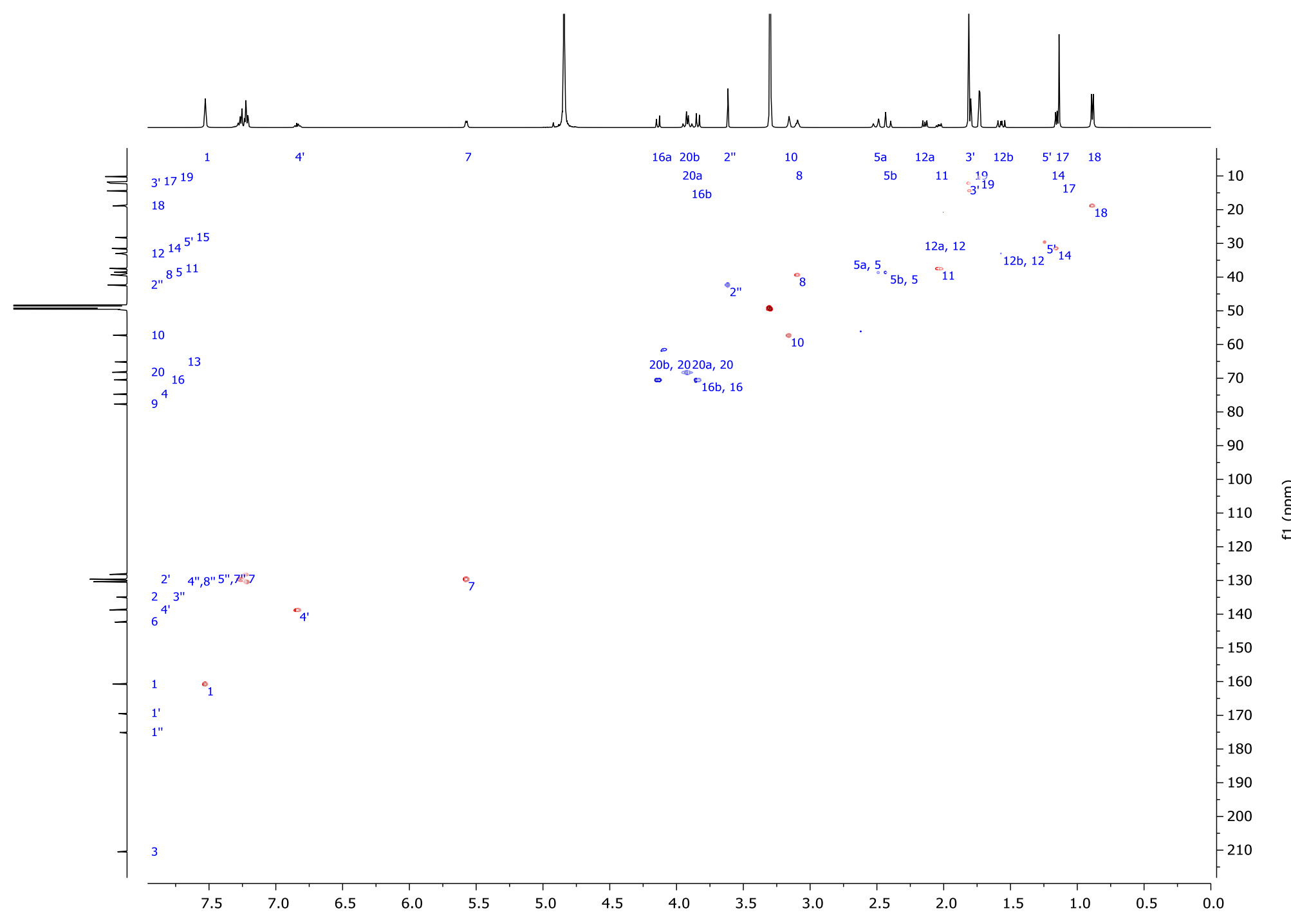

Figure S34. gHSQC (500 MHz, $\left.\mathrm{CD}_{3} \mathrm{OD}\right)$ spectrum of DPPT (11) 


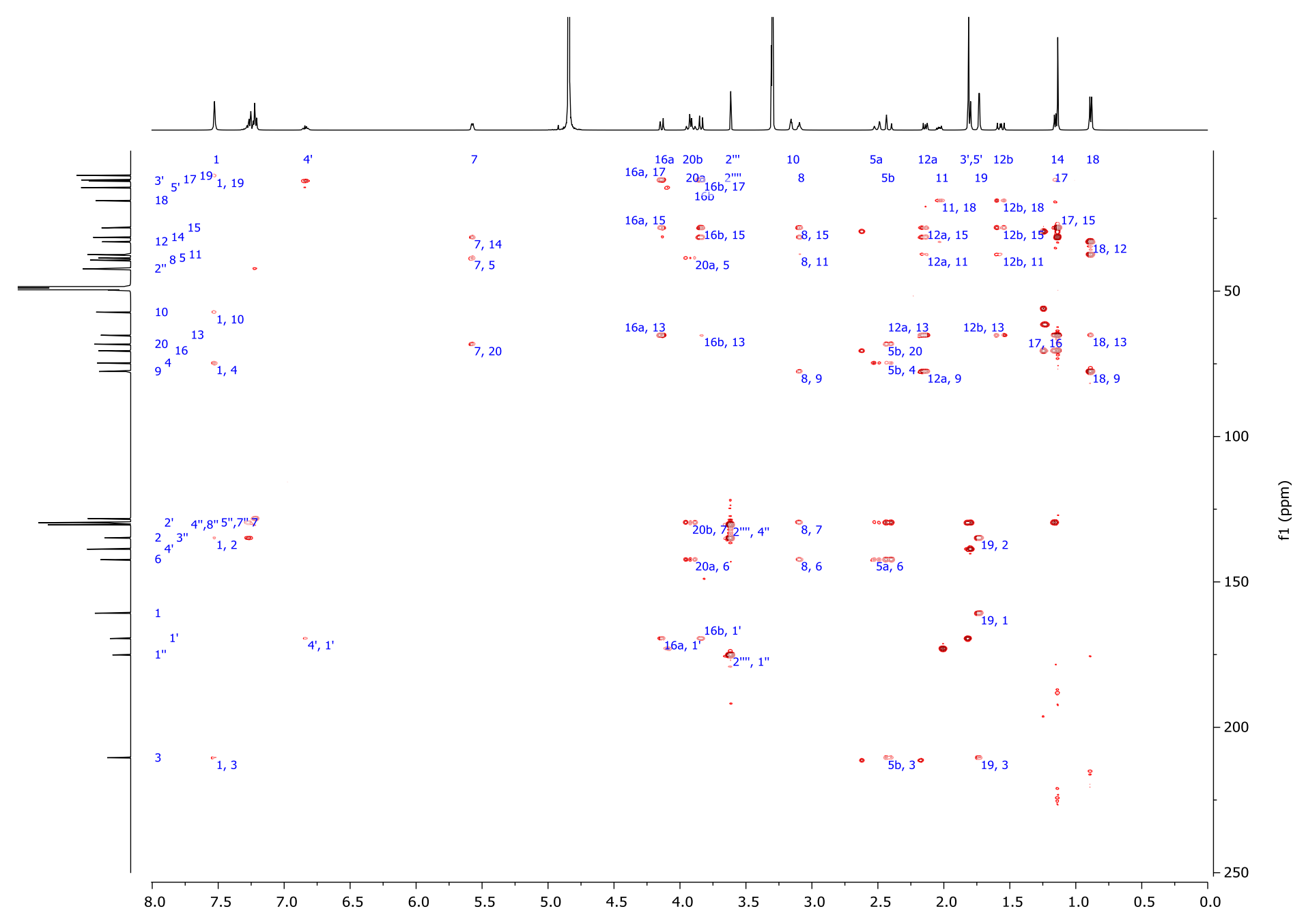

Figure S35. gHMBC ( $\left.500 \mathrm{MHz}, \mathrm{CD}_{3} \mathrm{OD}\right)$ spectrum of DPPT (11) 


\section{HPLC chromatograms for compounds 2-11}

\section{HPLC compound 2}

Chrom Type: Chromaster Channel : IR

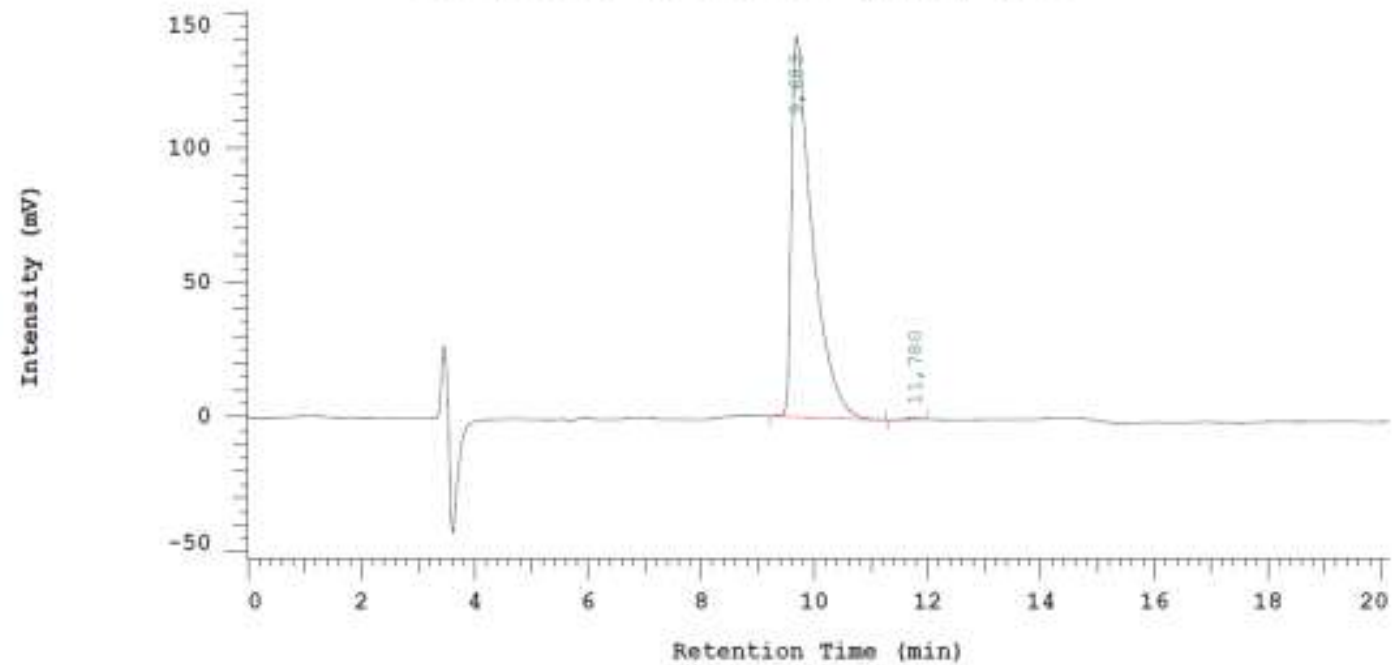

\begin{tabular}{rrrrr} 
No. & \multicolumn{1}{c}{ RT } & Area & Height & Area \& \\
\hline 1 & 9,683 & 3588305 & 141340 & 276 \\
\hline & 11,780 & 7707 & 99,786 \\
& & 3596012 & 141616 & 100,000
\end{tabular}

HPLC compound 3

Chrom Type: Chromaster Channel : IR

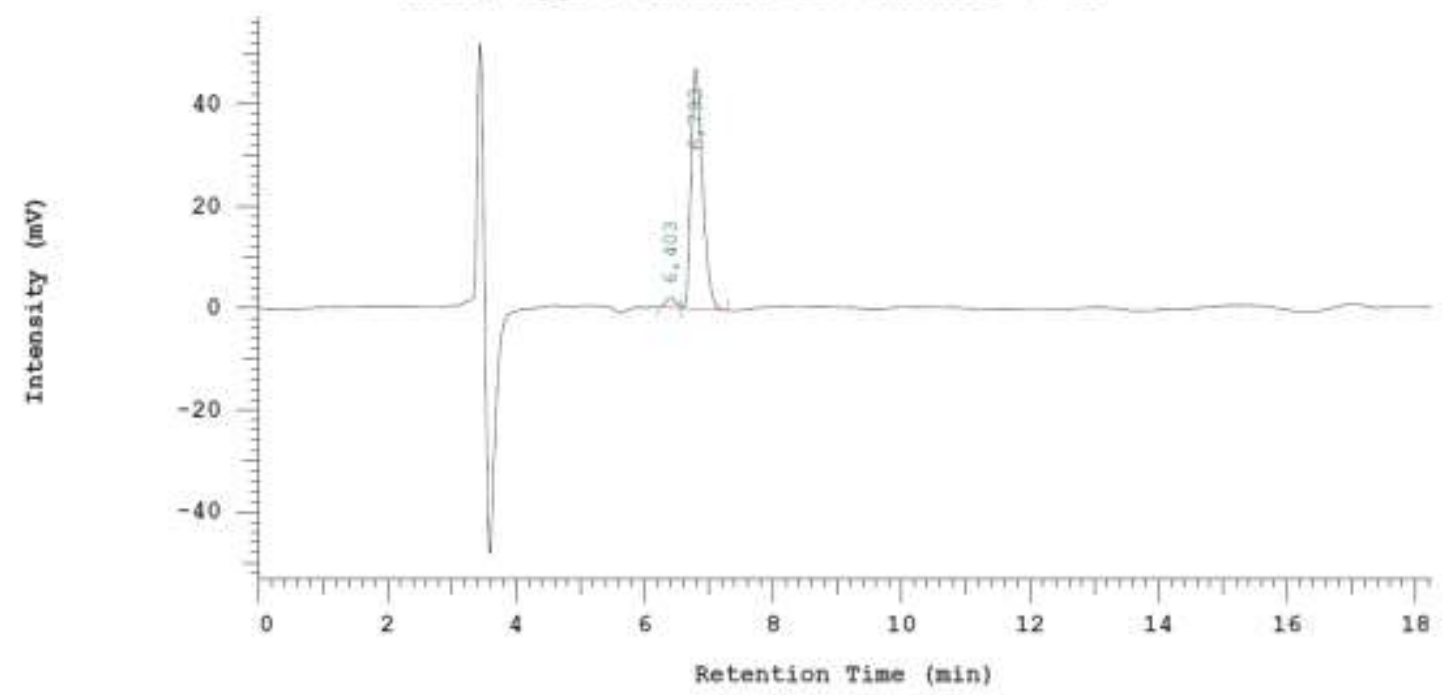

\begin{tabular}{|c|c|c|c|c|}
\hline No. & $\mathrm{RT}$ & Area & Height & Area क \\
\hline 1 & 6,403 & 20266 & 1950 & 3,380 \\
\hline 2 & 6,793 & 579427 & 47019 & 96,620 \\
\hline & & 599693 & 48969 & 100,000 \\
\hline
\end{tabular}




\section{HPLC compound 4}

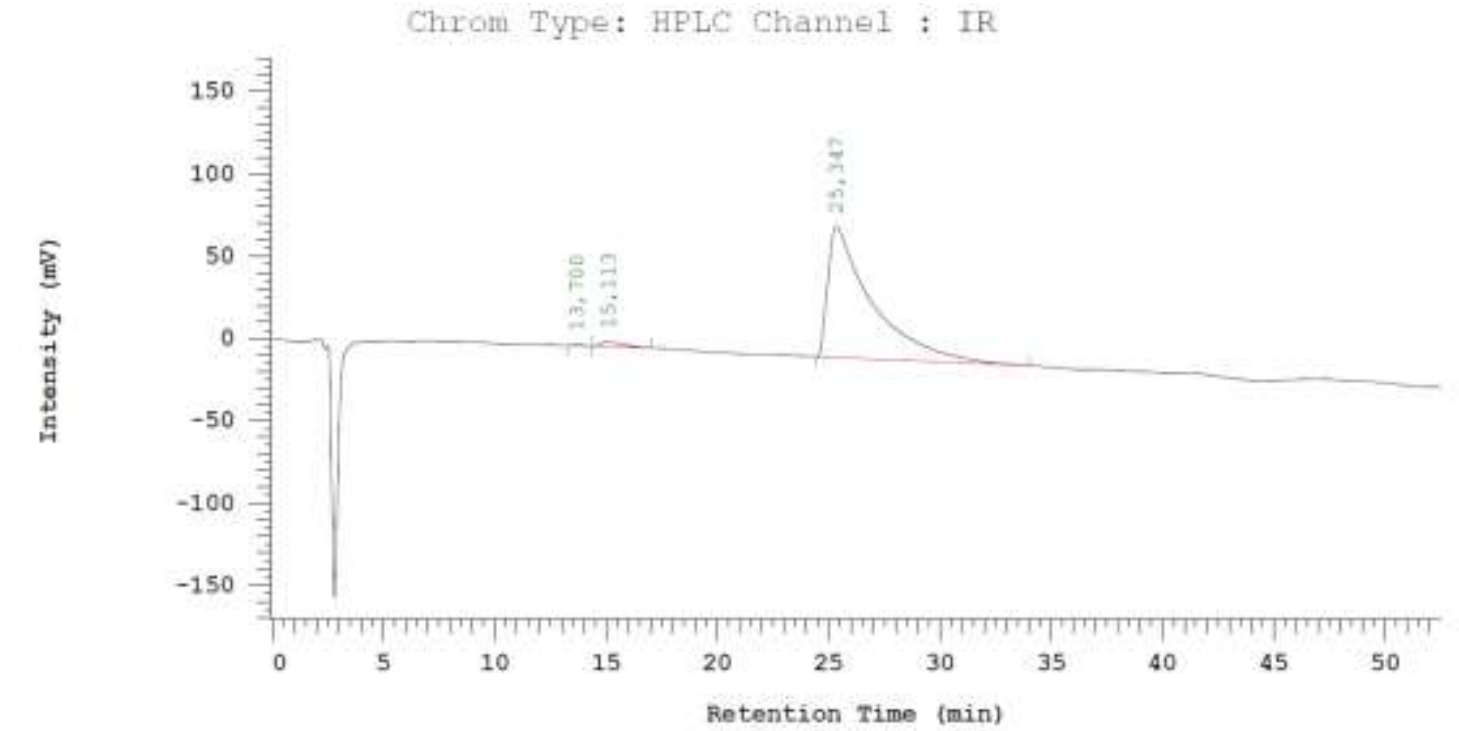

\begin{tabular}{|c|c|c|c|c|}
\hline No. & $R T$ & Area & Conc 1 & $\mathrm{BC}$ \\
\hline \multirow{4}{*}{$\begin{array}{l}1 \\
2 \\
3\end{array}$} & 13,700 & 19013 & 0,173 & $\mathrm{BB}$ \\
\hline & 15,113 & 190288 & 1,728 & $\mathrm{BB}$ \\
\hline & 25,347 & 10805898 & 98,100 & $B B$ \\
\hline & & 11015199 & 100,000 & \\
\hline
\end{tabular}

HPLC compound 5

Chrom Type: Chromaster Channel : IR

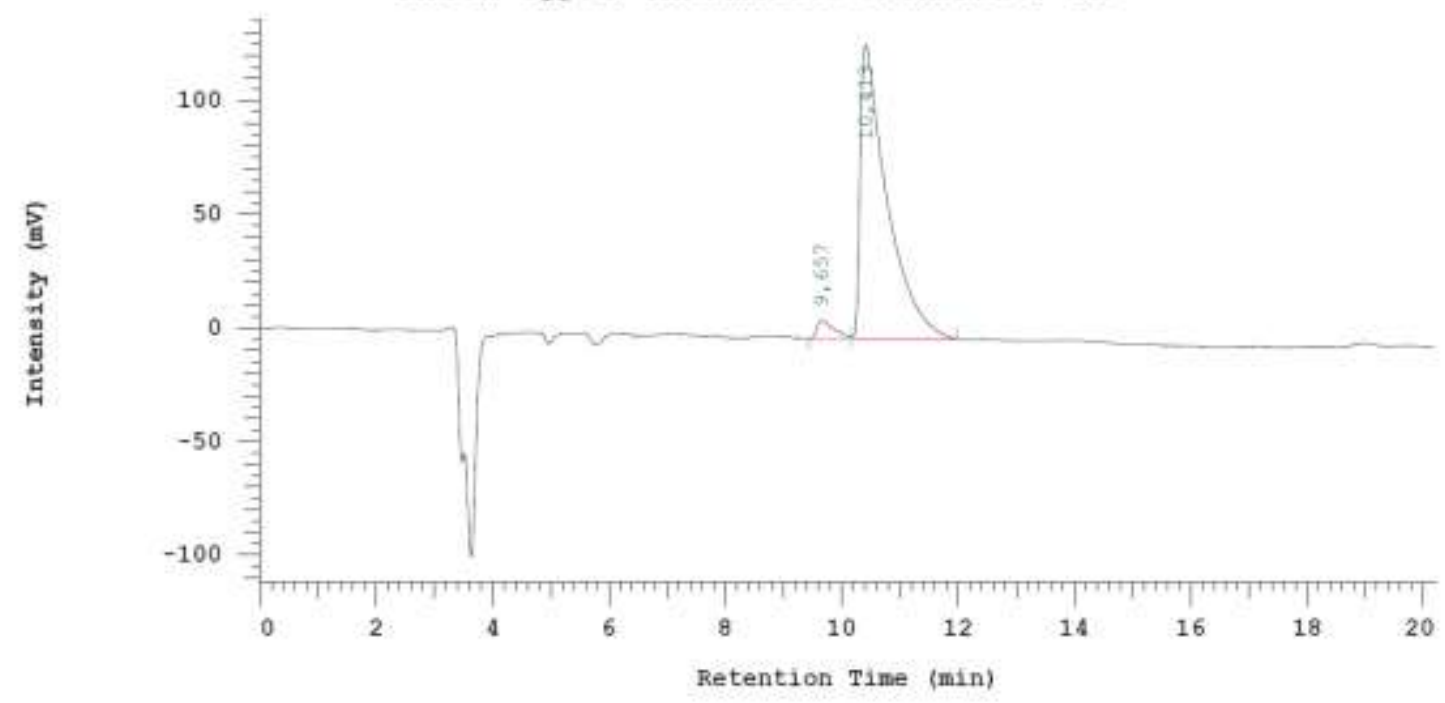

\begin{tabular}{rrrrr} 
No. & \multicolumn{1}{c}{ RT } & Area & Height & Area * \\
\hline 1 & 9,657 & 163006 & 7875 & 3,822 \\
2 & 10,413 & 4102426 & 129350 & 96,178 \\
\hline & 4265432 & 137225 & 100,000 \\
\hline
\end{tabular}




\section{HPLC compound 6}

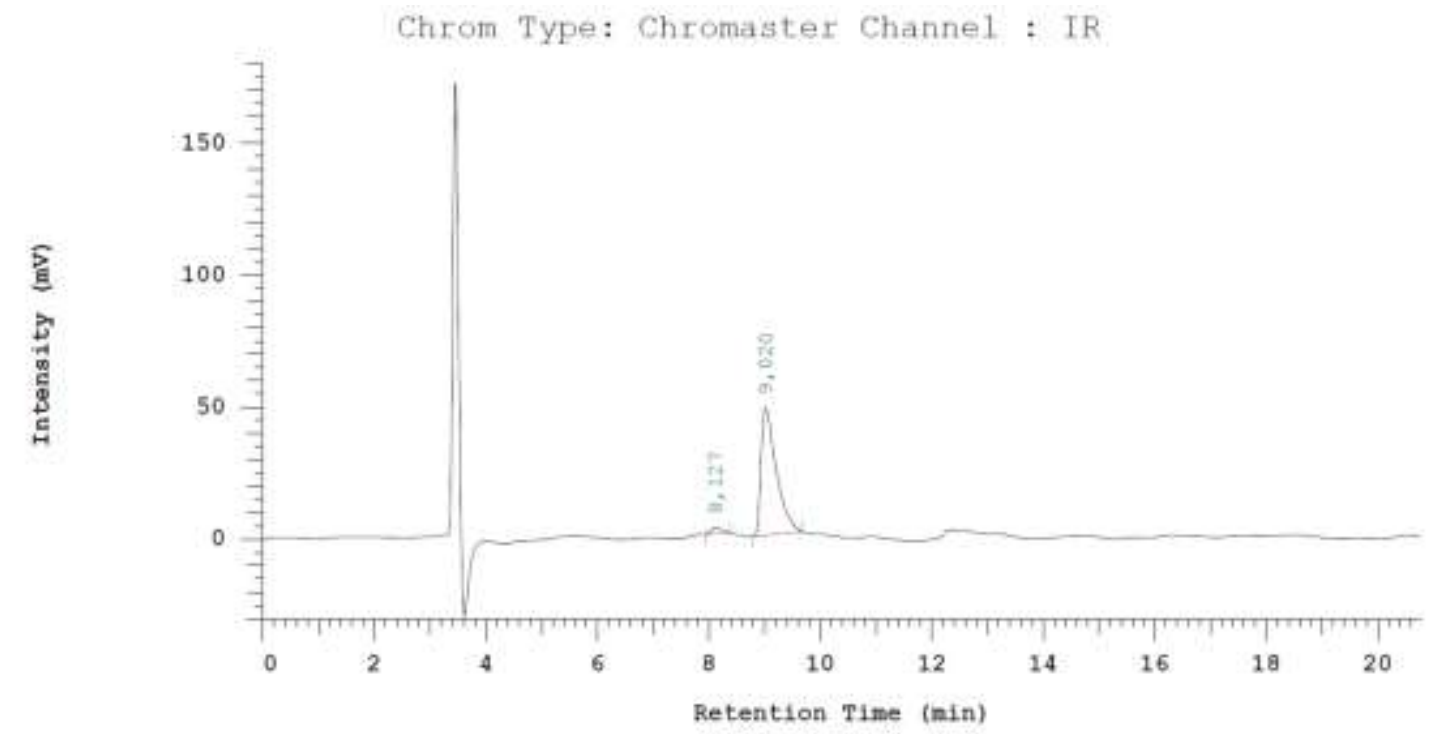

\begin{tabular}{|c|c|c|c|c|}
\hline No. & RT & Area & Helght & Area 8 \\
\hline 1 & 8,127 & 29984 & 2285 & 3,208 \\
\hline \multirow[t]{2}{*}{2} & 9,020 & 904744 & $\triangle 8043$ & 96,792 \\
\hline & & 934728 & 50328 & 100,000 \\
\hline
\end{tabular}

\section{HPLC compound 7}

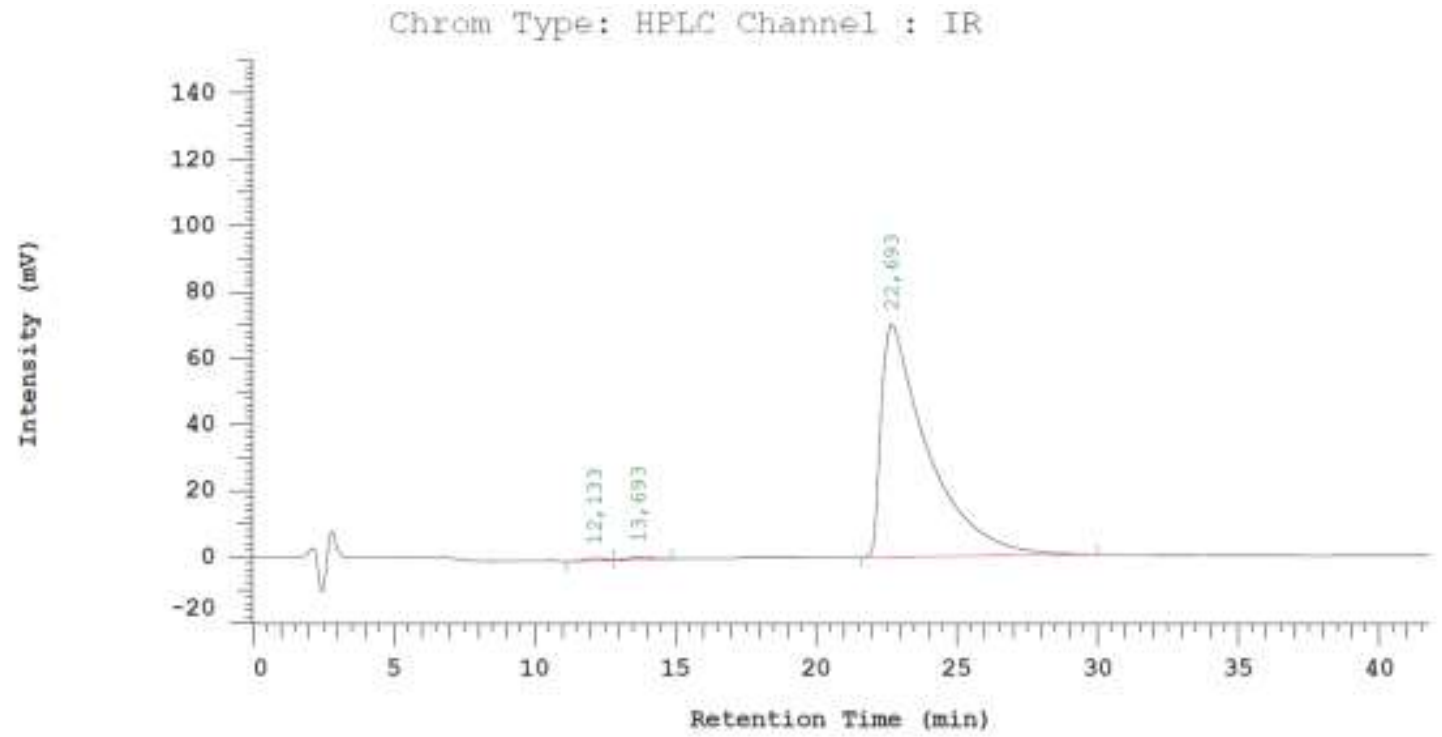

\begin{tabular}{crrrr} 
No. & RT & Area & Conc 1 & BC \\
\hline 1 & 12,133 & 34313 & 0,422 & BV \\
$\frac{2}{3}$ & 13,693 & 44304 & 0,545 & VB \\
\hline & 22,693 & 8055036 & 99,033 & BB \\
\hline
\end{tabular}


HPLC compound 8

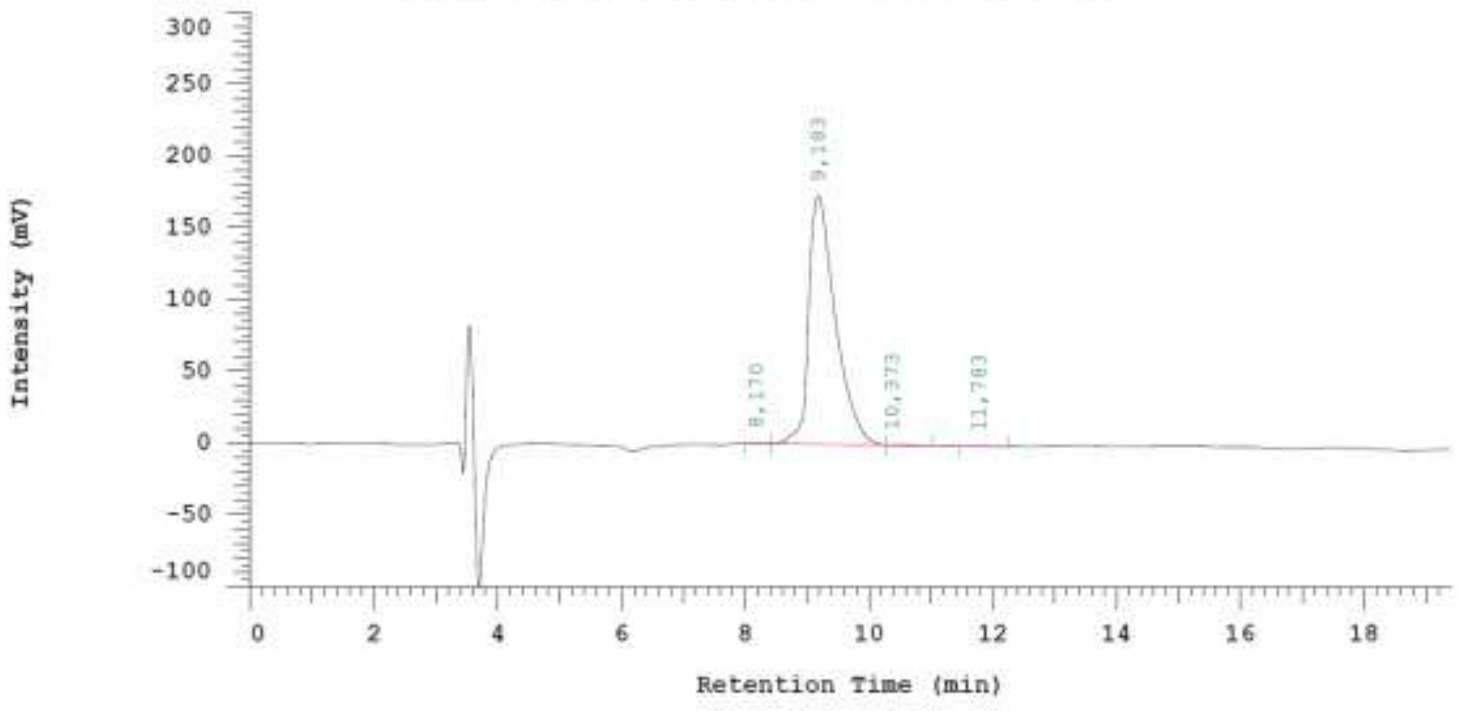

\begin{tabular}{rrrrr}
\multicolumn{1}{c}{ No. } & \multicolumn{1}{c}{ Area } & Height & Area of \\
\hline 1 & 8,170 & 9103 & 564 & 0,176 \\
2 & 9,183 & 5138327 & 172959 & 99,519 \\
3 & 10,373 & 7992 & 247 & 0,155 \\
4 & 11,783 & 7751 & 311 & 0,150 \\
\hline & & 5163173 & 174081 & 100,000 \\
\hline
\end{tabular}

\section{HPLC compound 9}

Chrom Type: HPLC Channel : IR

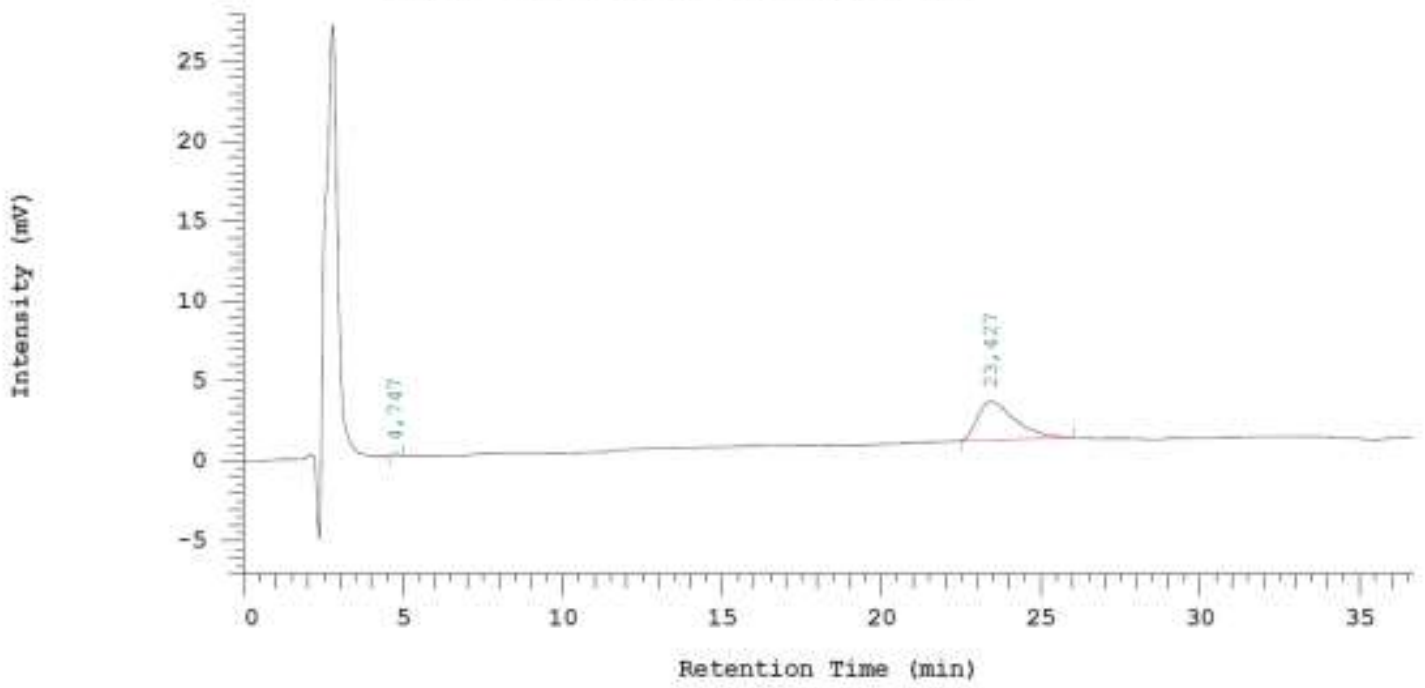

\begin{tabular}{rrrr} 
No. & \multicolumn{1}{c}{ RT } & Area & Conc 1 \\
\hline 1 & 4,747 & 1174 & 0,596 \\
2 & 23,427 & 195800 & 99,404 \\
\hline & & 196974 & 100,000
\end{tabular}


HPLC compound 10

Chrom Type: HPLC Channe1 : UV

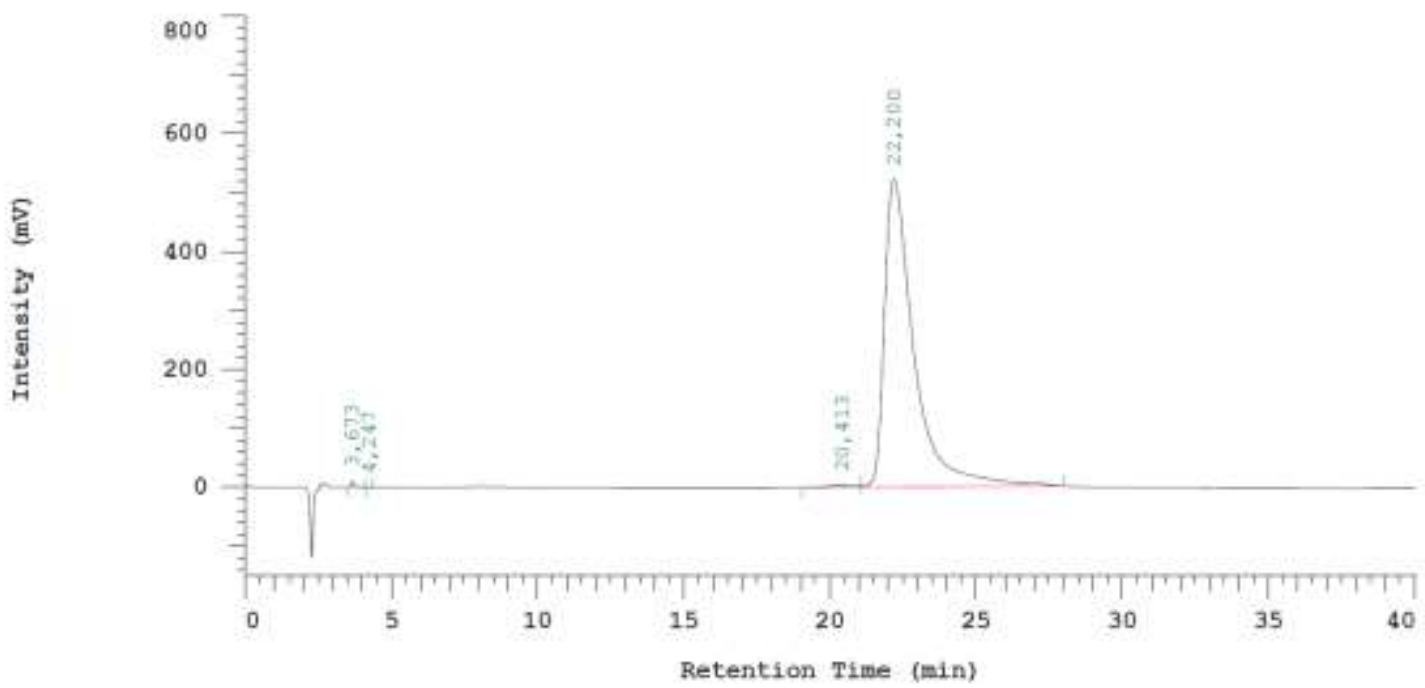

\begin{tabular}{rrrr} 
No. & \multicolumn{1}{c}{ RT } & \multicolumn{1}{c}{ Area } & Conc 1 \\
\hline 1 & 3,673 & 83102 & 0,225 \\
2 & 4,247 & 2077 & 0,006 \\
3 & 20,413 & 274897 & 0,743 \\
4 & 22,200 & 36631598 & 99,027 \\
\hline & & 36991674 & 100,000 \\
\hline
\end{tabular}

HPLC compound 11

Chrom Type: HPLC Channel : UV

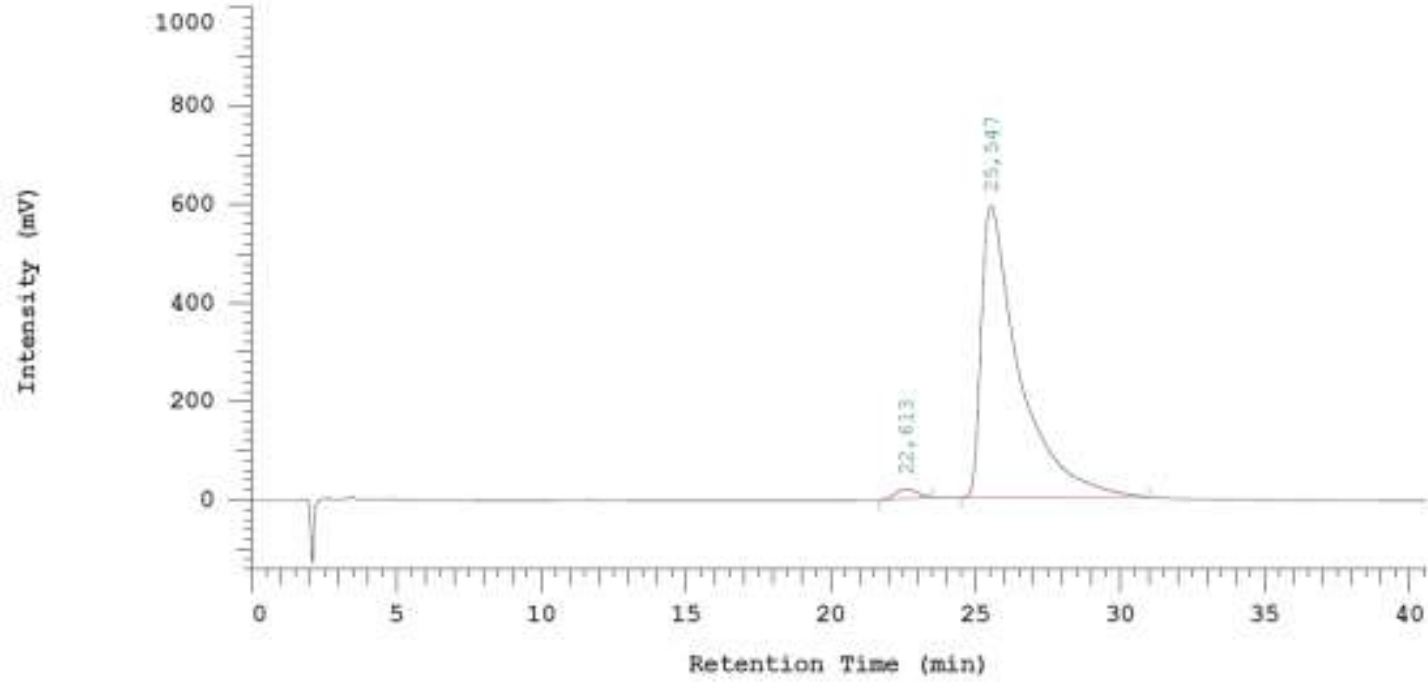

No.

RT

Area

Conc 1

\begin{tabular}{rrrr}
\hline 1 & 22,613 & 994220 & 1,821 \\
2 & 25,547 & 53604357 & 98,179 \\
\hline & 54598577 & 100,000 \\
\hline
\end{tabular}




\section{UPLC-HRMS Assisted Identification of 12-deoxyphorbol 13,16-diesters from E. resinifera}

XIC for m/z 575.2621 from Phorbol_Fr_E.R

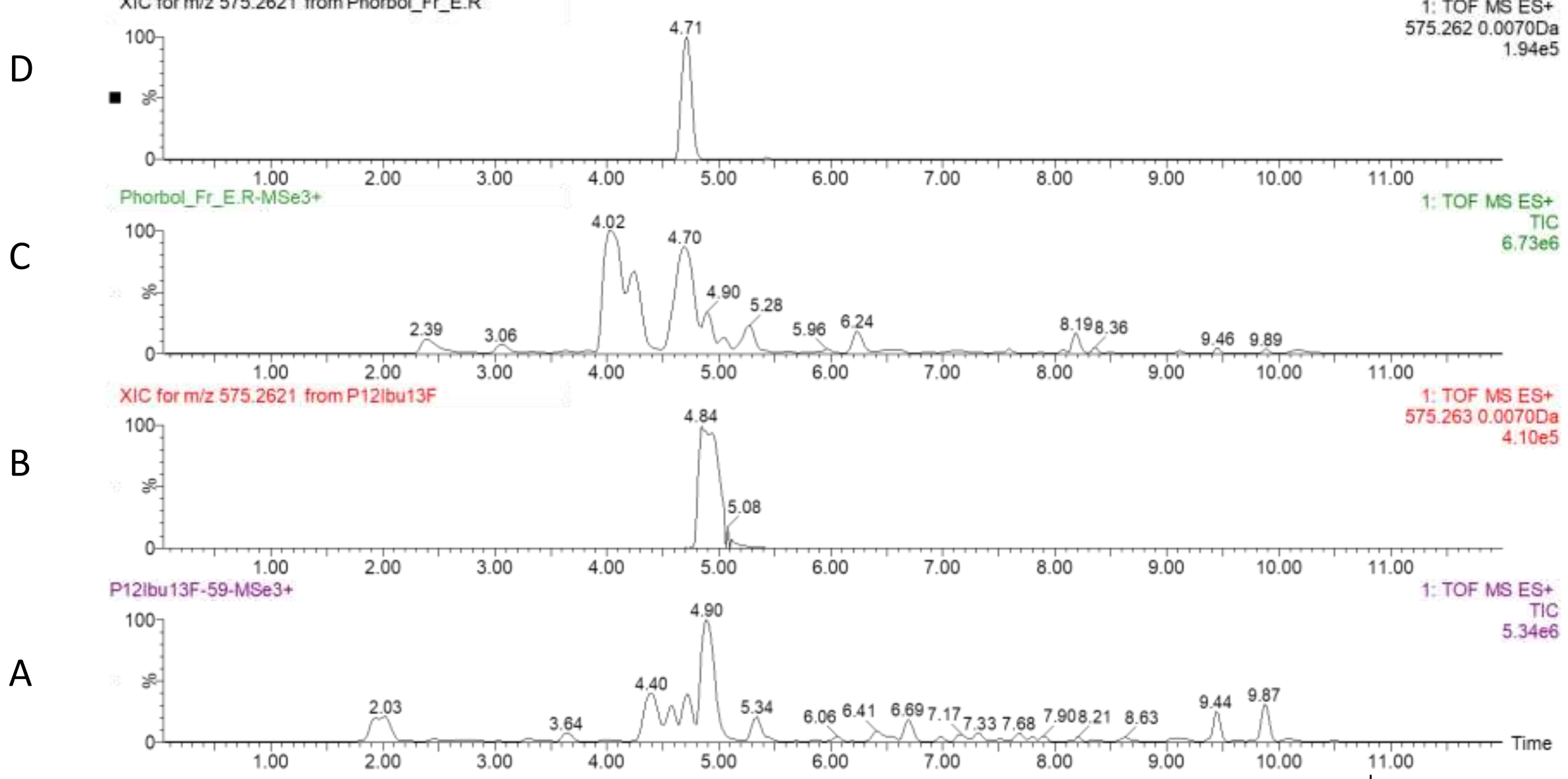

Figure S36. Total ion current chromatogram (TIC) and extracted ion chromatogram (XIC) for $\mathrm{m} / \mathrm{z}=575.2621\left([\mathrm{M}+\mathrm{Na}]^{+}\right)$in ESI $(-)$mode for a synthetic sample of compound 9 (P12lbu13PhAc) (A, B) and for E. resinifera fraction containing suspected 12-deoxy-16hydroxyphorbol 13,16-diesters (C, D). Chromatogram D shows an isobaric component to compound $\mathbf{9}$, with a different retention time (4.71 $\mathrm{min}$. in $\mathbf{D}$, versus 4.84 for compound $\mathbf{9}$ in $\mathbf{B}$ ). Both samples were run under equivalent elution conditions. 


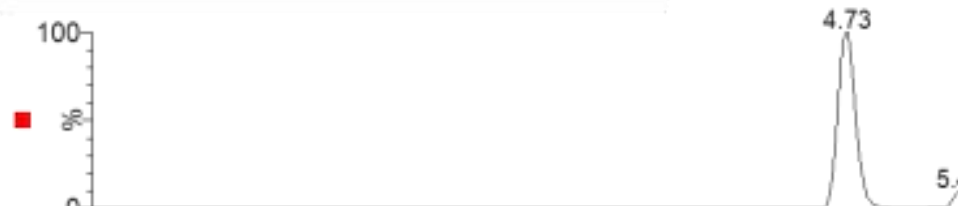

1.00 2.00

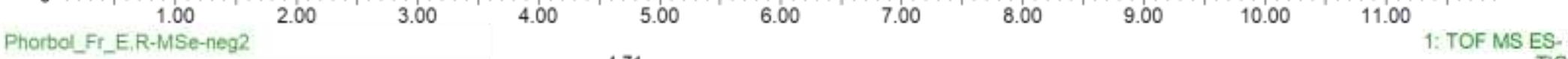
5.43

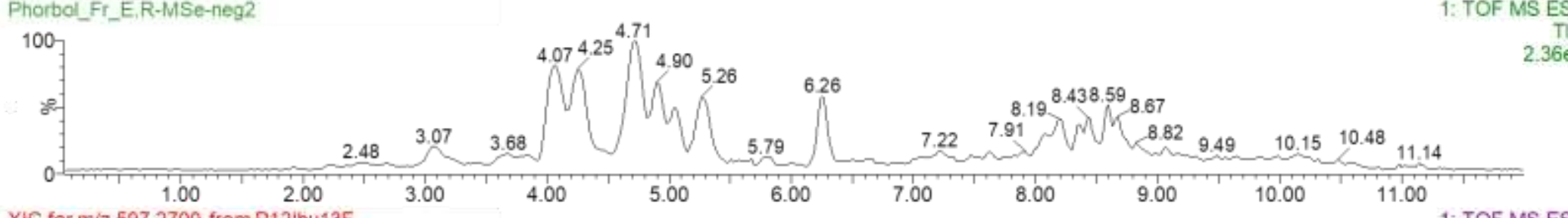

C

B

$\mathrm{XIC}$ for $\mathrm{m} / \mathrm{z} 597.2700$ from P121bu13F

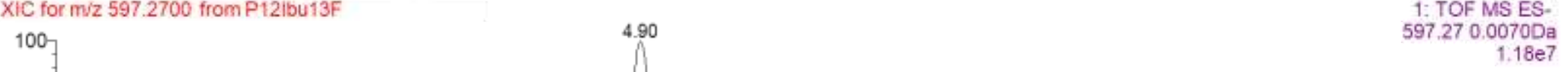

A
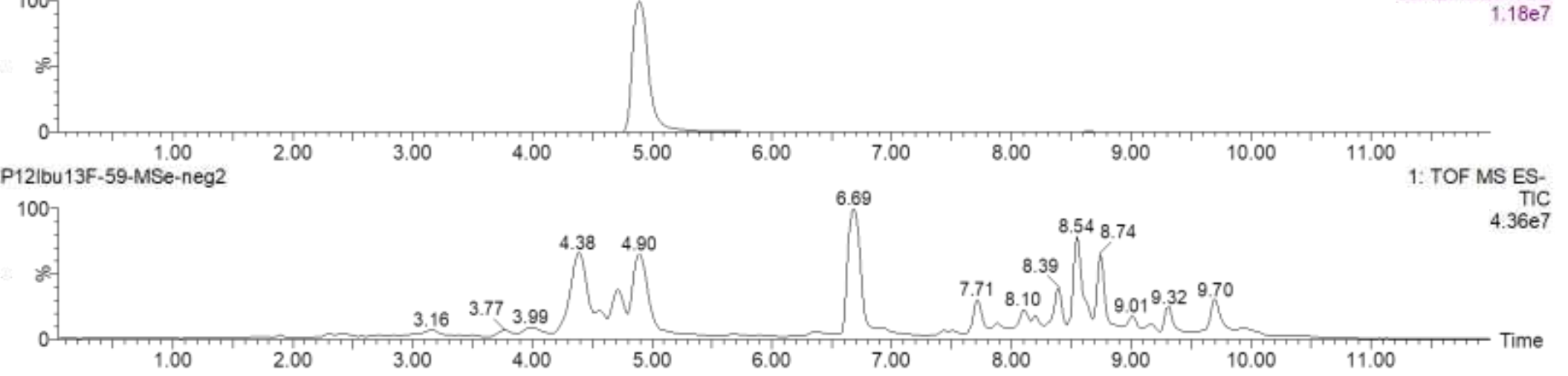

Figure S37. Total ion current chromatogram (TIC) and extracted ion chromatogram (XIC) for $\mathrm{m} / \mathrm{z}=597.2700\left([\mathrm{M}+\mathrm{HCOOH}-\mathrm{H}]^{-}\right)$ in ESI (-) mode for a synthetic sample of compound 9 (P12Ibu13PhAc) (A, B) and for E. resinifera fraction containing suspected 12deoxy-16-hydroxyphorbol 13,16-diesters (C, D). Chromatogram D shows an isobaric component to compound $\mathbf{9}$, with a different retention time (4.73 $\mathrm{min}$. in $\mathbf{D}$, versus 4.90 for compound $\mathbf{9}$ in $\mathbf{B}$ ). Both samples were run under equivalent elution conditions. 


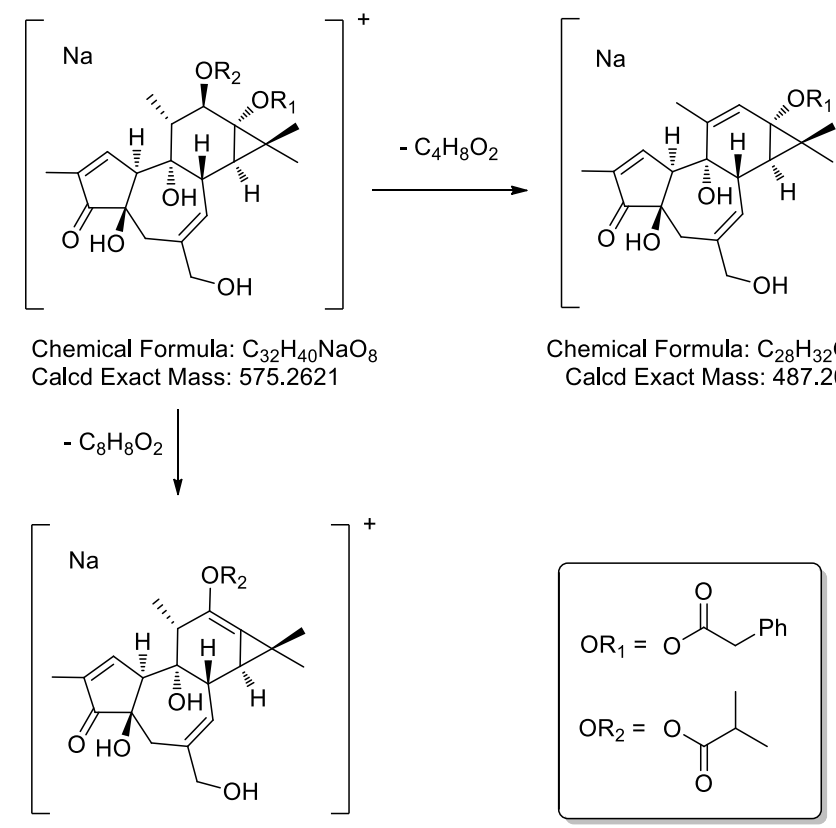

Chemical Formula: $\mathrm{C}_{24} \mathrm{H}_{32} \mathrm{NaO}_{6}$
Calcd Exact Mass: 439.2097

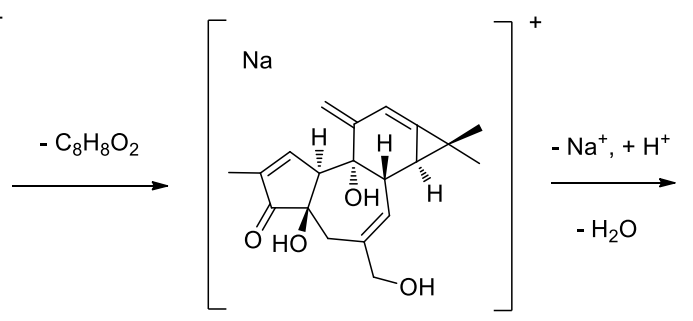

Chemical Formula: $\mathrm{C}_{20} \mathrm{H}_{24} \mathrm{NaO}_{4}$ Calcd Exact Mass: 351.15723

$-\mathrm{H}_{2} \mathrm{O}$

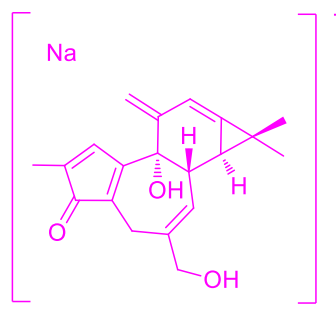

Chemical Formula: $\mathrm{C}_{20} \mathrm{H}_{2} \mathrm{NaO}_{3}$ Calcd Exact Mass: 333.14666

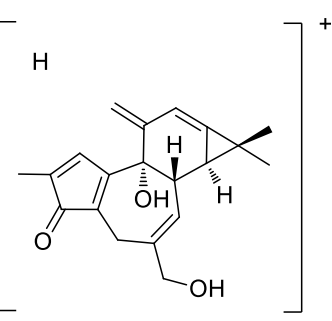

Chemical Formula: $\mathrm{C}_{20} \mathrm{H}_{23} \mathrm{O}_{3}$ Calcd Exact Mass: 311.16472

$-\mathrm{H}_{2} \mathrm{O}$

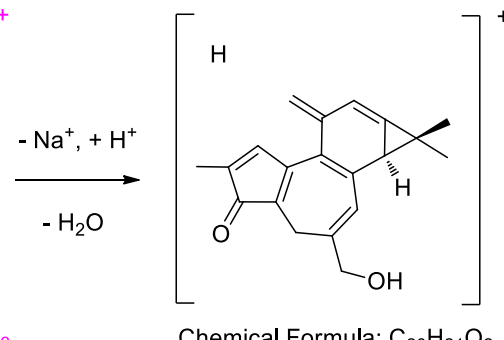

Chemical Formula: $\mathrm{C}_{20} \mathrm{H}_{21} \mathrm{O}_{2}$
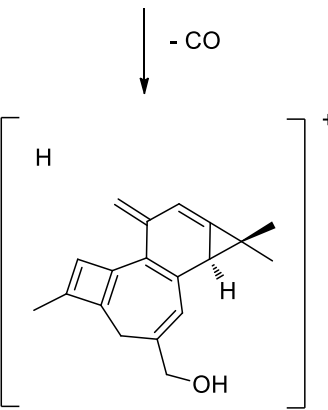

Chemical Formula: $\mathrm{C}_{19} \mathrm{H}_{21} \mathrm{O}$ Calcd Exact Mass: 265,1592

Scheme S2. Proposed fragmentation route for selected ion on $\mathrm{MS}^{\mathrm{E}}$ spectrum (Data Independent Acquisition) for compound 9. 


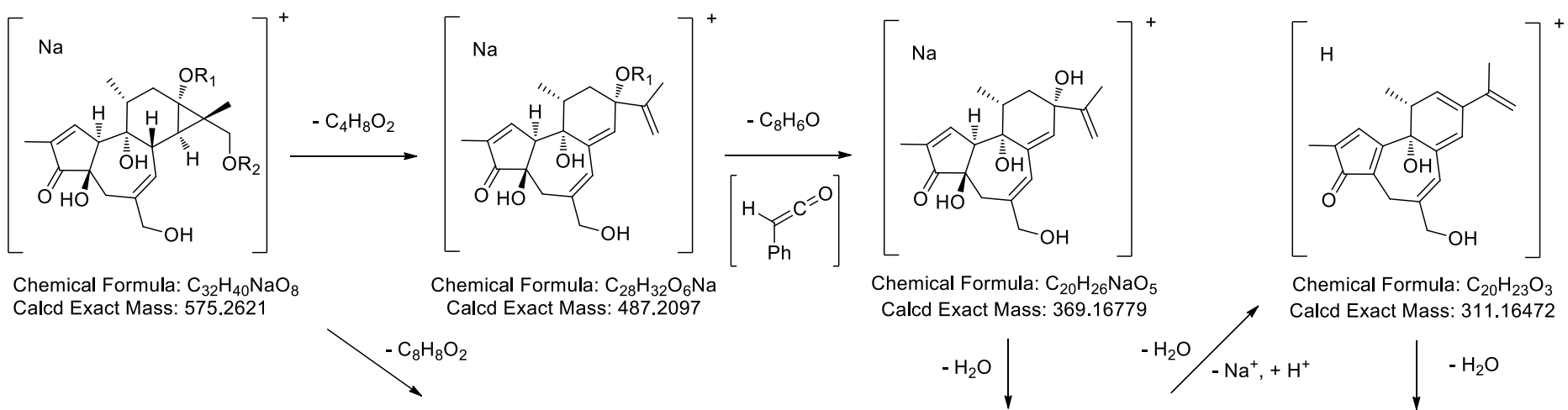

$$
\mathrm{OR}_{1}=\mathrm{OR}_{2}=\mathrm{O}_{\mathrm{O}}^{\mathrm{O}}
$$

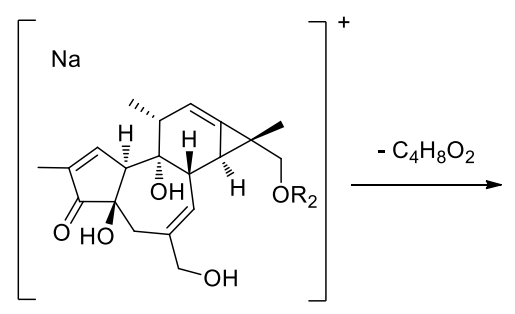

Chemical Formula: $\mathrm{C}_{24} \mathrm{H}_{32} \mathrm{NaO}_{6}$ Calcd Exact Mass: 439.2097

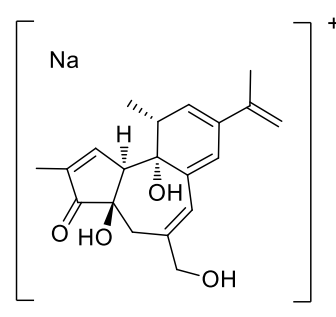

Chemical Formula: $\mathrm{C}_{20} \mathrm{H}_{24} \mathrm{NaO}_{4}$ Calcd Exact Mass: 351.15723

$$
\downarrow-\mathrm{co}
$$

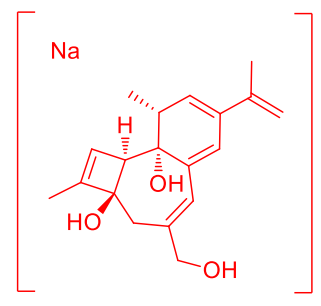

Chemical Formula: $\mathrm{C}_{19} \mathrm{H}_{24} \mathrm{NaO}_{3}$ Calcal Fors: 323.16231

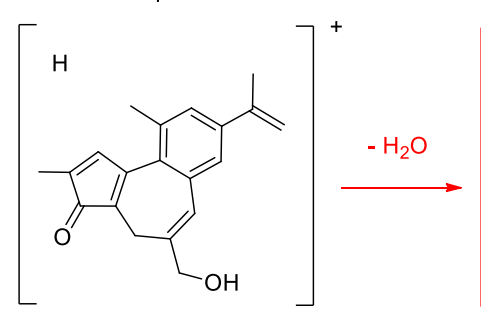

Chemical Formula: $\mathrm{C}_{20} \mathrm{H}_{21} \mathrm{O}_{2}$ Calcd Exact Mass: 293.15415<smiles></smiles>

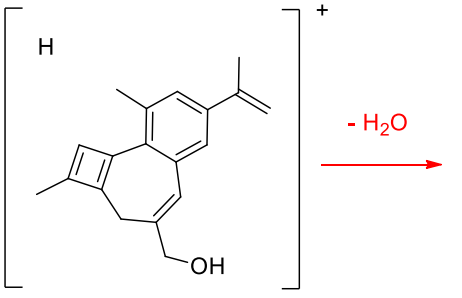

Chemical Formula: $\mathrm{C}_{19} \mathrm{H}_{21} \mathrm{O}$ Calcal

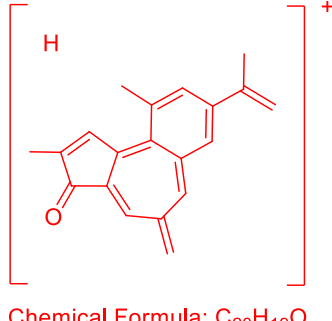

Chemical Formula: $\mathrm{C}_{20} \mathrm{H}_{19} \mathrm{O}$ Calcd Exact Mass: 275.14359 $\checkmark-\mathrm{co}$

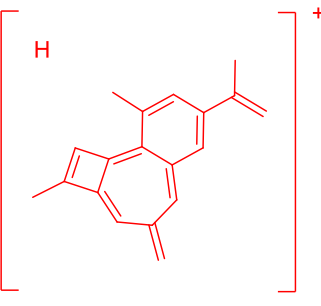

Chemical Formula: $\mathrm{C}_{19} \mathrm{H}_{19}$ Calcd Exact Mass: 247.14868

Scheme S3. Proposed fragmentation route for selected ions on $\mathrm{MS}^{\mathrm{E}}$ spectrum (Data Independent Acquisition) for compound 10. 


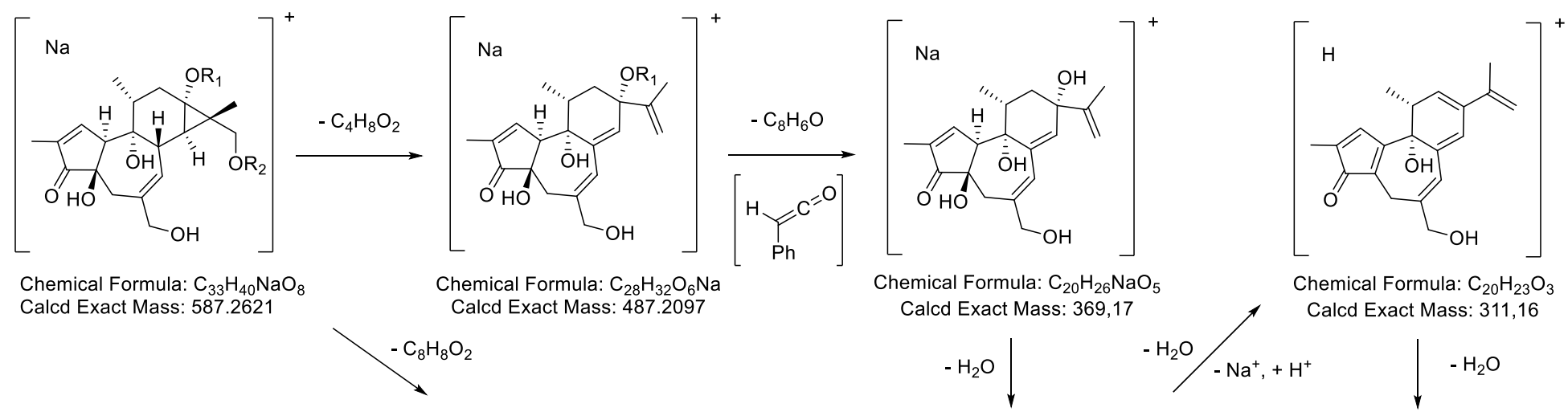

$\mathrm{OR}_{1}=\mathrm{O}_{\mathrm{O}}$

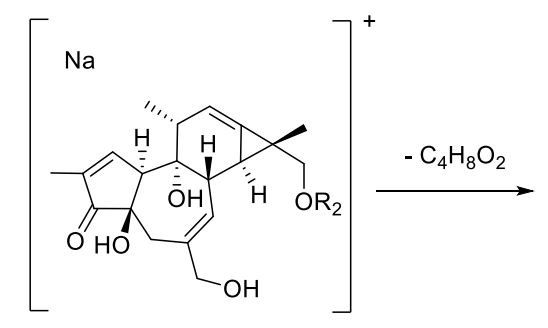

Chimecal Formula: $\mathrm{C}_{24} \mathrm{H}_{32} \mathrm{O}_{6} \mathrm{Na}$ Calcd Exact Mass: 451.2097

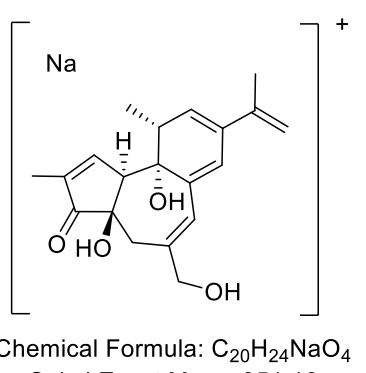
Calcd Exact Mass: 351,16 $-\mathrm{CO}$

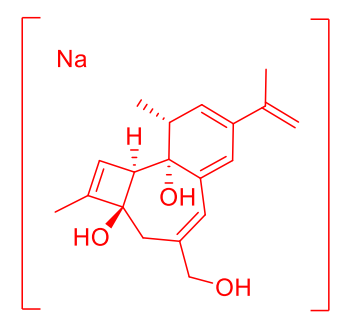

Chemical Formula: $\mathrm{C}_{19} \mathrm{H}_{24} \mathrm{NaO}_{3}$ Calcd Exact Mass: 323,16

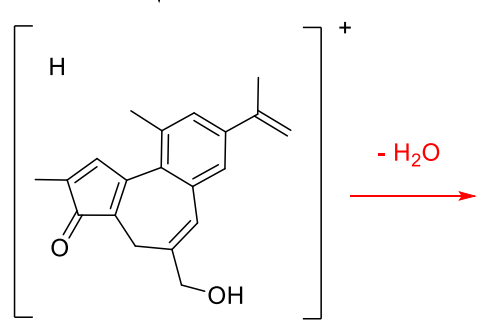

Chemical Formula: $\mathrm{C}_{20} \mathrm{H}_{21} \mathrm{O}_{2}$ Calcd Exact Mass: 293,15

$-\mathrm{CO}$

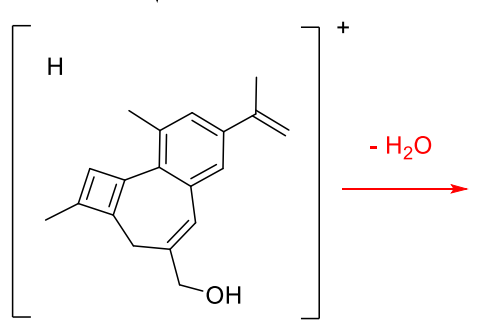

Chemical Formula: $\mathrm{C}_{19} \mathrm{H}_{21} \mathrm{O}$ Calcd Exact Mass: 265,16

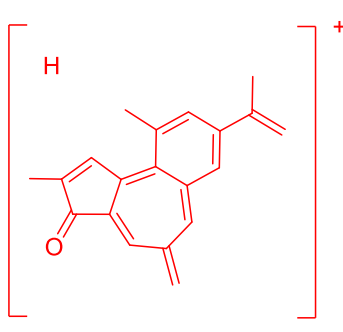

Chemical Formula: $\mathrm{C}_{20} \mathrm{H}_{19} \mathrm{O}$ Calcd Exact Mass: 275,14 $-\mathrm{co}$

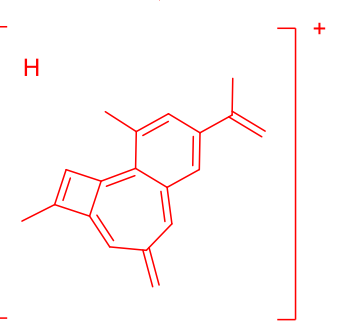

Chemical Formula: $\mathrm{C}_{19} \mathrm{H}_{19}$ Calcd Exact Mass: 247,15

Scheme S4. Proposed fragmentation route for selected ions on $\mathrm{MS}^{\mathrm{E}}$ spectrum (Data Independent Acquisition) for compound 11. 


\section{Effect of intranasal administration of compound 3}
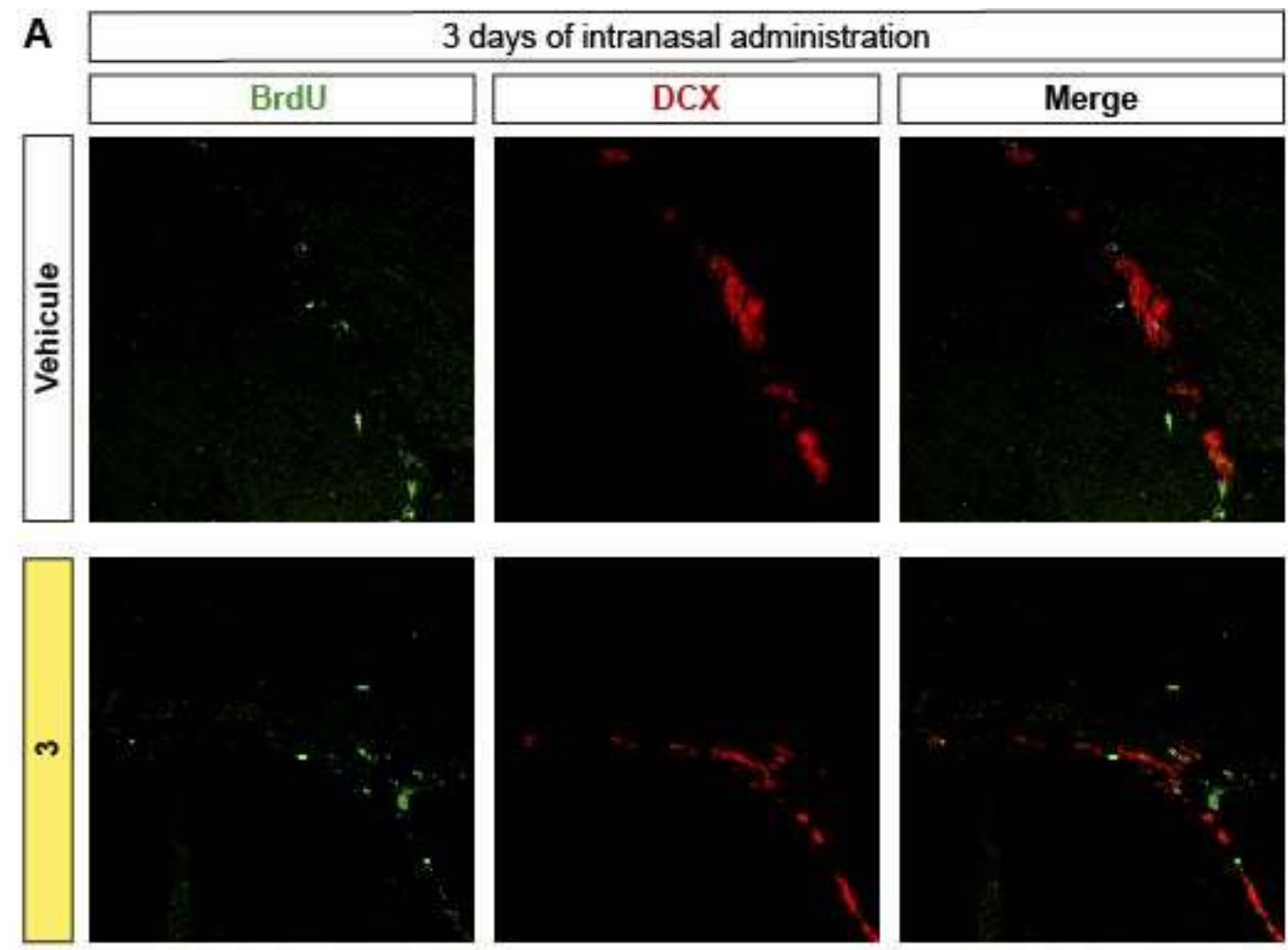

B
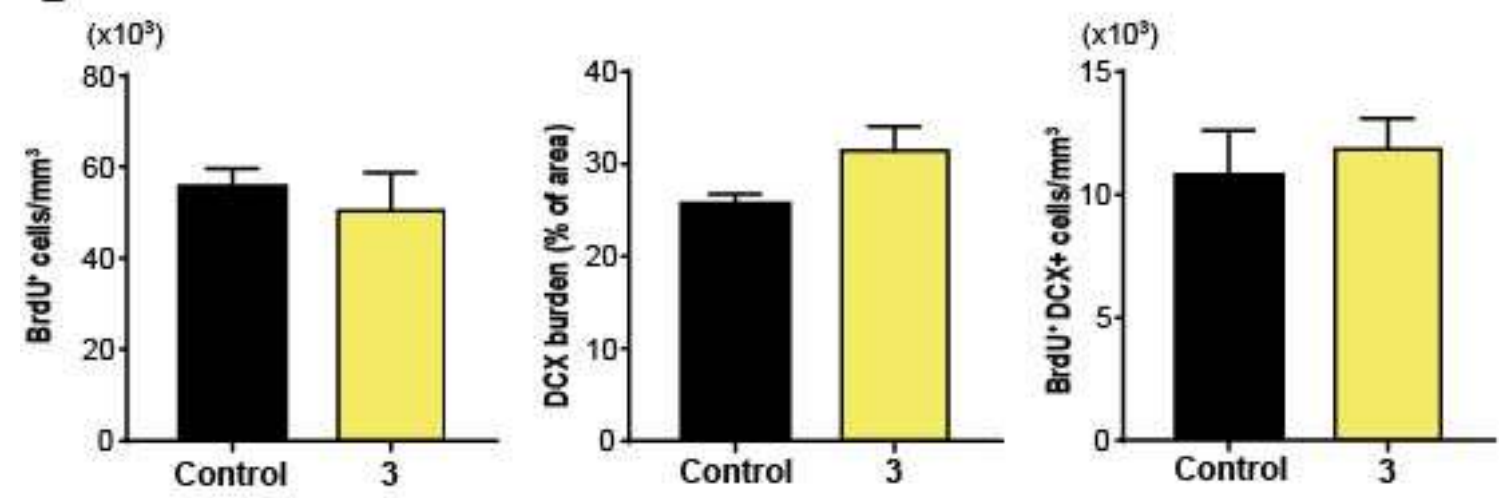

Figure S38. Effect of the intranasal administration of 3 on $\mathrm{BrdU}^{+}$and $\mathrm{DCX}^{+}$cells in the subventricular zone. A $100 \mathrm{nM}$ solution of compound $\mathbf{3}$ or only vehicle was administered intranasally to healthy adult 2 month-old mice during 3 consecutive days. All mice were intraperitoneally-injected with $\mathrm{BrdU}(100 \mathrm{mg} / \mathrm{kg})$ on the last day of treatment as described in methods. A. Confocal microcopy images of the SVZ of adult mice treated with $\mathbf{3}$ or only vehicle. Slices were processed for the immunohistochemical detection the proliferation marker BrdU and DCX. B. Graph shows the number of proliferating cells marked with $\mathrm{BrdU}$ per $\mathrm{mm}^{3}$, the relative $\mathrm{DCX}$ burden and the number of BrdU ${ }^{+}$cells that co-expressed DCX in the SVZ. Data shown are the mean \pm SEM; $n=6$ animals per group. Statistical analysis: ${ }^{*} p<0.05$ by Student's t-test comparing with the control group. 3: Phorbol 12,13-diisobutyrate 


\section{Physicochemical Properties}

Table S1. Calculated Molecular Properties (Drug-liness) by Molispiration Online Sofware for compounds 1-5; 7-11. Phorbol (1); phorbol 12,13-diacetate (2); phorbol 12,13-diisobutyrate (3); phorbol 12,13-diphenylacetate (4); phorbol 13-isobutyrate (5); phorbol 13-isobutyrate-12-phenylacetate (7); phorbol 13isobutyrate-12-tigliate (8); phorbol 12-isobutyrate-13-phenylacetate (9) ; DPPI (10); DPPT (11).

\begin{tabular}{|l|l|c|l|l|l|l|l|l|c|}
\hline \multicolumn{1}{|c|}{ Compounds } & $\begin{array}{l}\mathrm{mi} \\
\text { LogP } \\
(0-3)\end{array}$ & $\begin{array}{l}\text { Lipinski's } \\
\text { violations }\end{array}$ & R.B & M. R. & TPSA & M.W & H.B.A & H.B.D & Activity \\
\hline $\mathbf{1}$ & 0.52 & 0 & 1 & 92,82 & 118.21 & 364.44 & 6 & 5 & - \\
\hline $\mathbf{2}$ & 1.93 & 0 & 5 & 111.91 & 130.37 & 448.51 & 8 & 3 & + \\
\hline $\mathbf{3}$ & 3.75 & 1 & 7 & 130.24 & 130.36 & 504.62 & 8 & 3 & +++ \\
\hline $\mathbf{4}$ & 5.12 & 2 & 9 & 160.86 & 130.37 & 600.71 & 8 & 3 & ++ \\
\hline $\mathbf{5}$ & 2.14 & 0 & 4 & 111.53 & 124.29 & 434.53 & 7 & 4 & - \\
\hline $\mathbf{7}$ & 4.44 & 1 & 8 & 145.55 & 130.37 & 552.66 & 8 & 3 & ++ \\
\hline $\mathbf{8}$ & 4.08 & 1 & 7 & 134.84 & 130.37 & 516.63 & 8 & 3 & + \\
\hline $\mathbf{9}$ & 4.44 & 1 & 8 & 145.55 & 130.37 & 552.66 & 8 & 3 & ++ \\
\hline $\mathbf{1 0}$ & 4.33 & 1 & 8 & 150.17 & 130.37 & 552.66 & 8 & 3 & + \\
\hline $\mathbf{1 1}$ & 4.65 & 1 & 8 & 134.84 & 130.37 & 550.65 & 8 & 3 & + \\
\hline
\end{tabular}


Tabla S2. Calculated Molecular Properties (Drug-liness) by Molispiration Online Sofware for 12-deoxyphorbols

\begin{tabular}{|l|l|l|l|l|l|l|l|l|}
\hline \multicolumn{1}{|c|}{ Compounds } & miLogP & M. R. & R.B & TPSA & M.W & H.B.A & H.B.D & $\begin{array}{l}\text { Lipinski's } \\
\text { violations }\end{array}$ \\
\hline Prostratin & 2.14 & 100.99 & 3 & 104.06 & 390.48 & 6 & 3 & 0 \\
\hline 12-deoxyphorbol 13-phenyacetate (DPP) & 3.74 & 125.45 & 5 & 104.06 & 466.57 & 6 & 3 & 0 \\
\hline 12-deoxyphorbol 13-phenyacetate (DPA) & 3.38 & 114.73 & 4 & 104.06 & 430.54 & 6 & 3 & 0 \\
\hline 12-deoxyphorbol 13-phenyacetate (DPB) & 3.06 & 110.14 & 4 & 104.06 & 418.53 & 6 & 3 & 0 \\
\hline
\end{tabular}




\section{Docking Analysis of phorbol derivatives}

Figure S39. Molecular docking of Phorbol 12-phenylacetate-13-isobutyrate (7), phorbol 12,13diisobutyrate (3), 12-deoxy-16-hydroxyphorbol 13-phenylacetate-16-tigliate (DPPT, 11), and 12-deoxy-16-hydroxyphorbol 13-phenylacetate-16-isobutyrate (DPPI, 10) (top row) and phorbol (1), 12-deoxyphorbol 13-isobutyrate (DPB) and 12-deoxyphorbol 13-angelate (DPA) (bottom row) on PKC 8 1B (PDB: 1PTR). (Visualized by Discovery Studio visualizer)

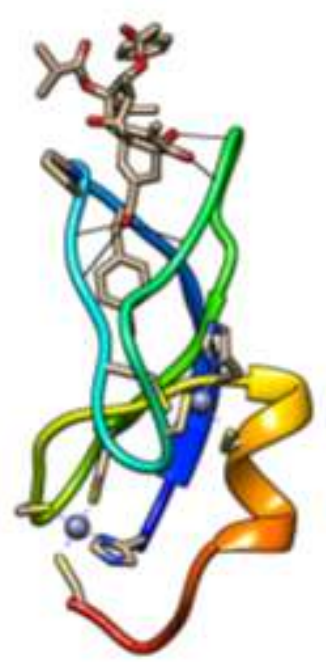

7

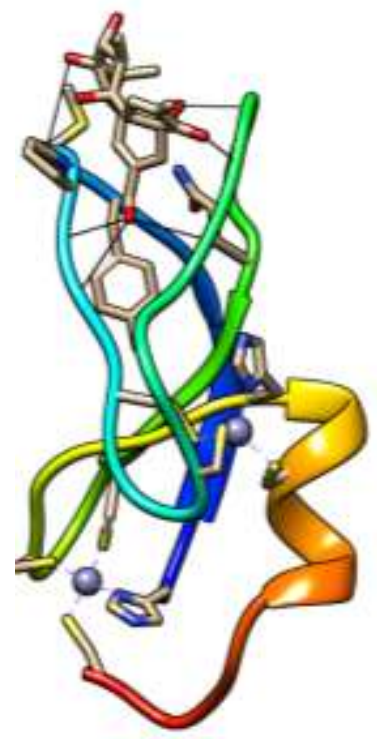

1

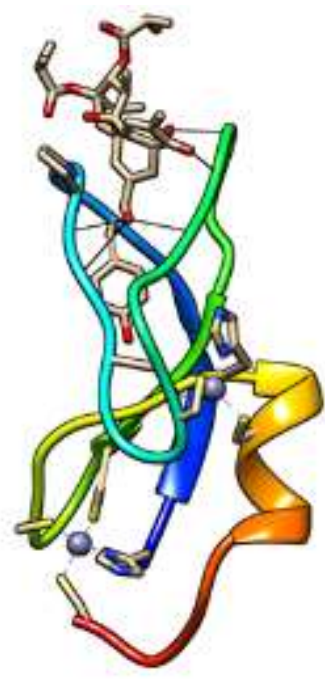

3

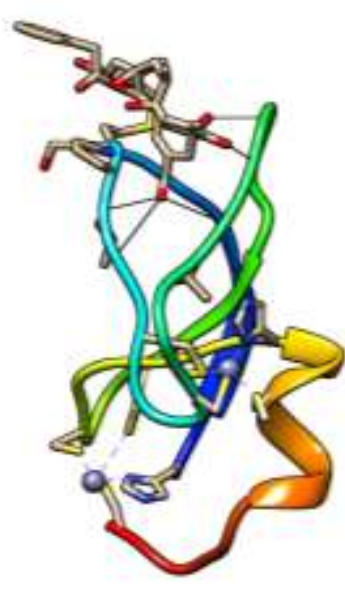

11

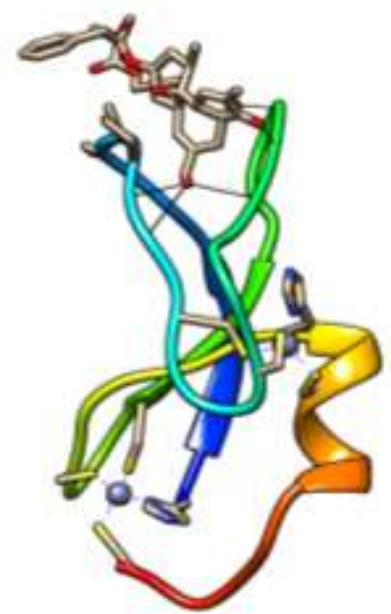

10

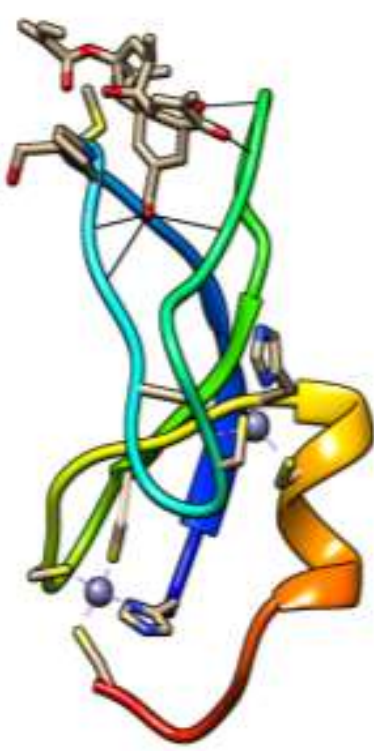

DPA

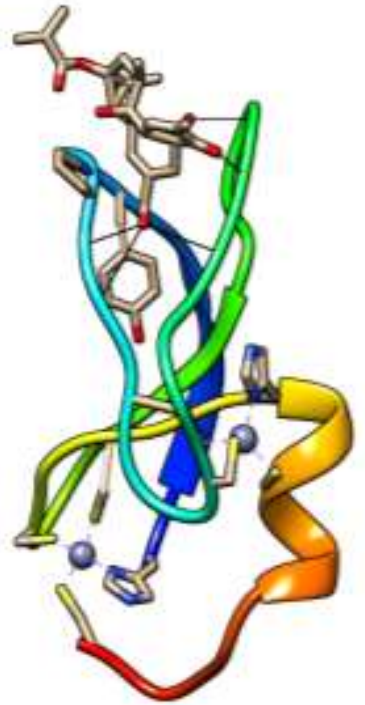

DPB 
Figure S40. Binding sites and the details of the predicted binding mode of phorbol 12-phenylacetate-13-isobutyrate (7), phorbol 12,13-diisobutyrate (3), 12deoxy-16-hydroxyphorbol 13-phenylacetate-16-tigliate (DPPT, 11), and 12-deoxy-16-hydroxyphorbol 13-phenylacetate-16-isobutyrate (DPPI, 10) (top row) and phorbol (1), 12-deoxyphorbol 13-isobutyrate (DPB) and 12-deoxyphorbol 13-angelate (DPA), (bottom row) on PKCDC1B (PDB: 1PTR): hydrogen bounds (Green), hydrophobic interaction (Purple). (Visualized by Discovery Studio Visualizer on PKC $\beta C 1 B)$ )
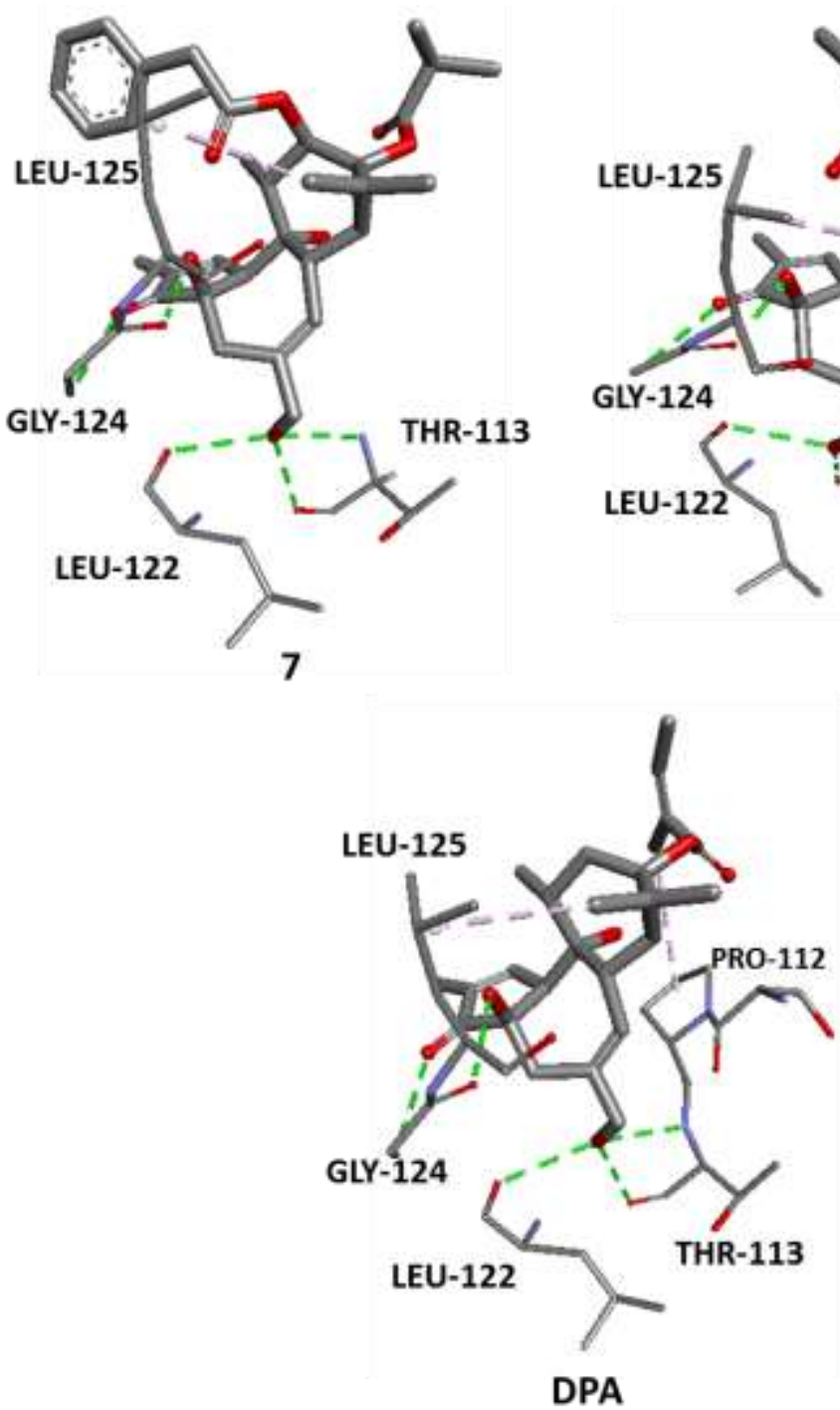

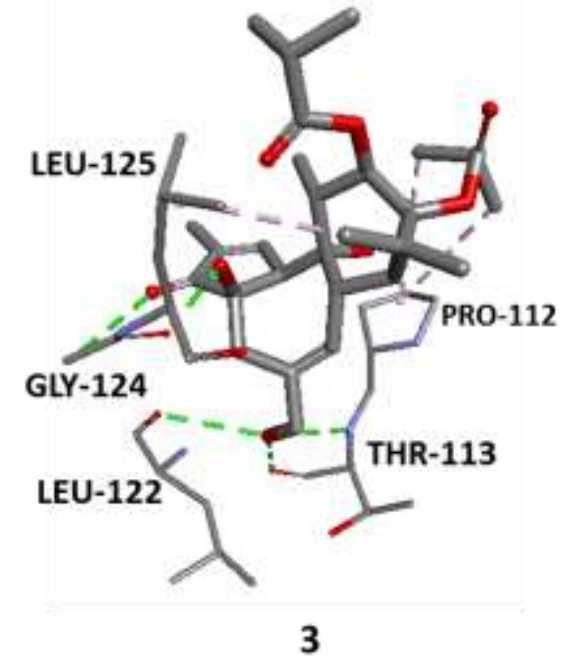

3

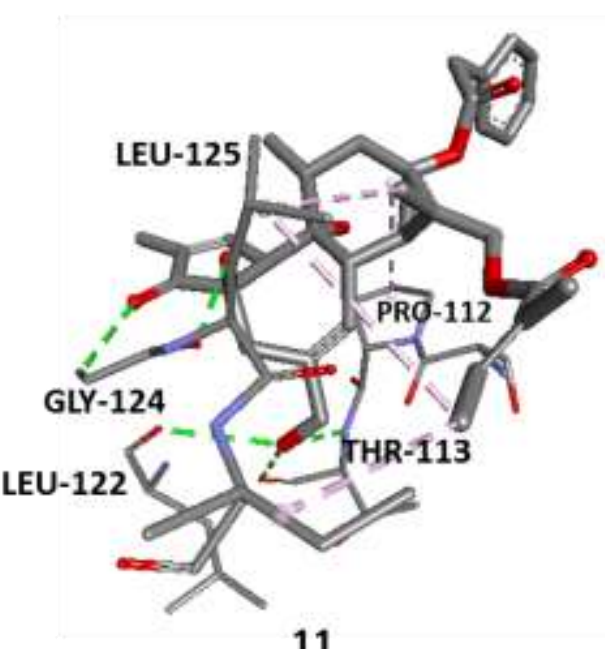

11

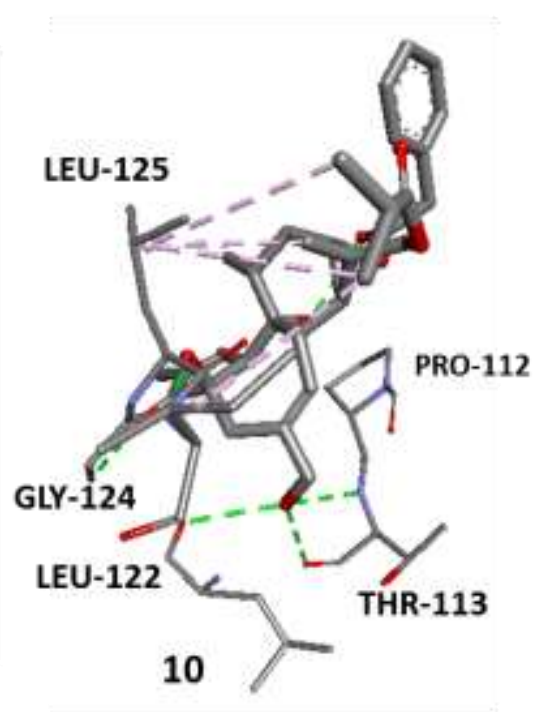

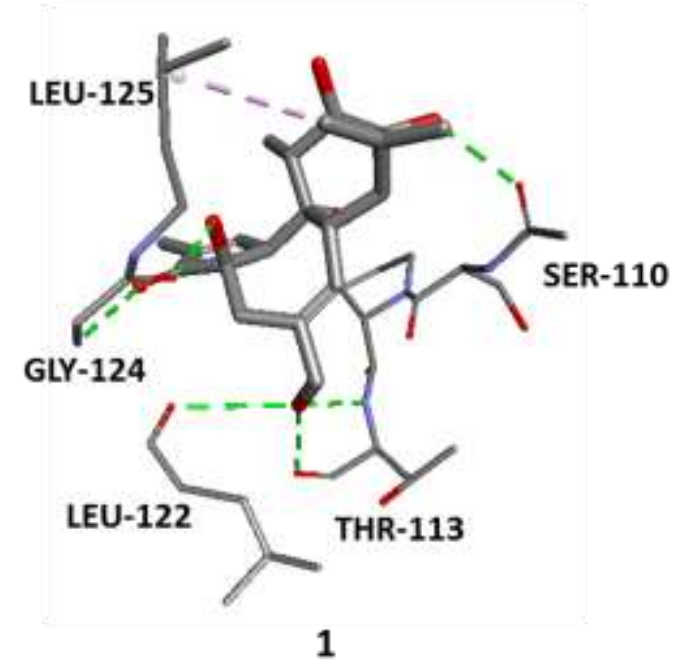

